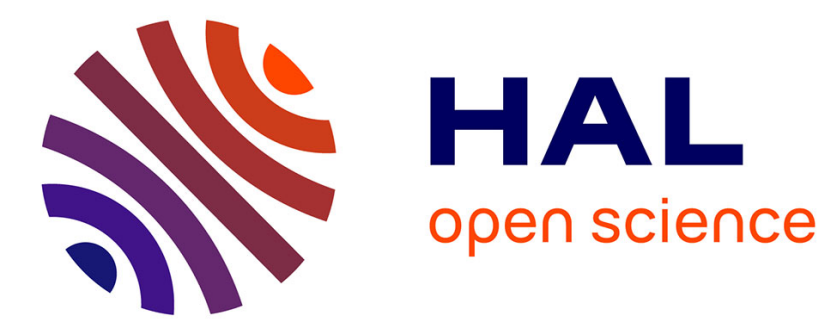

\title{
Palembang et Sriwijaya: anciennes hypothèses et recherches nouvelles (Palembang Ouest)
}

\author{
Pierre-Yves Manguin
}

\section{To cite this version:}

Pierre-Yves Manguin. Palembang et Sriwijaya: anciennes hypothèses et recherches nouvelles (Palembang Ouest). Bulletin de l'Ecole française d'Extrême-Orient, 1987, 76 (1), pp.337 - 402. 10.3406/befeo.1987.1731 . halshs-02512573

\section{HAL Id: halshs-02512573 \\ https://shs.hal.science/halshs-02512573}

Submitted on 19 Mar 2020

HAL is a multi-disciplinary open access archive for the deposit and dissemination of scientific research documents, whether they are published or not. The documents may come from teaching and research institutions in France or abroad, or from public or private research centers.
L'archive ouverte pluridisciplinaire HAL, est destinée au dépôt et à la diffusion de documents scientifiques de niveau recherche, publiés ou non, émanant des établissements d'enseignement et de recherche français ou étrangers, des laboratoires publics ou privés. 


\section{Palembang et Sriwijaya : anciennes hypothèses et recherches} nouvelles (Palembang Ouest)

Pierre-Yves Manguin

\section{Citer ce document / Cite this document :}

Manguin Pierre-Yves. Palembang et Sriwijaya : anciennes hypothèses et recherches nouvelles (Palembang Ouest). In: Bulletin de l'Ecole française d'Extrême-Orient. Tome 76, 1987. pp. 337-402;

doi : https://doi.org/10.3406/befeo.1987.1731

https://www.persee.fr/doc/befeo_0336-1519_1987_num_76_1_1731

Fichier pdf généré le 08/02/2019 


\title{
ETUDES SUMATRANAISES
}

\author{
I. PAlEMbang ET SRIWIJAYA: \\ ANCIENNES HYPOTHESES, RECHERCHES NOUVELLES \\ (Palembang Ouest)
}

PAR

PierRe-Yves MANGUIN

«On aurait dû s'en douter plus tôt; mais nous avons tous été victimes d'une illusion d'optique.»'

\section{Préambule}

Depuis 1976, le Centre de l'EFEO en Indonésie travaille dans le cadre d'un accord de coopération scientifique avec le Pusat Penelitian Arkeologi Nasional ${ }^{2}$. C'est en application de ce programme de collaboration que Mme. Satyawati Suleiman, ancienne directrice du Puslit Arkenas, m'a demandé en 1980 de me joindre au groupe de travail composé de chercheurs indonésiens et étrangers qui, depuis l'année précédente, avait repris les recherches sur les sites archéologiques controversés de Palembang et de ses environs ${ }^{3}$. Les résultats obtenus lors de ces missions de prospection ont amené le Puslit Arkenas à organiser deux brèves campagnes de fouilles en 1985 et 1987.

Par ailleurs, le SPAFA (SEAMEO Project on Archaeology and Fine Arts) a organisé en Indonésie et en Thailande, entre 1979 et 1985, une série de quatre longs «Workshops»

1 Ferrand 1922: 241.

${ }^{2}$ De son intitulé complet est tiré l'acronyme officiel Puslit Arkenas, qui sert habituellement à désigner en Indonésie ce «Centre National de la Recherche Archéologique». Je profite de cette occasion pour remercier ici tous ceux qui ont à un titre ou un autre facilité mes recherches à Palembang: M. R. P. Soejono le premier, Directeur du Puslit Arkenas jusqu'en 1987, qui m'a autorisé à travailler avec les archéologues de son service sur les sites de Sumatra; Mme. S. Suleiman qui m'a amicalement poussé à m'engager dans ces recherches et M. O. W. Wolters qui m'a toujours encouragé, sur le terrain ou par correspondance, à persévérer dans la voie choisie; Mmes. Suchitra et Rosa C. P. Tenazas, coordinatrices au SPAFA, qui m'ont donné l'occasion de travailler avec cet organisme et m'y ont toujours accueilli avec gentillesse; enfin le Ministère des Affaires Etrangères qui, à plusieurs reprises, a financé mes missions en Asie du Sud-Est auprès du SPAFA.

${ }^{3}$ Outre Mme. Suleiman et l'auteur de cet article, les participants réguliers à ce groupe de travail ont été Mme. Sri Soejatmi Satari, M. O. W. Wolters, Bambang Budi Utomo, Abu Ridho et E. E. McKinnon. Mme. Sumara Adhyatman et $\mathbf{M}$. Boechari nous ont largement fait bénéficier de leur expérience respective de céramiciste et d'épigraphiste. 
consacrés aux études sur Sriwijaya ${ }^{4}$, qui ont rassemblé les archéologues et historiens des pays d'Asie du Sud-Est concernés et quelques autres chercheurs étrangers à la région (pour des raisons administratives, la Malaysia ne s'est pas jointe au projet). Ces séminaires itinérants et les fructúeuses discussions qui y ont pris place ont été à l'origine de projets de recherche spécifiques en Indonésie et en Thailande et ont donné l'occasion à tous les participants de visiter la quasi-totalité des sites importants associés de plus ou moins près à Sriwijaya en Thailande méridionale et à Sumatra ${ }^{5}$.

Que ce soit avec le groupe informel réuni par Mme. Suleiman, avec les archéologues du Puslit Arkenas ou lors des séminaires du SPAFA auquel je participais comme consultant, il ne s'est plus passé une année, depuis 1980, sans que je ne fasse un ou plusieurs séjours dans la capitale de la province de Sumatra Sud et dans ses environs, pour reconnaître les sites en question et travailler dessus. L'article qui suit constitue une simple présentation des recherches menées à Palembang par l'ensemble des chercheurs mentionnés ci-dessus ${ }^{6}$. Il ne traitera dans le détail que des sites de Palembang Ouest. Des recherches plus sommaires ont aussi été effectuées sur d'autres sites de la ville et de ses environs depuis 1979 , qui devraient déboucher en 1988 sur des fouilles de sauvetage, suite aux pillages et destructions de grande ampleur des sites des environs de Geding Suro en $1987^{7}$.

Le présent article fait le point de la situation en 1979, lorsque les travaux ont repris, pour exposer ensuite les différentes étapes des nouvelles recherches dans l'ouest de Palembang et pour tenter d'en faire - en particulier par une cartographie sommaire des sites - une première, et très provisoire, synthèse. D'emblée il me faut en effet bien préciser que les quelques conclusions atteintes aujourd'hui ne s'appuyent encore, pour l'essentiel, que sur des prospections et des échantillonnages de surface, les fouilles du Puslit Arkenas ayant jusqu'ici été limitées dans le temps comme dans l'espace. Ces conclusions sont fondées aussi, de façon peut-être moins orthodoxe en archéologie, sur la comparaison des données archéologiques, des sources historiques et des traditions orales encore vivantes dans la région, à travers la toponymie et les légendes.

D'autres articles dans cette série continueront donc à présenter les travaux historiques et archéologiques menés à Sumatra dans le cadre de cette collaboration avec le Puslit Arkenas.

\section{L'ETAT DES CONNAISSANCES EN 1979}

George Coedès, dès 1918 , écrivait à propos de Sumatra que «le voisinage de Java, toute couverte de vestiges archéologiques, lui a certainement fait du tort aux yeux de l'histoire».

4 J'adopte tout au long de cet article, pour plus de commodité, l'orthographe officielle indonésienne (et malaysienne) du nom de Sriwijaya, plutôt que sa translittération Śrivijaya.

${ }^{5}$ On trouvera en annexe la liste des communications présentées lors de ces quatre séminaires, qui ne concernent bien entendu pas le seul site de Palembang.

- Cet article laisse entièrement de côté les autres sites de Sumatra (Jambi surtout), de Malaysia (dans l'Etat de Kedah) ou de Thailande méridionale, auxquels il ne sera fait référence qu'occasionnellement: tous ont connu un renouveau d'intérêt pendant ces dix dernières années, sous l'impulsion en particulier des séminaires du SPAFA.

7 Ces travaux feront l'objet d'un prochain article dans cette série d'Etudes Sumatranaises. Une bonne vue d'ensemble de tous les sites de Palembang (et des autres sites de Sumatra Sud) est donnée avec un essai d'analyse par E. E. McKinnon dans son article de 1985. Les travaux récents de Wolters (1979, 1979a, 1984, 1986) et Kulke (sous presse) tiennent compte des recherches récentes sur l'ensemble de Palembang. 
En 1936, c'est encore lui qui affirmait que «l'histoire de Çrivijaya a subi dans ces dernières années les plus étranges vicissitudes». Ces réflexions, comme celle de Gabriel Ferrand citée en exergue, à propos de l'illusion d'optique dont ont été victimes les chercheurs qui ont travaillé sur Sriwijaya, résument bien les mésaventures qu'a connu ce premier demi-siècle d'études $^{8}$. Mais le sort ne s'est pas arrêté là et - après la période de grâce des années 1918-1930 - il a continué de s'acharner jusqu'à nos jours à entraver la bonne marche des travaux sur Sriwijaya: délaissement par les archéologues de l'Oudheikundig Dienst plus occupés à Java, pièces essentielles recueillies sans détails aucuns śur le lieu de leur découverte, municipalité peu respectueuse de son patrimoine, destruction de l'inventaires de l'ancien musée et, tout récemment, sites pillés ou détruits par une urbanisation galopante, la liste est longue des déboires subis par Palembang et Sriwijaya. On serait tenté d'affirmer, au risque de ne pas être pris au sérieux, que le seul fait de trouver encore aujourd'hui à Palembang matière à étude sur la période sriwijayenne pourrait constituer une preuve suffisante de l'importance du rôle joué par cette ville dans l'histoire du premier grand Etat maritime de Sumatra ...

On se souviendra que Coedès avait le premier établi un rapport direct entre: - des inscriptions du $7 \mathrm{e}$ et $8 \mathrm{e}$ siècles provenant de Palembang et de la Péninsule Malaise mentionnant clairement un souverain de l'Etat de Śrivijaya (et non pas comme on l'avait cru jusque là un roi nommé Śrivijaya); - des textes chinois faisant état, entre le 7e et le 14e siècles, dans l'ouest de l'Insulinde (et dans certains cas, plus spécifiquement à Palembang-même), d'un Etat commerçant portant selon les époques une variété de noms apparentés (Fo-shi, Shi-li-fo-shi, San-fo-qi); - deux chartes du 1le siècle écrites en tamoul par les Colas et faisant état d'un pays de Śrivijaya; - des textes arabes mentionnant le riche souverain de Sribuja; - et enfin les quelques découvertes archéologiques effectuées à Palembang et dans ses environs (pour l'essentiel de la statuaire bouddhique). Il signait ainsi, dans un article publié au BEFEO en 1918, l'acte de naissance du «Royaume de Sriwijaya» et réitérait en 1930 avec force dans ce même Bulletin ses arguments en traduisant plusieurs nouvelles incriptions en vieux malais trouvées entretemps à Palembang. D'emblée, prenant l'ensemble des sources disponibles dans leur acception la plus directe, les lisant avec un bon sens appuyé par de solides arguments philologiques, il avait placé la première capitale de Sriwijaya sur le site de la ville de Palembang, capitale de l'actuelle province indonésienne de Sumatra Sud.

On se souviendra aussi que, dès après les premiers travaux de G. Coedès sur Sriwijaya en 1918 , nombre de controverses étaient nées à propos de la localişation de cette capitale. Ces débats de philologues découlaient pour l'essentiel de l'existence, ailleurs à Sumatra et sur l'isthme de la Péninsule malaise, de sites archéologiques plus riches que Palembang, d'inscriptions appartenant ou émanant d'Etats ayant des liens indéniables avec Sriwijaya, et de l'ambiguïté ou des difficultés d'interprétation des sources chinoises et arabes décrivant la région. Tout en tentant d'intégrer le développement de ces sites secondaires ou parfois marginaux dans l'histoire de Sriwijaya, Coedès maintînt jusqu'au bout sa position initiale: de tous les sites possibles, celui de Palembang, malgré sa relative pauvreté en vestiges archéologiques, avait le plus de chances d'avoir vu naître l'Etat de Sriwijaya au 7e siècle et d'en avoir constitué la première capitale, jusqu'au 11 e siècle au moins ${ }^{9}$. J. G. de Casparis a par la

${ }^{8}$ Coedès 1918: 25; 1936: 3; Ferrand 1922: 241.

9 Pour une vue d'ensemble de la question, lire les passages relatifs à Sriwijaya dans sa grande synthèse des Etats hindouisés (Coedès 1964); il apporte une contradiction plus circonstanciée aux diverses théories auxquelles il s'opposait dans ses articles de 1936 et 1959. 
suite traduit et analysé avec le plus grand soin les inscriptions trouvées à Palembang après 1930, et en particulier la longue inscription de Telaga Batu (ou de Sebokinking) trouvée dans l'est de Palembang, inscription «centrale» s'il en fut, et il ne s'est pas écarté sur ce point de l'hypothèse de départ de Coedès ${ }^{10} . \mathrm{O}$. W. Wolters, qui a consacré une grande partie de son œuvre d'historien à Sriwijaya, sans avoir d'abord fait du débat sur la localisation de la capitale le centre de ses préoccupations, a continué, suivant en cela Coedès et ceux qu'il nomme les «vétérans», à situer cette première capitale à Palembang ${ }^{11}$. Mais si l'on doit signaler encore quelques combats d'arrière-garde parmi les historiens tentés de ravir à Sumatra-Sud le privilège d'avoir abrité la prestigieuse ville ${ }^{12}$, c'est du côté de l'archéologie de terrain qu'est venue en 1974 l'attaque la plus sérieuse pour les tenants d'une localisation à Palembang.

En effet, une campagne conjointe de l'University of Pennsylvania Museum et du service archéologique indonésien, après trois mois de fouilles à Palembang et dans ses environs, amenait Bennet Bronson, responsable de l'équipe américaine, à diffuser largement ses conclusions radicales sur la question: les sites de Palembang ne pouvaient en aucun cas témoigner de l'existence d'un site urbain important avant le $14 \mathrm{e}$ ou le $15 \mathrm{e}$ siècle; toutes les statues et les inscriptions datées du 1er millénaire en provenance de ces sites ne pouvaient qu'être le résultat d'une «redéposition» systématique et à grande échelle par un Etat postérieur soucieux de consolider par les signes extérieurs du pouvoir d'un autre son propre pouvoir sur la région. Et de généraliser à partir de ces conclusions, devenues axiomes, sur le retard du développement urbain en Insulinde. Il admettait néanmoins, comme une arrière-pensée, que les villes d'un Etat maritime tel que Sriwijaya aient pu être radicalement différentes de celles qui ont vu le jour au cœur des grands Etats agraires de la Péninsule Indochinoise ${ }^{13}$.

Le but de cet article et de l'ensemble des recherches menées à Sumatra n'est pas de discuter de façon abstraite de modèles de développement urbain en Asie du Sud-Est, mais bien de proposer, à partir des travaux effectués à Palembang après 1979, une lecture des résultats obtenus sur le terrain radicalement différente de celle de Bronson. C'est donc dans un premier temps aux arguments avancés pour la datation des sites qu'il faudra répondre ici. L'absence d'un rapport de fouilles circonstancié pour la campagne de 1974 ne facilite pas la tâche, d'autant plus qu'aucune illustration ne vient córroborer l'identification des quelques 2.000 tessons de céramique d'importation qui ont permis de dater les sites (seul un comptage sommaire de ces pièces en provenance des trois principaux sites a vu le jour sous forme de tableau dans l'un des articles précités).

10 Casparis 1956 et, pour une récente réitération de ce point de vue, sa communication de 1982 («this inscription strongly indicates that the capital was in the Palembang area during the period when the stone was in use»). Kulke (sous presse) a récemment effectué une nouvelle lecture du contenu de l'inscription de Telaga Batu et continue d'en faire une inscription émanant du centre politique de l'Etat-mandala de Sriwijaya. Il faut noter ici que deux nouvelles inscriptions de 7e siècle ont été découvertes ces dernières années, qui toutes deux contiennent, comme celles déjà connues de Karang Brahi (Jambi) et de Kota Kapur (Bangka) des variantes du texte-imprécation de l'inscription de Telaga Batu. Elles ont été trouvées dans la province de Lampung, qui sépare celle de Sumatra-Sud du détroit de la Sonde, l'une à la pointe sud de Sumatra, l'autre plus à l'est: l'inscription de Telaga Batu devient ainsi, plus que jamais, une inscription «centrale» (Boechari 1979 et communication personnelle).

1 Wolters 1967: 22-23. Les travaux plus récents de Wolters, qui se fondent sur les nouvelles recherches menées à Palembang dont il est fait état ici, s'adressent plus directement au problème de la localisation de la capitale de Sriwijaya.

12 Voir les articles sans grande substance de Chand 1974 et Wright 1983 et, plus récemment, celui, très stimulant, de Pisit 1985.

${ }_{13}$ Bronson \& Wisseman 1974 (rapport préliminaire, non publié) et 1976; Bronson 1975 et 1979. Le rapport détaillé sur la campagne de 1974 n'a jamais été publié. 
«The entire vicinity of Palembang does not contain enough pre-14th century domestic artifacts to make one small village ${ }^{14}$. C'est autour de cette proposition on ne peut plus catégorique - et, on le verra, bien téméraire - que s'organise le reste de l'argumentation. Ces «artefacts domestiques» trouvés en situation, céramiques produites localement ou importées, sont opposés à tous ceux qui sont directement associés au pouvoir royal et aux cultes religieux (bouddhiques pour l'essentiel), qui ont pu être déplacés de façon volontaire depuis des sites éloignés, et qui sont donc peu fiables pour la datation des sites où ils ont été découverts. Un total de 2.277 tessons de céramiques chinoises, vietnamiennes et thai (en provenance des trois seuls sites principaux de fouilles), a été isolé parmi «plusieurs dizaines de milliers» de tessons recensés pendant les fouilles de la campagne de 1974, et a fait l'objet d'une datation par styles ${ }^{15}$.

Or que nous apprend ce tableau? Il nous y est dit dans une note que «si peu est connu au sujet des diverses pièces à glaçure brune et des grès sans glaçure (unglazed stoneware) - dont l'essentiel parait avoir été constitué de grandes jarres pour le transport-que ni lieu ni date de manufacture ne peuvent être précisés pour la plupart d'entre elles». Or on verra plus loin que de très nombreuses pièces que l'on doit dater avec certitude de la dynastie des Tang, entre le $8 \mathrm{c}$ et le $9 \mathrm{e}$ siècles, ont été trouvées à Palembang et que ce sont précisément des grès grossiers, le plus souvent des jarres, dont la glaçure a ceci de particulier qu'elle s'écaille très facilement, laissant ainsi à nu la poterie. Elles appartiennent à la famille dite «vert-olive» (olive-green wares): provenant des fours du Guangdong, elles sont caractérisées par une pâte souvent grossière, gris clair ou crème, avec une engobe blanche (devenant parfois rouge par oxydation) bien visible vers le pied des pièces que ne recouvre jamais la glaçure. Celle-ci, de couleur vert-jaune («vert-olive»), est assez grossière, avec de nombreuses coulures, et souvent fortement craquelée. La famille comprend des jarres de formes et tailles diverses, avec ou sans bec-verseur, aux parois et bases épaisses, des bassins, des bols aux formes très caractéristiques, sans pieds ou avec des pieds pleins, portant à l'intérieur de larges marques laissées sans glaçure ${ }^{16}$. Il se glisse donc déjà ici, à la lecture de ce tableau, un premier doute sur sa validité. Il se trouve en outre que le Musée Badaruddin à Palembang a conservé quelquesunes des céramiques trouvées en surface par l'équipe de 1974, dont celles de Bukit Seguntang: parmi les 18 pièces conservées pour ce site, il n'en est pas une seule qui ne puisse être datée entre le $8 \mathrm{e}$ et le $12 \mathrm{e}$ siècles (on y trouve en particulier 12 splendides spécimens de bols de type

14 Bronson \& Wisseman 1976: 233.

15 Bronson \& Wisseman 1976: 227 et table 1. On nous dit aussi que les céramiques d'importation comptaient pour $20 \%$ du total recueilli. Les 2.277 tessons portés au tableau publié sont loin de constituer les $20 \%$ de «plusieurs dizaines de milliers». Il est probable que les céramiques d'importation provenant des sites fouillés en dehors des trois principales localisations devraient expliquer cette forte différence; mais on aurait aimé en savoir plus.

${ }^{36}$ Voir à propos de ces pièces les articles de Harrisson (1965 et 1966), Zainie (1967) et Whitehouse (1973) (tous antérieurs aux fouilles de 1974) et plus récemment, les études précises de Sumara Adhyatman, fondées sur les pièces trouvées en Indonésie et des comparaisons avec les collections conservées en Chine (voir sa Note on Yue-type ware dans ce même $B E F E O$, les illustrations de quelques unes de ces pièces dans son livre de 1981 et surtout son étude de 1983 où l'on trouvera de nombreuses illustrations). Ces pièces ont été trouvées en Chine dans une tombe chinoise datée de $740 \mathrm{AD}$, et apparaissent souvent à Java Central dans les dépots de fondation des temples du 8e et $9 \mathrm{e}$ siècles (Adhyatman 1983 et Dumarçay, communication personnelle). On les retrouve dans des sites situés tout au long de l'Océan Indien, jusqu'au Moyen-Orient et en Afrique de l'Est. A Siraf, parmi les céramiques chinoises les plus anciennes, des bols avec les marques de cuisson caractéristiques ont été retrouvés en grand nombre et ne peuvent y être postérieurs au début du 9e siècle (Whitehouse 1973, 1979). 
Yue des $9 \mathrm{e}-10 \mathrm{e}$ siècles) (ill.) ${ }^{17}$. Toutes pièces d'époque sriwijayenne qui auraient dû, à tout le moins, faire l'objet de commentaires de l'auteur.

Cependant, bien plus encore que ces (non-)identifications hasardeuses, une simple critique interne de ce tableau révèle deux graves erreurs de jugement. D'une part on y voit apparaître la catégorie «Misc. Sung-Ming celadons», qui couvre une période qui va du $10 \mathrm{e}$ au $17 \mathrm{e}$ siècle, soit une bonne partie de l'époque sriwijayenne, et qui regroupe par exemple, sans plus de discernement, 28,7\% des pièces de Bukit Seguntang. D'autre part, si l'on additionne les deux catégories de pièces non identifiées et donc non datables dont il est fait état dans la note citée ci-dessus, l'on arrive à un total de $41,6 \%$ des céramiques importées ... soit pas loin de la moitié du corpus servant à dater ces sites. Dans le cas du site de Bukit Seguntang, qui avait le plus de chances de livrer des pièces anciennes, le total est de $48 \%$, dont $40,3 \%$ pour les seuls «grès sans glaçure» (et on atteint même les $76,7 \%$ si l'on ajoute à ceux-ci la catégorie des «Misc. Sung-Ming Celadons» dans laquelles les pièces de type Yue ont de bonnes chances de s'être retrouvées) ${ }^{18}$.

Des conclusions aussi catégoriquement exprimées, et dont on infère une théorie générale sur le retard de l'urbanisation en Insulinde, lorsque qu'elles sont fondées sur un corpus dont moins de $60 \%$ des pièces sont datées, laissent entrevoir l'une de ces aberrations optiques dont les archéologues travaillant à Palembang paraissent avoir. souffert plus qu'il n'est d'usage.

\section{LA REPRISE DES RECHERCHES A PALEMBANG}

Les conclusions ci-dessus ont occupé le devant de la scène pendant quelques années, alors même que le peu qui était publié des fouilles sur lesquelles elles étaient censées se fonder portait en soi les contradictions que nous venons de voir. C'est dans ces circonstances qu'une nouvelle équipe, convaincue du bien fondé de la thèse des «vétérans», se rendit sur les sites de Palembang en 1979, sous la houlette de Mme. Satyawati Suleiman et de O. W. Wolters. Dès cette première exploration, l'accent a été mis sur les relations entre les sites, connus et potentiels, et l'environnement très particulier de Palembang et de ses environs, comme sur la toponymie de la ville (telle qu'elle nous a été rapportée depuis le début du $18 \mathrm{e}$ siècle). Il a été mis aussi sur les traditions malaises, dans la littérature ou vivantes, qui nous ont conservé des récits légendaires concernant la ville de Palembang et certains de ses lieux-dits, parmi lesquels figure de façon exemplaire la colline de Bukit Seguntang, site sacré entre tous pour les Malais et, rappelons-le, lieu d'origine de nombre d'inscriptions et de statues d'époque sriwijayenne. Nous reviendrons plus loin sur ces divers points. Mais il est à noter ici que dès cette nouvelle incursion en territoire supposé sriwijayen, l'impression qui s'est dégagée était la cohérence sur le terrain de ces sites potentiels, lorsqu'ils étaient considérés dans leur ensemble. E. E. McKinnon a alors pu recueillir en surface sur le flanc nord-est de Bukit Seguntang et identifier avec précision quelques tessons de céramique chinoise de type Yue,

17 Pour des raisons techniques liées à la composition de ce Bulletin, il n'a pas été possible de préciser dans les renvois du texte le numéro d'ordre des illustrations photographiques. Ces renvois porteront donc seulement la mention «ill.», indiquant que le lecteur pourra se reporter à une photographie illustrant ce passage particulier du texte.

18 A ma connaissance, seules des pièces très précisément identifiables, datées des Song ou des Yuan, ont jamais été fabriquées «sans glaçure» et importées en Insulinde: il s'agit de ces bouteilles en grès étroites, sans goulot, dites parfois «jarres à mercure» car on y a trouvé des restes de ce métal (qui était vraisemblablement importé en Insulinde pour purifier l'or). 
datables de la première moitié du $10 \mathrm{e}$ siècle $^{19}$. Forts de ces premières constations qui contredisaient les conclusions des travaux de 1974, Mme. S. Suleiman et le Puslit Arkenas furent à l'origine de bien d'autres visites, d'explorations systématiques et de fouilles de sites à Palembang, la dernière en date dont cet article tienne compte ayant pris place en septembre $1987^{20}$. Abandonnant donc ici le récit chronologique des évènements ayant mené au renouveau des recherches sur Palembang, je traiterai désormais de façon individuelle des divers sites de l'ouest de la ville, pour tenter ensuite seulement d'en fournir une vue d'ensemble.

Les sites de Palembang ont été regroupés en quatre grandes zones (ouest, centre, est et sud) pour en simplifier la description mais aussi, on le verra, parce que les données encore très déséquilibrées dont on dispose aujourd'hui donnent à penser que cette division pourrait bien être traduite dans une classification fonctionnelle et chronologique de ces sites (cartes 2 et 3) ${ }^{21}$. La zone ouest (par laquelle je commencerai et à laquelle est consacré l'essentiel de ce premier article), avec Bukit Seguntang en son centre symbolique, est celle qui, de très loin, a fait l'objet de plus de travaux depuis 1979: 1312 tessons de céramique d'importation recueillis en surface en proviennent, soit plus de $87 \%$ de ceux qui ont été comptés et classés pour l'ensemble de Palembang (le reste se répartissant à parts égales entre le centre et l'est) ${ }^{22}$.

19 On trouvera les conclusions de ce premier travail à Palembang dans McKinnon \& Milner 1979 et dans McKinnon 1979. La note de Sumara Adhyatman publiée dans ce même BEFEO fait le point des connaissances actuelles sur les pièces de type Yue.

${ }^{20}$ Ce travail continu sur le terrain a donné lieu à nombre de publications et de rapports inédits auxquels le présent travail doit beaucoup, même lorsqu'ils ne sont pas cités expressément: Ambary 1982, Budi Utomo 1985, 1987, 1987a, Budi Utomo \& Nurhadi Rangkuti 1985, Brown 1987, Kulke sous presse, Manguin 1982, 1982a, 1984, 1984a, 1986, 1987, McKinnon 1979, 1984, McKinnon \& Milner 1979, Satari 1985, Sukatno 1983, Suleiman 1982, Surastopo 1985, Tim Pemetaan 1984, Wolters 1979, 1979a, 1984, 1986. On lira aussi les articles suivants, qui ne sont pas directement liés à ces nouvelles recherches de terrain, mais qui les ont en quelque sorte accompagnées: Boechari 1986, De Casparis 1982, 1985, Hassan Shuhaimi 1979, Noerhadi Magetsari 1985, Roxas-Lim 1985, Suleiman 1983, 1985, Yamamoto 1983, 1985. La liste des communications présentées pendant les «Workshop» du SPAFA, que l'on trouvera en annexe, contient encore nombre d'autres travaux publiés depuis 1979 et qui peuvent de plus ou moins loin concerner Palembang.

${ }^{21} \mathrm{Du}$ fait que le présent article présente les résultats de recherches archéologiques effectuées surtout en surface, j'utilise le mot site dans une acception assez large: j'entends par là un lieu qui a soit livré une concentration suffisante de vestiges archéologiques (en général des céramiques) pour être jugée pertinente - même si des fouilles ne sont pas encore venues confirmer la valeur intrinsèque du site -, soit présente des caractéristiques topographiques vérifiées sur le terrain qui établissent clairement qu'il est fait de main d'homme et a des chances d'être ancien. Sauf exception signalée, les nombreux autres sites potentiels repérés sur les seules photos aériennes et non encore vérifiés sur le terrain ne seront pas mentionnés (on trouvera une carte à peu près exhaustive de ces derniers pour l'ensemble de Palembang dans Surastopo 1985).

22 Ce corpus de 1503 tessons de céramique d'importation trouvés en surface (ou, pour quelques-uns seulement, en fouille non contrôlée) est entreposé aujourd'hui à Palembang (au Musée Badaruddin, pour les quelques pièces recueillies antérieurement à 1979, et au Service Historique et Archéologique du Ministère de l'Education et de la Culture) et à Jakarta (au Puslit Arkenas). Il est composé, pour une très grande part, des pièces recueillies depuis 1979 lors des diverses campagnes mentionnées ci-dessus; quelques trouvailles de surface de la campagne américanoindonésienne de 1974, et quelques pièces de provenances diverses ont été inclues dans ce dénombrement lorsque leur site d'origine était établi avec certitude. Ce corpus a été compté et classé par Bambang Budi Utomo, Abu Ridho et moi-même, avec la collaboration de Sumara Adhyatman, à Palembang et Jakarta, en septembre 1985. Il a fait l'objet d'une publication signée de Budi Utomo (1985). Les pièces recueillies en surface depuis cette date ont été inclues dans le corpus, ce qui explique que mes totaux et ceux publiés par Bambang Budi Utomo puissent différer (sans que les pourcentages en soient d'ailleurs affectés de façon pertinente, sauf pour Bukit Seguntang, dont le flanc sud-ouest a livré en 1986 nombre de céramiques des 9-10e siècles: cf. Manguin 1986). 
La zone du centre est occupée par la ville moderne et, si elle a révélé au hasard des constructions quelques vestiges archéologiques importants, elle est pratiquement perdue pour la recherche archéologique. La zone est, qui regroupe des monuments - aujourd'hui restaurés - que l'on date aisément de la période post-sriwijayenne, a aussi livré la principale inscription du 7e siècle (dite de Telaga Batu ou de Sebokinking). Des sites religieux récemment pillés paraissent bien devoir aussi être rattachés à la période de Sriwijaya. La rive droite de la Musi n'a pas fait à ce jour l'objet d'études détaillées, mais outre que l'on y trouve encore l'un des sites sacrés de la tradition malaise, le petit Gunûng Mahameru, elle présente, sur les photos aériennes, des indications de sites monumentaux non relevées encore par les archéologues sur le terrain qui mériteront que l'on s'y attarde (mais qui pourraient bien dater de la période du Sultanat).

\section{L'ENVIRONNEMENT}

La ville de Palembang est construite à la limite orientale d'une formation tertiaire, plio-pleistocène pour être plus précis, qui forme du nord au sud de Sumatra une pénéplaine s'abaissant doucement jusqu'à rejoindre à l'est les basses terres marécageuses (de formation plus récente), couvertes d'abord de forêt, puis de mangrove; cette dernière zone est large de $80 \mathrm{~km}$ à la hauteur de Palembang. Très plate, elle permet à la marée de s'engouffrer à l'intérieur des terres, permettant notamment à de gros navires de remonter la Musi jusqu'à la ville (carte 1). Certains géologues, qui se fondaient par ailleurs sur des documents cartographiques portugais mal interprétés, ont cru que cette formation était très récente et que la côte avait pu progresser à la latitude de Palembang de $80 \mathrm{~km}$ en l'espace d'un millénaire: ils avaient ainsi transformé Sriwijaya/Palembang en port côtier. Le ré-examen de sources chinoises du $15 \mathrm{e}$ siècle, puis celui de diverses sources portugaises du $16 \mathrm{e}$, ont prouvé que la ligne de côte n'avait en fait pas bougé depuis un demi-millénaire et qu'elle n'avait donc aucune chance d'avoir parcouru ces $80 \mathrm{~km}$ en moins de cinq siècles ${ }^{23}$. C'est donc bien un site construit au bord d'un fleuve que l'on doit envisager pour Palembang à l'époque de Sriwijaya, et c'est sur ces prémisses que je me fonderai pour tenter de le comprendre.

Située à la limite d'une avancée de cette pénéplaine surélevée et des basses terres marécageuses, la ville de Palembang et ses sites ne peuvent se comprendre autrement qu'inscrits dans cette symbiose avec le milieu fluvial de la Musi. Si la ville moderne a aujourd'hui profondément modifié ce dialogue en draînant et comblant massivement cet environnement naturel, les banlieues est et surtout ouest présentent encore bien des caractéristiques qui devaient encore être celles de la ville toute entière au début de ce siècle ${ }^{24}$. Au fur et à mesure

23 Voir Wolters 1979a et Manguin 1982, et la bibliographie citée pour l'historique du débat. Obdeijn, dans les années 1930, a été l'exposant le plus convaincu de cette théorie, souvent adoptée ensuite sans esprit critique. Récemment, Sartono a tenté de la ressusciter (voir, en annexe, les titres de ses communications aux séminaires SPAFA).

${ }^{24}$ Palembang est aujourd'hui un ville portuaire prospère (787.000 habitants en 1980), qui connait une forte croissance. Elle avait 25.000 habitants seulement au début du 19e siècle, 74.000 en 1920 (Court 1821: 105; Jackson 1973: 4-5).

Il sera régulièrement fait référence dans cet article à des photos aériennes de la région de Palembang. Sauf indication contraire, le jeu de photos qui a été utilisé est une série au 1/5000e en noir et blanc datant de 1972-73 qui porte les références suivantes: «Peta jalur n¹62/PENAS/1973, reg. nVII/312A/TR-Chp». Ces photos, qui ont servi 
de l'interprétation des sites décrits plus loin, des détails seront donnés sur cet environnement qui viendront compléter cette présentation sommaire en y ajoutant en outre une certaine profondeur historique. Il me suffit de préciser ici les grandes lignes de la topographie des lieux ${ }^{25}$.

La ville traditionnelle - du moins celle qui n'était pas faite de maisons flottant sur le fleuve, mais était construite sur les berges et leur arrière-pays immédiat, jusqu'à environ $2 \mathrm{~km}$ vers l'intérieur - s'est toujours emparée des nombreux îlots de terrain surélevé que forment, d'une part, la pénéplaine en venant en ces lieux rejoindre les formations plus récentes, d'autres part les levées naturelles parfois larges de quelques centaines de mètres qui contiennent le cours du fleuve. Les premiers, appelés talang dans la région, peuvent être de taille et de hauteur variables, et sont entourées de dépressions marécageuses inondées en saison des pluies, les lebak, qui les séparent aussi des levées naturelles formant les berges de la Musi. C'est donc à cette dialectique entre l'humide et le sec, entre ce qui est régulièrement inondé et ce qui ne peut l'être, que l'on est partout confronté lorsqu'on cherche des sites archéologiques à Palembang et dans ses environs.

Le niveau de l'eau dans la région est affecté par deux facteurs principaux. D'une part, le goulet d'étranglement à travers lequel passe la Musi précisément à la hauteur de la banlieue ouest de Palembang affecte de façon considérable le niveau de l'eau et l'environnement du lebak situé immédiatement en amont, dans lequel coule la petite Sungei Lamidaro: cette dépression sert en quelque sorte de déversoir (comme d'ailleurs, à plus grande échelle, toute celle, bien plus vaste, dans laquelle coule la Musi en amont de Palembang) ${ }^{26}$. Il faut tenir compte d'autre part du fait qu'en ces lieux la Musi est encore affectée par une marée diurne qui, en période de vives eaux d'équinoxe, peut atteindre une amplitude de plus de quatre mètres (un mètre environ en période de mortes eaux de solstice) ${ }^{27}$.

à identifier les sites de Karang Anyar en 1984 (Manguin 1984a), ont ensuite fait l'objet d'une étude en collaboration entre le Puslit Arkenas et des spécialistes de photointerprétation (Surastopo 1985, Surastopo \& Sutikno 1985). L'autorisation de publier des photos aériennes étant un processus très long en Indonésie, elle n'a pu être obtenue à temps pour cet article. Je donne néanmoins en illustration une mauvaise photo du site principal de Karang Anyar prise par moi-même à partir du hublot d'un vol commercial en 1985.

Les cartes qui ont été le plus utiles sont: - Hoofdplaats Palembang, 1/5.000, 1922, en 6 feuilles (sur relevés de 1914-15). Elle a l'avantage d'indiquer pour les parties moins densément construites les courbes de niveau, et de différencier l'habitat en bois de celui construit en dur; - Town plan of Palembang, Hind 1051, 1/10.000, 10 édition de 1945, en 2 feuilles (sur des données de 1941); - Peta Kota Palembang, Firma Rhama and Co., 1/15.000, 1955.

${ }^{25}$ De nombreuses études environnementales ont été réalisées depuis quelques années sur Palembang et ses environs, la région subissant aujourd'hui, comme bien d'autres provinces indonésiennes, les effets d'un fort dévéloppement urbain et agricole. Outre l'expérience acquise sur le terrain, j'ai surtout utilisé ici les articles rassemblés par Tsubouchi \& Iljas 1980 et le livre de Scholz (1983, particulièrement le chapitre 6.3: «The Palembang Hinterland lebak Area»).

${ }^{26}$ Ce goulet d'étranglement a été créé lorsque, abandonnant son vieux lit qui faisait une boucle rallongeant sont cours de quelques $7 \mathrm{~km}$, la Musi a fini par couper à travers l'une des extrêmités de la formation plio-pleistocène au bord de laquelle est construite Palembang. Cet ancien bras est clairement visible sur les photos aériennes (spectre infra-rouge) au 1/50.000e de la série BAKO 78-01/1-1-1/2, toute comme sur l'imagerie Landsat. Sur les phénomènes d'ensemble de constriction du lit de la Musi et de la Komering par cette formation géologique à la hauteur de Palembang, voir Kaida (1980: 11) et Scholz 1983: 154.

27 Alkemade 1883: 53; Admiralty Tide Tables, vol. 3; Kaida 1980. 


\section{LES SITES DE LA ZONE OUEST}

\section{Le complexe de Karang Anyar}

Le complexe de Karang Anyar comprend un ensemble de trois sites situés dans le kampung du même nom, à $5 \mathrm{~km}$ environ du centre de Palembang sur la rive gauche de la Musi (cartes 3 et 4). Il est traversé par la route menant au kampung Gandus, situé $6 \mathrm{~km}$ plus loin en amont, sur la même rive de la Musi. Les trois principaux sites du complexe seront nommés ici A, B, C pour plus de commodité, en l'absence d'une toponymie bien établie localement.

\section{A. La topographie}

\section{Site A}

Situé au centre du complexe, ce site se distingue nettement de $\mathrm{B}$ et $\mathrm{C}$ par sa forme et sa complexité. Nommé parfois Kota Haur («la ville, ou l'enceinte, aux bambous haur») par les habitants du lieu, il a la forme d'un rectangle de $525 \mathrm{~m}$ sur $275 \mathrm{~m}$ de côté et se compose, pour l'essentiel, d'une terrasse centrale de $240 \mathrm{~m}$ sur $325 \mathrm{~m}$ entourée d'eau ${ }^{28}$. Les fossés est et ouest ne sont que de simples canaux d'environ $10 \mathrm{~m}$ de large qui relient les réservoirs nord et sud. Celui du sud n'est large que de $50 \mathrm{~m}(50 \mathrm{~m} \times 250 \mathrm{~m})$; celui du nord, par contre, est trois fois plus large $(140 \mathrm{~m} \times 250 \mathrm{~m})$ et, en son centre géométrique, on y trouve une petite île carrée de $40 \mathrm{~m}$ de côté (A' sur la carte 4; elle est appelée parfois Pulau Cempaka, l'«île aux arbres cempaka»). La grande terrasse du site A s'élève d'environ $0,50 \mathrm{~m}$ au-dessus du niveau de l'eau des réservoirs et fossés en fin de saison des pluies, lorsque leur surface est presque toute entière utilisée pour la culture du riz inondé29. Par contre, l'île au centre du réservoir nord est nettement plus haute et s'élève de façon régulière de ses berges vers son centre géométrique, où elle atteint environ $2 \mathrm{~m}$ au-dessus du niveau de l'eau.

Le sud de la terrasse centrale est aujourd'hui coupé d'est en ouest par la route asphaltée menant à Gandus, qui traverse aussi les deux canaux latéraux du site sur des levées de terre (traversées de conduites en ciment pour laisser circuler l'eau). Les deux côtés de la route ont été assez récemment occupés et construits, car nous sommes ici très exactement sur le front ouest du processus d'urbanisation de la ville: sur les photos aériennes de 1972, une seule rangée de maisons apparaissait et la terrasse centrale, hors cette rangée, était libre de toute construction et encore plantée de grands arbres fruitiers. Depuis, deux écoles et de nombreuses maisons particulières ont été construites sur cette terrasse et le processus parait s'accélerer, oblitérant ainsi nombre de sites potentiels. Seul le quart nord-est de la terrasse est à ce jour libre de toute construction et planté de manioc. L'île A' porte de grands arbres fruitiers et elle est aussi plantée de manioc.

${ }^{28}$ Ces dimensions sont approximatives et on été relevées sur les photos aériennes au 1/5.000. Seul quelquesunes d'entre elles ont été vérifiées par des mesures sur le terrain, et elles nous ont permis de confirmer sans équivoque l'échelle des photos aériennes (Manguin 1984a).

29 En période de vives eaux, lorsque l'amplitude des marées peut atteindre $4 \mathrm{~m}$ à l'embouchure de la Musi, la partie sud de la terrasse peut à l'occasion se trouver sous quelques dizaines de cm d'eau comme j'ai pu le constater en novembre 1986. Mais la déforestation galopante en amont de Palembang parait aujourd'hui être à l'origine d'un rehaussement du lit de la rivière par excès de sédimentation, qui a pour conséquence une tendance croissante à l'inondation des zones situées en arrière des levées de terre formant les berges de la Musi (Kaida 1980: 11). 
La surface de la terrasse principale, telle qu'elle peut encore être observée aujourd'hui, est pratiquement plane. Cependant, un examen approfondi des photos aériennes, doublé de vérifications in situ lorsque cela était encore possible, révèle certaines particularités topographiques intéressantes dont il faudrait pouvoir prouver qu'elles sont anciennes et qui mériteront de ce fait d'ế re fouillées. Ainsi, un petit réseau de canaux isole clairement le quart nord-est de la terrasse. Un canal de $6 \mathrm{~m}$ de large court sur environ $150 \mathrm{~m}$ perpendiculairement à la berge nord, en direction du sud (en raison des constructions modernes, il est impossible aujourd'hui de savoir s'il rejoignait la berge sud de la terrasse). Sur la photo aérienne de 1972, ce canal bifurquait à une trentaine de mètres de la berge nord, pour courir ensuite vers le sud, parallèle au premier canal, à $15 \mathrm{~m}$ plus à l'est. Entre ces deux canaux, une petite éminence (environ 1,5m de haut) est encore clairement visible sur le terrain (point ra) sur la carte 4). Ce deuxième canal semble ensuite s'écarter pour rejoindre le fossé est, mais il se perd dans une zone marécageuse qui rend difficile la vérification de ce point sur le terrain. Une légère élévation de l'angle nord-ouest de la terrasse mériterait aussi attention. Enfin, en me fondant sur les seules photos aériennes, j'ai porté en pointillé sur la carte quelques autres particularités topographiques qui pourraient indiquer un site antérieur (mais qui sont aujourd'hui presque entièrement oblitérées par des constructions récentes).

Site $B$

A quelques $200 \mathrm{~m}$ au sud-ouest du site $\mathrm{A}$, il s'agit d'un réservoir carré d'environ $150 \mathrm{~m}$ de côté, avec en son centre géométrique une île carrée de $50 \mathrm{~m}$ de côté. Ces mesures ne sont pas précises car, sur les photos aériennes, les contours n'apparaissent pas aussi clairement que ceux du site A. En effet, sa partie inondée n'est que partiellement utilisée pour des rizières et le quartier nord-est est maintenant presque comblé et relié à la terre ferme environnante. Les autres berges, tant de l'île que du réservoir, sont encore bien visibles sur le terrain. La surface de l'île centrale est irrégulière, s'élevant parfois jusqu'à $1,5 \mathrm{~m}$ au-dessus du niveau de l'eau. En 1984, l'île était encore inhabitée et portait de nombreux grands arbres fruitiers.

Aucun vestige n'a été découvert en surface lors d'une brève visite du site. Des témoignages selon lesquels beaucoup de tessons auraient été trouvés le long du petit canal qui court de la berge est du réservoir vers un cours d'eau menant à la Musi n'ont pas pu être vérifiés.

Site $C$

Ce site jouxte le flanc est du site A, dont il n'est séparé que par une langue de terre de $150 \mathrm{~m}$ de large. Les dimensions extérieures de ce très grand réservoir carré sont d'environ $350 \mathrm{~m}$ de côté. Ici encore, une petite île centrale, carrée elle aussi $(60 \times 60 \mathrm{~m})$, est présente en son centre géométrique. Les limites entre le réservoir et les terrains émergés qui l'entourent sont sans équivoque sur les photos aériennes, mais par endroits indétectables sur le terrain, en particulier dans sa moitié nord, très marécageuse.

L'île centrale, qui n'a été que très brièvement explorée, n'a à ce jour rien livré en termes de vestiges archéologiques.

\section{Orientation des sites}

Les trois sites $\mathrm{A}, \mathrm{B}$, et $\mathrm{C}$ de Karang Anyar sont très précisément orientés selon une grille orthogonale. Les plus longs côtés du site principal A suivent un axe orienté à $352^{\circ}$ (écarté de $8^{\circ}$ à peine d'un axe nord-sud). Les autres côtés des trois réservoirs et de leurs îles centrales 
sont parallèles ou perpendiculaires à cet axe principal (la berge nord du réservoir nord du site A, en fait, n'est pas parfaitement perpendiculaire au côte le plus long du rectangle et se rapproche légèrement d'un axe est-ouest).

\section{Les canaux}

Les trois sites de Karang Anyar, lorsqu'on les étudie sur les photos aériennes, s'intègrent assez clairement au sein d'un réseau de canaux suivant en général la même grille orthogonale: ils relient, semble-t-il, non seulement les sites entre eux, mais aussi ceux-ci au long canal de Suak Bujang au nord et, au sud, peut-être au fleuve lui-même. Le développement urbain sur la zone située entre la route de Gandus et la rive de la Musi, qui en a amené en grande partie le comblement par apport récent de terre, ne permet malheureusement plus aujourd'hui de vérifier grand chose sur le terrain. Mais si l'on compare la carte au 1/5.000 de 1922, les photos aériennes de 1973 et la situation présente (en faisant abstraction des apports artificiels), il apparait qu'il y a quelques décennies seulement la zone située au sud immédiat et au sud-est du site $A$ était marécageuse et séparée du fleuve par une levée de terrain large de $100 \mathrm{~m}$ à $200 \mathrm{~m}$ seulement, situation fréquemment rencontrée en amont de Palembang ${ }^{30}$. Les traces d'une ancienne embouchure de rivière apparaissent même assez clairement sur les vues aériennes, à une centaine de mètres à peine au sud du site $\mathrm{A}$. Il est difficile dans ces conditions de comprendre la situation exacte des sites $\mathrm{A}, \mathrm{B}$ et $\mathrm{C}$ par rapport au fleuve à l'époque de leur creusement. J'ai porté sur la carte les quelques tracés qui m'ont paru les mieux attestés. Je tenterai plus loin d'analyser leurs fonctions.

\section{B. Les vestiges archéologiques}

Le site A de Karang Anyar a livré à ce jour, en ordre dispersé, nombre de vestiges archéologiques isolés, et a fait en outre en 1985 l'objet d'une fouille rapide et peu fructueuse par le Puslit Arkenas.

\section{Les céramiques trouvées en surface}

Dès sa découverte en 1984, ce site a eu pour particularité de livrer, outre une quantité notable de tessons de terres cuites locales, indatables dans l'état présent des recherches, des céramiques chinoises de dates assez homogènes, puisqu'il s'agit à $86,5 \%$ de pièces de la famille «vert-olive» et à $92,9 \%$ de pièces contemporaines de Sriwijaya.

Tessons de céramique chinoise trouvés en surface à Karang Anyar (totaux et pourcentages)

\begin{tabular}{|c|c|c|c|c|c|c|c|c|}
\hline Siècles: & $8-9$ & $9-10$ & $11-13$ & 14 & $15-17$ & $18-19$ & $?$ & Total \\
\hline & $257(86.5 \%)$ & 0 & $3(1.0 \%)$ & $16(5.4 \%)$ & $4(1.3 \%)$ & $12(4.0 \%)$ & $5(1.7 \%)$ & $297(100 \%)$ \\
\hline & \multicolumn{3}{|c|}{$\begin{array}{c}\text { Sriwijaya } \\
276(92.9 \%)\end{array}$} & $\begin{array}{c}\text { post-Sriwijaya } \\
16(5.4 \%)\end{array}$ & $5(1.7 \%)$ & $297(100 \%)$ \\
\hline
\end{tabular}

30 Kaida 1980. 


\section{Autres vestiges}

Le site a encore livré en surface quelques perles de verre et surtout bon nombre de briques. Deux fosses d'un mètre de côté et profondes d'environ $1 \mathrm{~m}$, creusés par les habitants dans le quartier nord-ouest de la terrasse centrale, ont clairement révélé l'amorce de rangées de grosses briques à environ $0,40 \mathrm{~m}$ de profondeur (ill.). Quelques fragments ont été trouvés en surface, provenant de briques de grande taille $(29 \times 6 \times 19 \mathrm{~cm}$ ou plus $)$, de facture ancienne: la pâte est souvent grisâtre en son cœur, il y apparait des incrustations de fragments de céramique et de mica et des trous laissés par des grains de riz ayant servi à empêcher les briques de se fendre à la cuisson.

Sur la petite île de Pulau Cempaka (A'), les paysans ont dégagé des centaines de briques de taille moyenne ( $\mp 27 \times 4 \times 13 \mathrm{~cm}$ ), de pâte plus homogène, semble-t-il, que celle de plus grande taille trouvées ailleurs (ill.). Ils y ont trouvé aussi nombre de fragments de tuile, des perles en verre et en terre cuite (ill.), ainsi que des fragments de verre. Des sondages géo-magnétiques effectués sur l'île en 1985, suivis de carottages, ont confirmé qu'elle était littéralement truffée de fragments de brique, et paraissent indiquer que le sud a plus de chances de livrer encore des structures en bon état ${ }^{31}$.

Entre les sites $\mathrm{A}$ et $\mathrm{C}$, à une centaine de mètres du coin nord-ouest de $\mathrm{C}$ (point $\mathrm{D}$ sur la carte), près d'un petit hameau, d'assez nombreuses briques de grande taille sont visibles à la surface du sol, et les habitants du lieu disent en trouver régulièrement lorsqu'ils creusent.

\section{Les fouilles du Puslit Arkenas de 1985}

Une campagne limitée en temps et en moyens a été organisée en 1985 par le Puslit Arkenas, sous la direction de Bambang Budi Utomo ${ }^{32}$. Un puits de sondage de $1 \mathrm{~m}$ de côté et trois carrés de $2 \mathrm{~m}$ de côté ont été fouillés par couches artificielles de $10 \mathrm{~cm}$ d'épaisseur dans le quartier nord-ouest de la terrasse principale, dans l'axe supposé des deux amorces de rangées de briques révélées dans les trous creusés par les habitants du lieu (cf. supra et ill.). En ce qui concerne ces structures supposées, le résultat a été très décevant: si des fragments de briques anciennes ont été trouvés en grand nombre, ainsi que quelques briques entières, aucune structure n'est apparue et il est clair que le site a été dérangé à une date antérieure.

Les couches productives ne vont pas plus profond qu'une soixantaine de centimètres; elles sont composées d'une argile friable et humide de couleur brune, avec quelques tâches noires semblant indiquer la présence de débris organiques. On y a trouvé, en quantités faibles si on les compare aux trouvailles de surface, outre les poteries locales, des céramiques d'importation et des perles de verre ${ }^{33}$.

\section{Le STIE DE LORONG JAMBU}

\section{A. La topographie}

Entre $300 \mathrm{~m}$ et $400 \mathrm{~m}$ à l'est du réservoir $\mathrm{C}$, immédiatement au nord de Jalan Gandus, l'examen des photos aériennes révèle encore des particularités topographiques qui ne peuvent

31 Surastopo 1985: iv. 30.

${ }^{32}$ Les indications qui suivent sont tirées du rapport de fouilles (Budi Utomo \& Nurhadi Rangkuti 1985).

${ }^{33}$ L'identification et le dénombrement précis des céramiques trouvées pendant la fouille n'apparait pas dans le rapport inédit de fouilles (Budi Utomo \& Nurhadi 1985). Leur nombre était faible, de l'ordre de la trentaine par 
qu'être faites de main de l'homme et qui ont été confirmées par une inspection sur le terrain (carte 4). Ici encore, l'urbanisation de la banlieue ouest de Palembang a oblitéré bien des détails, car nous sommes déjà ici à la limite du tissu urbain des années 1970 et une partie de la topographie est déjà difficilement lisible sur les photos de l'époque.

Il n'en reste pas moins qu'on y distingue une plateforme surélevée d'environ $0,50 \mathrm{~m}$ au-dessus d'un terrain avoisinant plus fréquemment inondé, aux côtés nettement perpendiculaires les uns par rapport aux autres dans la partie la plus occidentale, tandis que la partie est, plus construite, était déjà difficilement lisible en 1972. Ce côté ouest du site, le seul mesurable, court sur environ $100 \mathrm{~m}$ et il est prolongé, perpendiculairement, par une langue de terre, pareillement surélevée, de $200 \mathrm{~m}$ de long et de $25 \mathrm{~m}$ de large. Les berges nord du site sont bordées par un bras de rivière qui se jette dans la Sungei Tatang et qui joignait ainsi encore, sur les photos aériennes de 1972, la Musi au réservoir C. Ce cours d'eau (mentionné, comme on le verra plus loin, dès le $16 \mathrm{e} / 17 \mathrm{e}$ siècle) pouvait encore être remonté en bateau jusqu'aux années 1960, mais son cours est aujourd'hui interrompu.

\section{B. Les vestiges archéologiques}

Sur les chemins non encore pavés et entre les pilotis bas des maisons traditionnelles densément construites sur cet îlot, la surface du site a révélé une quantité notable de tessons de céramique chinoise dont la datation est particulièrement intéressante. On y trouve en effet une très forte proportion de céladons d'excellente qualité datant des Song et des Yuan, soit du 11e ou 14e siècles, à l'exclusion totale des périodes antérieures (pas une seule pièce des familles «vert-olive» ou Yue si courantes sur les sites voisins de Karang Anyar et Bukit Seguntang). Aucune pièce Ming n'a été encore trouvée et l'occupation du site parait ne reprendre qu'après le 18ème siècle, à en juger par ces seuls vestiges de surface. Quelques-unes des céramiques Song ont été trouvées sur la section mise à nu lors du creusement, par les habitants, d'un petit canal coupant la langue de terre, à environ $0,40 \mathrm{~m}$ de profondeur.

Tessons de céramique chinoise trouvés en surface à Lorong Jambu

(totaux et pourcentages)

\begin{tabular}{|c|c|c|c|c|c|c|c|c|}
\hline Siècles: & $8-9$ & $9-10$ & $11-13$ & 14 & $15-17$ & $18-19$ & $?$ & Total \\
\hline & 0 & 0 & $135(56.2 \%)$ & $58(24.2 \%)$ & 0 & $42(17.5 \%)$ & $5(2.1 \%)$ & $240(100 \%)$ \\
\hline & $\begin{array}{c}8-10 \\
0\end{array}$ & $\begin{array}{c}11-14 \\
193(80.4 \%)\end{array}$ & $\begin{array}{c}15-17 \\
0\end{array}$ & $42(17.5 \%)$ & $5(2.1 \%)$ & $240(100 \%)$ \\
\hline
\end{tabular}

Quelques perles de verre ont été trouvées en surface. Des habitants du lieu nous ont dit avoir trouvé de nombreuses et grandes briques dans la partie est du site, mais nous n'avons pas pu le vérifier.

carré de fouilles, et composé exclusivement de tessons de la famille vert-olive (communication personnelle de B. Budi Utomo). 


\section{Entre Karang Anyar et Buktt Seguntang}

Pour des questions de commodité, nous regrouperons ici nombre de particularités topographiques et de sites qui soit ont été fouillés, soit ont livré une assez forte concentration de vestiges en surface pour être identifiés comme tels. A l'exception des canaux, et contrairement aux sites précédents, aucun d'entre eux ne possède encore de caractéristiques bien définies sur le terrain.

\section{A. Le canal de Suak Bujang}

La toponymie locale attribue à ce cours d'eau le qualificatif de suak «zone basse, marécageuse», telle qu'on les rencontre en particulier le long du cours d'une rivière; bujang désigne en général les «célibataires», mais, sous sa forme affixée «perbujangan», il sert à qualifier des objets ou des lieux associés à la royautée ${ }^{34}$.

Il s'agit ici, avec les sites de Karang Anyar, de l'un des éléments les plus saillants de la topographie de l'ouest de Palembang, telle qu'elle apparait sur le jeu de photos aériennes utilisé: un cours d'eau presque parfaitement rectiligne, de trois kilomètres de long (orienté $255^{\circ} / 75^{\circ}$ ), intersecte le méandre de la Musi à l'intérieur duquel sont situés les sites de Karang Anyar, les isolant ainsi en quelque sorte de la terre ferme à leur nord. Ce canal est normalement en eau en saison des pluies. Il a environ $12 \mathrm{~m}$ de large (mesurés sur la photo aérienne et vérifiés sur le terrain, au nord de Karang Anyar, là où les berges en sont bien définies, car entretenues par la riziculture) (ill.).

En un point situé à environ $1 \mathrm{~km}$ à l'ouest de Karang Anyar, le cours du Suak Bujang coupe sur environ $200 \mathrm{~m}$ droit à travers une petite élévation de terrain (d'environ $5 \mathrm{~m}$ au-dessus du niveau de l'eau). Cette particularité, outre le fait que son parcours est parfaitement rectiligne, permet d'affirmer que le Suak Bujang est sans aucun doute possible un canal fait de main d'homme. A l'ouest de cette éminence, son cours est aujourd'hui interrompu par la levée de terrain sur laquelle a été construite la piste en terre menant de Jalan Gandus au Kampung Bukit Lama. A l'ouest de cette levée, il se perd d'abord aujourd'hui dans une zone basse, souvent inondée, avant de redevenir plus visible vers sa jonction avec la Musi, où il coupe à travers un terrain plus élevé (environ $1,5 \mathrm{~m}$ du niveau de l'eau un mois de juin). Il rejoint à environ 150m de la rive du fleuve un court affluent de la Musi, la Sungei Rambutan.

A l'est de Karang Anyar, le Suak Bujang a un cours bien rectiligne jusqu'à son confluent avec un affluent de la Musi, la rivière dite aujourd'hui Sungei Kedukan Bukit, à $1 \mathrm{~km}$ en amont du confluent de cette dernière avec le fleuve. Ce cours d'eau reste bien dans l'axe du canal qu'il prolonge vers l'est, mais ses rives sont désormais moins rectilignes et il fait sur $500 \mathrm{~m}$ quelques méandres, avant de retrouver un cours parfaitement rectiligne sur ses derniers $500 \mathrm{~m}$, en traversant la zone densément peuplée qui borde le fleuve, construite de maisons traditionnelles en bois sur pilotis. La Kedukan Bukit des cartes modernes prend sa source à environ deux kilomètres au nord de son confluent avec le Suak Bujang, le long du versant oriental de Bukit Seguntang. Au début du siècle, on pouvait ainsi encore aisément rejoindre cette colline par la rivière. Ces particularités indiquent donc bien que le canal creusé de main d'homme rejoint en fait le cours naturel d'une rivière, régularisé à son tour dans ses derniers $500 \mathrm{~m}$ en zone d'habitat dense.

34 Voir le dictionnaire malais de Wilkinson, s.v. 
En fait, la comparaison des photos aériennes de 1972-73, de la carte de 1922 et d'un passage du Sejarah Melayu permettent de mieux reconstituer encore la topographie ancienne des lieux: la légende de l'origine des souverains de Melaka, transcrite vers les $16 \mathrm{e}-17 \mathrm{e}$ siècles, mais encore vivante au début du 20e siècle à Palembang, dit bien que «la rivière de Palembang s'appelle la Tatang»; elle dit aussi que, en amont, près de Bukit Seguntang, elle porte le nom de Sungei Melayu (un toponyme, rappellons-le, associé à Sriwijaya dès le récit de I-Jing au $7 \mathrm{e}$ siècle $)^{35}$. Or les cartes indiquent toutes que la Tatang débouche sur la Musi quelques $300 \mathrm{~m}$ au sud de l'embouchure de la Kedukan Bukit (et on a vu qu'elle rejoignait le réservoir C de Karang Anyar; cf. la description du site de Lorong Jambu). En fait, un bras aujourd'hui pratiquement comblé la reliait sur la carte de 1922 à la Kedukan Bukit, précisément à l'aval des méandres cités plus haut (voir carte 3). Il est donc clair que c'est bien la Sungei Tatang (alias Sungei Melayu) qui coulait de Bukit Seguntang à la Musi et que le canal de Suak Bujang la rejoignait en amont des méandres, au point où elle infléchit son cours vers l'est. La partie rectiligne, en aval des méandres et jusqu'à la Musi, constituait probablement un autre de ces bras de rivière qui coupent à travers la levée naturelle formant la rive du fleuve et il a probablement été canalisé à une époque postérieure.

Le terme kedukan définit l'action de «creuser de main d'homme»: le toponyme complet kedukan bukit pourrait donc être traduit par «creusement de la colline». Le cours inférieur de la Kedukan Bukit des cartes modernes ne traverse pas de relief notoire en aval de son confluent avec le canal de Suak Bujang: il y a donc très vraisemblablement eu déplacement du toponyme Kedukan Bukit du canal de Suak Bujang lui-même (dont on a vu qu'il coupait bien à travers le relief) vers l'ancienne rivière Tatang, dont le cours se confondait auparavant en partie avec celui du canal ${ }^{36}$.

\section{B. Sites divers (carte 3)}

Lorsque l'on franchit le canal de Suak Bujang, au nord du site A de Karang Anyar et pendant $1 \mathrm{~km}$ environ vers le nord, le terrain limité à l'est par la Sungei Kedukan Bukit et à l'ouest par la piste en terre reliant Jalan Gandus au Kampung Bukit Lama est plat et sec dans son ensemble, présentant néanmoins parfois de faibles éminences. Ce triangle d'environ $1 \mathrm{~km}^{2}$ a livré un nombre important de sites appartenant clairement à l'époque de Sriwijaya; le tableau cidessous est sans ambiguïté: l'occupation de cette zone ne parait avoir repris qu'après le 18e siècle. On rappelera que nombre de fragments de statues et surtout l'une des principales inscriptions de cet Etat, celle de Kedukan Bukit, proviennent de points malheureusement indéterminés le long du cours de la rivière de même nom, qui borde à l'est ce triangle ${ }^{37}$.

Aux environs de Karang Anyar des tessons isolés de céramique vert-olive ont été trouvés

35 Le passage dit, dans la version Raffles: Ada sebuah negeri di tanah Andelas, Palembang namanya (...) Muara Tatang nama sungeinya. Maka di hulu Muara Tatang itu ada sabuah sungei, Melayu namanya, dalam sungei itu ada sebuah bukit Siguntang Mahameru namanya (Winstedt 1938: 54; voir aussi Westenenk 1923 pour une discussion de ce passage). Pour le texte de I-jing, voir Takakusu 1896, Chavannes 1894, et le nouveau commentaire de Wolters (1986) pour ses passages sur Sriwijaya. Le Malayu du temps de I-jing n'a jamais été précisément localisé et il est évidemment tentant, sur la base de ce passage du Sejarah Melayu, de suggérer la zone de Bukit Seguntang.

${ }^{36}$ Le toponyme Suak Bujang (swa-boedjang) est déjà attesté dans Praetorius (1843: 387), à côté de Bukit Seguntang, pour désigner une région à la périphérie de Palembang, sans qu'il y soit fait mention d'un canal.

37 Voir sur ces inscriptions Coedès 1930, Casparis 1956, 1982 et les điverses publications de Schnitger pour la statuaire. 
en surface, aux abords immédiats du canal de Suak Bujang. En outre, en septembre 1987, à la fin d'une saison sèche exceptionnellement rigoureuse, les paysans avaient creusé $1 \mathrm{~m}$ sous la surface du fond du canal asséché pour atteindre la nappe phréatique. L'examen de la terre retournée a livré de nombreux tessons de ces mêmes céramiques vert-olive, des perles de verre et de terre cuite et quelques fragments de verre brut. A l'ouest, au pied de la colline que traverse le canal, quelques autres tessons de céramique datée des Tang on été trouvés en surface (associés à des terres cuites et à quelques tessons bleus et blancs tardifs; site $\mathrm{E}$ sur la carte).

A une centaine de mètres au nord du Suak Bujang, et immédiatement au nord du site A de Karang Anyar, le lieu-dit Kramat Pule, légèrement surélevé par rapport au terrain avoisinant, a livré des céramiques Tang en nombre notable (non décomptées).

A quelques dizaines de mètres de la berge nord de Suak Bujang, à l'intersection avec la petite route asphaltée suivant une conduite d'adduction d'eau (Jalan PAM, abrégé en JP sur le tableau suivant et sur la carte), la surface du sol a livré une concentration de tessons surtout composée de tessons du $8 \mathrm{e}$ ou $9 \mathrm{e}$ siècles et de quelques pièces récentes, ainsi que des terres cuites locales. Les paysans nous ont dit y avoir trouvé des «statues» qui, à en juger par les descriptions, seraient très rudimentaires.

Un peu plus à l'ouest encore, à environ $100 \mathrm{~m}$ au nord du Suak Bujang, au lieu-dit Ladang Sirap (LS), une petite éminence arasée par une entreprise de travaux publics a livré une forte quantité de tessons presque exclusivement de la famille vert-olive (8e-9e siècles), provenant pour la plupart de jarres d'assez grosse taille. On y a aussi trouvé, comme à l'accoutumée, des perles, des fragments de verre et des céramiques locales. Une école (SMP Negeri 32) a depuis été construite sur le site.

Tessons de céramique chinoise trouvés en surface entre KA et BS (totaux et pourcentages)

\begin{tabular}{|c|c|c|c|c|c|c|c|c|}
\hline Siècles: & $8-9$ & $9-10$ & $11-13$ & 14 & $15-17$ & $18-19$ & $?$ & Total \\
\hline JP & $24(53.3 \%)$ & 0 & $2(4.4 \%)$ & $2(4.4 \%)$ & $1(2.2 \%)$ & $9(20.0 \%)$ & $7(15.6 \%)$ & $45(100 \%)$ \\
\hline $\mathrm{KU}$ & $126(58.1 \%)$ & 0 & $4(1.8 \%)$ & $2(1.0 \%)$ & $1(0.5 \%)$ & $81(37.3 \%)$ & $3(1.3 \%)$ & $217(100 \%)$ \\
\hline LS & $160(92.0 \%)$ & 0 & $2(1.2 \%)$ & $2(1.1 \%)$ & $1(0.6 \%)$ & $9(5.2 \%)$ & 0 & $174(100 \%)$ \\
\hline Totaux & $310(71.1 \%)$ & 0 & $8(1.8 \%)$ & $6(1.4 \%)$ & $3(0.7 \%)$ & $99(22.7 \%)$ & $10(2.3 \%)$ & $436(100 \%)$ \\
\hline & \multicolumn{4}{|c|}{$\begin{array}{c}\text { Sriwijaya } \\
324(74.3 \%)\end{array}$} & $\begin{array}{c}15-17 \\
3(0.7 \%)\end{array}$ & $\begin{array}{c}18-19 \\
99(22.7 \%)\end{array}$ & $\begin{array}{c}? \\
10(2.3 \%)\end{array}$ & $436(100 \%)$ \\
\hline
\end{tabular}

$\mathrm{JP}=$ Jalan Pam $\quad \mathrm{KU}=$ Kambang Unglen $\quad$ LS $=$ Ladang Sirap

\section{Les fouilles du Puslit Arkenas à Kambang Unglen}

Le directeur de l'école SMP PGRI 7 située à proximité du lieu-dit Kambang Unglen, a rassemblé depuis près d'une année, dans les environs de son école, nombre de tessons de céramique (dont beaucoup d'époque Tang et quelques pièces Song), des perles, deux abouts de tuile, un lingam de facture très rudimentaire et un fragment d'inscription (ill.). Un examen sommaire de la seule photo de l'inscription par MM. de Casparis et Bœchari parait indiquer qu'il s'agirait bien là encore d'une inscription en vieux malais, mais qu'elle serait du $8 \mathrm{e}$ siècle (soit plus tardive que les autres inscriptions de Palembang). 
Le site de Kambang Unglen est connu depuis longtemps pour avoir livré en surface une forte quantité de perles, en verre pour la plupart, mais aussi en pierres semi-précieuses (ills.). Le fait que ces perles ont été trouvées en association avec, à la fois, des fragments de verre brisé (matière première certainement importée d'Inde ou du Moyen-Orient) et des scories de verre fondu permet d'inférer qu'il s'agit là très vraisemblablement d'un centre de production de ces perles, si courantes en Asie du Sud-Est dans les sites du premier millénaire ${ }^{38}$.

En 1985, deux puits de sondage de 1m de côté ont été fouillés et un inventaire systématique des vestiges de surface effectué ( 11 carrés de $5 \mathrm{~m}$ de côté, soit $275 \mathrm{~m}^{2}$ ). Les puits indiquent que les vestiges archéologiques (en particulier le verre, avec quelques fragments de brique et quelques tessons de céramiques locales et d'importation) sont plus nombreux en surface qu'en profondeur: le site semble donc avoir été bouleversé. La zone stérile a été atteinte dès $25 \mathrm{~cm}$ de profondeur. L'inventaire systématique de surface, outre des tessons de céramiques locales et d'importation et quelques fragments de tuile, a livré 2458 pièces de verre, perles entières ou brisées, matière première ou scories de verre fondu ${ }^{39}$.

En 1986, une exploration des environs de Kambang Unglen a révélé l'amorce d'une surface pavée de briques, à l'arrière de l'école SMP PGRI $7^{40}$. Cette découverte a rapidement été suivie d'une campagne de fouille du Puslit Arkenas, plus longue et fructueuse que celle de 1985.

Onze carrés de $2 \mathrm{~m}$ sur $2 \mathrm{~m}$ y ont été fouillés par couches artificielles en deux zones écartées de $2 \mathrm{~m}$. Entre $15 \mathrm{~cm}$ et $50 \mathrm{~cm}$ environ de la surface du sol, essentiellement plat en cet endroit, ces fouilles ont révélé une couche unique de briques alignées, endommagée par endroits. Les limites de ce plancher n'ont pas été clairement atteintes, et on doit estimer à ce stade qu'il couvrait une surface minimale de $10 \mathrm{~m} \times 7 \mathrm{~m}$. A en juger par l'orientation des briques, l'un des axes de cette structure devait s'écarter de $10^{\circ}$ vers l'est d'un axe nord-sud. Certaines briques présentaient des trous circulaires de $10 \mathrm{~cm}$ de diamètre, et quelques trous d'un diamètre de $30 \mathrm{~cm}$ environ ont été creusés à travers plusieurs briques; leur fonction n'a pas encore été éclaircie car leur position ne parait pas être régulière.

Cette couche unique de briques de taille moyenne $(31 \times 16 \mathrm{~cm})$, posée sur un sol assez meuble, est difficile à interpréter tant qu'une plus grande surface de ce site ne sera pas fouillée. Il ne peut en aucun cas s'agir d'un bâtiment construit en briques. Peut-être est-on en présence du plancher d'un pavillon couvert d'un toit (on a trouvé des fragments de tuiles dans les environs), ou peut-être aussi d'un chemin pavé menant à un site encore à découvrir.

Les minces couches fouillées pour atteindre ce plancher ont révélé un assortiment de céramiques locales, de perles et de céramiques d'importation comparable aux trouvailles de surface; les céramiques d'importation (dont le dénombrement précis n'était pas effectué à la date de rédaction de cet article) présentaient une séquence s'étendant jusqu'au $17 \mathrm{e}$ siècle, mais avec une majorité de tessons d'époque Tang ${ }^{41}$.

38 Voir Sukendar 1975 pour une brève analyse des perles de Kambang Unglen. Sur les perles trouvées dans les sites de l'Asie du Sud-Est et leur production, lire en particulier Lamb 1965, 1966, plus particulièrement consacrés à des sites associès à Sriwijaya; voir aussi Harrison 1964, Kemchati Thepchai 1983a.

39 Budi Utomo \& Nurhadi 1985. On trouvera dans ce rapport une analyse typologique détaillée des perles trouvées à Kambang Unglen. Pour mieux comprendre la fonction de tels sites, il faudrait pouvoir comparer ces résultats, complétés par des analyses chimiques, à ceux obtenus dans les nombreux sites sriwijayens et présriwijayens qui ont livré de telles perles, puis, en ce qui concerne surtout la matière première, aux verres trouvés dans les sites indiens et moyen-orientaux. Il y a là matière à recherche.

40 Manguin 1986.

41 Budi Utomo 1987 et communication personnelle. 
Les fouilles n'ont pas été poursuivies au-delà de la surface de briques lorsque celle-ci était présente et intacte: on ne peut donc avoir la preuve que ce plancher constitue un terminus a $q u o$, au-delà duquel les céramiques chinoises ne seraient plus présentes (même si lorsqu'elle était endommagée, la couche stérile parait avoir été vite atteinte). Le seul carré de fouilles où l'on a trouvé une couche de briques intacte n'a pas quant à lui livré un seul tesson de céramique; mais ce plancher s'y trouve à moins de $30 \mathrm{~cm}$ de la surface d'un sol dont on sait qu'il a été retourné pour la culture du manioc et cette absence n'est donc en soi pas significative.

\section{Les sites de Talang Kikm}

\section{Talang Kikim}

A l'ouest d'une ligne qui mènerait de l'embouchure de la Sungei Rambutan jusqu'à Bukit Seguntang on trouve une région dans laquelle les petites dépressions (lebak) et les petites éminences (talang) alternent d'abord avant de se transformer, plus à l'ouest, en une vaste dépression marécageuse, au centre de laquelle coule une petite rivière, la Sungei Lamidaro. Quelques talang y émergent néanmoins qui ne sont accessibles, même en saison sèche, qu'en franchissant des diguettes, des chemins de planches surélevés ou encore en pirogue ${ }^{42}$. L'un de ces îlots, de surface considérable, situé à $1 \mathrm{~km}$ au sud-ouest de Bukit Seguntang, sur la rive gauche de la Lamidaro, porte le nom de Talang Kikim. Un hameau est construit dessus. Les alentours de ce hameau ont livré, en surface, quelques tessons de céramiques de provenance diverses (Chine, Viêt-nam et Thailande), dont plus de $84 \%$ sont postérieurs au $15 \mathrm{e}$ siècle, ce qui indique clairement une occupation tardive du talang (TK sur le tableau ci-dessous).

\section{Talang Kikim (seberang)}

Mais si l'on traverse la Lamidaro (navigable en cet endroit par des barques) et que l'on parcourt quelques $300 \mathrm{~m}$ vers l'ouest, la situation est alors toute autre. On se trouve dans une zone marécageuse qui, il y a une dizaine d'années, a commencé à être draînée pour la culture du riz. En défrichant leurs champs, les paysans nouvellement installés trouvèrent en certains points des quantités considérables de tessons de céramiques. Plusieurs visites des lieux ont confirmé leur richesse: les grosses digues des rizières nouvellement ouvertes étaient en certains points pratiquements faites de tessons. Or tous les tessons trouvés sur ce site (TKS sur le tableau ci-dessous) appartiennent, sans véritable exception, à la famille vert-olive et datent donc des $8^{\mathrm{e}}$ ou $9^{\mathrm{e}}$ siècles. Tout l'éventail de formes y est représenté: bols à pied plein et marques de cuisson, bassins et surtout une quantité considérable de fragments de jarres de tailles diverses, avec des pièces dont la base pouvait atteindre plus de $20 \mathrm{~cm}$ de diamètre (soit des jarres, si on les compare aux pièces entières que l'on connait par ailleurs, de près de $0,50 \mathrm{~m}$ de haut). Un échantillon de 124 tessons choisis au hasard est dénombré ci-dessous (TKS).

\section{Sungei Tapak}

A la hauteur de Talang Kikim, un petit cours d'eau se jette dans la Lamidaro, la Sungei Tapak, venant de l'est. L'examen des photos aériennes de la région révèle que son ancien

${ }^{42}$ Ici encore, je décris un paysage qui se modifie à un rythme accéléré: la Lamidaro a aujourd'hui été canalisée pour draîner cette dépression, un boulevard périphérique passe au pied sud de Bukit Seguntang, et bien des zones inaccessibles lorsque nous nous sommes rendus pour la première fois dans la région en 1979 sont aujourd'hui atteintes à sec. 
Tessons de céramique chinoise trouvés en surface à Talang Kikim (totaux et pourcentages)

\begin{tabular}{|l|r|r|c|c|c|c|c|c|}
\hline Siècles: & $8-9$ & $9-10$ & $11-13$ & 14 & $15-17$ & $18-19$ & $?$ & Total \\
\hline TK & 0 & 0 & $3(15.8 \%)$ & 0 & $11(57.9 \%)$ & $5(26.3 \%)$ & 0 & $19(100 \%)$ \\
TKS & $124(99.2 \%)$ & 0 & 0 & 0 & 0 & 0 & $1(0.8 \%)$ & $125(100 \%)$ \\
ST & $7(100.0 \%)$ & 0 & 0 & 0 & 0 & 0 & 0 & $7(100 \%)$ \\
\hline
\end{tabular}

TK $=$ Talang Kikim - TKS $=$ Talang Kikim (seberang) - ST $=$ Sungei Tapak

cours se prolongeait en droite ligne vers l'est sur quelques $500 \mathrm{~m}$, avant de tourner à angle droit vers le sud pour rejoindre le cours de la Sungei Rambutan, le court affluent de la Musi dans lequel vient déboucher l'extrêmité ouest du canal de Suak Bujang. Ceci a été confirmé par un vieux résident de Talang Kikim qui m'a affirmé en 1985 que la Tapak, «de son vrai et ancien nom Sungei Rambutan, coulait encore dans sa jeunesse jusqu'à la Musi». S'agit-il d'une rivière naturelle ou bien d'un canal? La rectilinéarité de son cours, le fait qu'il traverse (avant d'obliquer vers le sud) un talang qui parait bien avoir été creusé de main d'homme, l'angle droit qu'il fait, tout ces éléments laissent bien penser qu'il s'agit d'un canal. Mais la difficulté d'accès de la région, souvent inondée, nous a jusqu'ici interdit d'en suivre le cours tout entier et de confirmer cette hypothèse.

A $500 \mathrm{~m}$ à l'est de Talang Kikim, sur la rive sud de la Tapak, une trace parfaitement circulaire est clairement visible sur les photos aériennes, dont l'existence est confirmée sur le terrain par une petite butte surélevée et non cultivée d'environ $30 \mathrm{~m}$ de diamètre. Les environs immédiats n'ont livré en surface ni céramiques ni briques ( 7 tessons vert-olive ont été trouvés $200 \mathrm{~m}$ plus à l'ouest; site ST), mais seule une fouille pourra confirmer l'existence ou non en ce point d'une structure circulaire (un stupa?). D'autres traces comparables, mais moins claires, sont visibles sur la couverture aérienne près des rives de la Lamidaro, à quelques 500 mètres en amont de Talang Kikim. Elles n'ont pas encore été vérifiées sur le terrain.

\section{Les Srres de Bukt Seguntang}

\section{A. La topographie}

Bukit Seguntang est sans doute l'un des toponymes du monde malais qui a fait le plus couler d'encre. Cette colline de $25 \mathrm{~m}$ de haut, couverte de très grands arbres fruitiers, est le seul relief de la région qui ait quelque chance d'être aperçu de loin, vu de ces lebak inondés ou de ces talang de $1 \mathrm{~m}$ à $5 \mathrm{~m}$ de haut à peine que forment les terrains avoisinants. En ce sens, elle est déjà remarquable dans la topographie de la région. Une colline plus basse, puis une dépression inondée, séparent son flanc sud du triangle riche en sites que nous avons décrit auparavant. A l'ouest et au sud-ouest, ses pentes moịns fortes vont mourir, en un contour nettement visible sur le terrain, dans la dépression marécageuse qui a Talang Kikim en son centre. La vallée de la Lamidaro, dont on a vu qư'elle était encore navigable à la hauteur de Talang Kikim, pouvait vraisemblablement fournir un accès par voie d'eau à la colline, depuis l'amont de Karang Anyar.

Les pentes orientales de Bukit Seguntang, d'où l'on découvre tout le centre de Palembang, 
sont nettement plus abruptes et descendent vers la petite vallée de la Sungei Kedukan Bukit/Tatang, cours d'eau qui donnait encore il y peu accès par bateau vers la Musi, en aval de Karang Anyar.

Au nord enfin, les pentes de la colline ne descendent pas au niveau de l'eau mais se raccordent directement sur une vaste avancée de la pénéplaine tertiaire, formant une étendue où l'on doit probablement reconnaître le Padang Penjaringan du Sejarah Melayu.

Pratiquement libres de constructions en 1979, sauf le hameau de Tanjung Rawa («le cap des marécages», sur l'une des pointes s'avançant vers la dépression dans le sud-ouest de la colline), les pentes occidentales de la colline connaissent aujourd'hui un essor considérable (le sommet lui-même en est protégé) et un boulevard périphérique passe à raser sa face sud-ouest. Ici encore, cet assaut de travaux publics nous a aidé - vraisemblablement trop tard - à situer des sites potentiels.

\section{B. Les vestiges archéologiques}

Bukit Seguntang est, pour les Malais, le lieu d'origine de la lignée des sultans de la prestigieuse Melaka. D'après les récits légendaires qui ouvrent le Sejarah Melayu, le souverain qui régnait à Palembang descendait de souverains indiens, mais aussi d'Iskandar Zulkarnain, l'Alexandre le Grand de la tradition littéraire islamique, dont la tombe supposée est encore montrée aux pélerins qui montent sur la colline ${ }^{43}$. Elle s'y trouve associée à une demidouzaine d'autres tombes musulmanes qui forment en ce sommet sacré l'un de ces lieux de pélerinage (kramat) si typiques de l'Insulinde ${ }^{44}$. Au début du $18 \mathrm{e}$ siècle, les chefs des populations vivant en amont de Palembang en symbiose économique avec la ville (lui fournissant produits agricoles contre, entre autres choses, le sel), venaient en ce lieu sacré rendre hommage et prêter serment au Sultan de Palembang: ils l'assuraient de ne jamais entrer en révolte contre lui, une réminiscence, plus de dix siècles après, de l'imprécation contre tous les révoltés potentiels, contenu premier du texte de la stèle de Telaga $\mathrm{Batu}^{45}$.

C'est sur le flanc est de Bukit Seguntang qu'a été découvert le grand Buddha dit de Bukit Seguntang et bien d'autres vestiges, statuaire et fragments d'inscription ${ }^{46}$. Tous les rapports des archéologues de l'Oudheidkundig Dienst citent les stupas dont les restes étaient encore visibles au début du siècle, et dont les briques avaient servi à paver la route menant à la colline, mais, à ma connaissance, aucune illustration ou localisation précise n'en a jamais été donnée.

L'équipe américano-indonésienne de 1974 a fouillé quelques carrés sur son sommet, sans grand succès en ce qui concerne les structures en brique et avec les erreurs d'identification que l'on a vu en ce qui concerne les céramiques d'importation, concluant ici comme ailleurs à l'absence de toute trace sérieuse d'implantation sriwijayenne.

C'est sur le flanc est de Bukit Seguntang que les premières céramiques de type Yue furent découvertes et aussitôt publiées en 1979 par E. E. McKinnon, donnant ainsi l'impulsion de

43 Winstedt 1938: 54; Westenenk 1923.

44 Curieusement, contrairement aux autres tombes musulmanes du site, la tombe d'Iskandar n'est pas orientée correctement vers la Mecque (berkiblat). Serait-ce là une confirmation de la réutilisation d'un site pré-musulman?

4s Sevenhoven 1825: 60; Casparis 1956: 15-46. La stèle de Telaga Batu a été trouvée à Palembang Est, pas à Bukit Seguntang.

46 Il est aujourd'hui conservé au Musée Badaruddin de Palembang. Voir à son propos les diverses publications de Schnitger. La plus récente analyse du grand Buddha est celle de Hassan Shuhaimi (1979). 
départ à ces nouveaux projects. Les campagnes suivantes ramenèrent toutes des céramiques datant des $8 \mathrm{e}$ au $14 \mathrm{e}$ siècles (dont certaines trouvées dans leur couche d'origine, sur les parois de puits ou de fosses creusés par les habitants). On a vu que celles trouvées en surface en 1974 étaient bel et bien des céramiques de type Yue (ill.). En fait, ce sont près de $89 \%$ d'un corpus de 188 tessons de surface qui datent de la période de Sriwijaya (avec un pourcentage plus fort pour la période des $9 \mathrm{e}-10 \mathrm{e}$ siècles, mais il n'est pas sûr que ces différences soient très pertinentes sur un corpus qui ne compte après tout que 188 tessons).

Tessons de céramique chinoise trouvés en surface à Bukit Seguntang

(totaux et pourcentages)

\begin{tabular}{|c|c|c|c|c|c|c|c|c|}
\hline Siècles: & $8-9$ & $9-10$ & $11-13$ & 14 & $15-17$ & $18-19$ & ? & Total \\
\hline & $57(30.3 \%)$ & $87(46.3 \%)$ & $17(9.0 \%)$ & $6(3.2 \%)$ & 0 & $3(1.6 \%)$ & $18(9.6 \%)$ & $188(100 \%)$ \\
\hline & \multicolumn{4}{|c|}{$\begin{array}{c}\text { Sriwijaya } \\
167(88.8 \%)\end{array}$} & \multicolumn{2}{|c|}{$\begin{array}{c}\text { post-Sriwijaya } \\
3(1.6 \%)\end{array}$} & $18(9.6 \%)$ & $188(100 \%)$ \\
\hline
\end{tabular}

Le sommet de la colline possède bien encore aujourd'hui quelques signes d'occupation ancienne: une pierre taillée arrondie, vraisemblablement une partie d'un petit stupa, et surtout de très nombreux fragments de briques de taille moyenne et grande ${ }^{47}$. Mais ce sont surtout les flancs de la colline qui ont livré des vestiges, et en particulier ses pentes occidentales. Tout du long, à mi-pente, des tessons de céramique ont été découverts. A Tanjung Rawa, le creusement d'un puits et de fondations pour des maisons d'habitation ont récemment livré des centaines des très grandes briques d'excellente qualité (jusqu'à $37 \times 6 \times 19 \mathrm{~cm}$ ), maintenant utilisées par les habitants pour paver leurs cuisines et arrières-cours (ill.). Certaines d'entre ces briques sont sculptées et, vu leur forme arrondie, faisaient sans doute partie d'un stupa (ill.). Sur une coupe de terrain, certaines de ces briques apparaissaient encore en 1986 en deux ou trois couches superposées. C'est sur ce site que bon nombre de tessons de type Yue du tableau ci-dessus a été comptabilisé ${ }^{48}$.

\section{L'ANALYSE DES DONNEES}

Ne m'étant pas jusqu'ici préoccupé d'analyser les sites décrits dans leur fonction ou leur chronologie, j'ai traité pour plus de commodité de tous ceux-ci, quelles que soient leurs caractéristiques propres, comme s'ils étaient du même type ou comparables terme à terme. Dès lors qu'on essaye de progresser dans l'analyse, il faut établir une distinction bien claire entre, d'une part, les concentrations de céramiques ou d'autres vestiges datables, dont la

47 Des mesures géo-magnétiques ont été effectuées sur le sommet de la colline en 1985 sans grand succès, car la présence de très nombreuses briques dans le sol, même à l'état fragmentaire, parait brouiller les mesures (Surastopo 1985).

48 Manguin 1986. 
seule présence sur le terrain indique une occupation des lieux qui leur est contemporaine et, d'autre part, des sites archéologiques indéniablement construits de main d'homme, mais dont rien, du moins dans l'état présent des recherches, ne permet de fixer la date de construction et d'utilisation. La constante superposition sur le terrain à l'Ouest de Palembang des deux types est certes une première présomption en faveur de leur contemporanéité, mais elle pourrait aussi, phénomène particulièrement fréquent sur les sites d'Insulinde, n'être littéralement qu'une «superposition» de vestiges représentatifs de périodes différentes. C'est donc en sériant les problèmes que l'on doit tenter une analyse plus fine des sites de l'Ouest de Palembang.

\section{Sriwijaya a Palembang}

Avant de procéder plus avant et d'aborder l'analyse des sites construits de main d'homme, il est un certain nombre de données qui prouvent, à mon sens sans ambiguïté aucune, que la région de Palembang Ouest examinée dans cet article a été occupée de façon régulière pendant la durée de vie de l'Etat de Sriwijaya.

Laissant très provisoirement de côté les vestiges épigraphiques et iconographiques, dont on a vu qu'ils avaient été soupçonnés de «redéposition», il nous suffira pour être convaincus d'examiner le tableau suivant, qui regroupe l'ensemble des données statistiques présentées jusqu'ici par site ou par groupes de sites:

Ensemble des tessons de céramique chinoise trouvés en surface à Palembang Ouest (totaux et pourcentages)

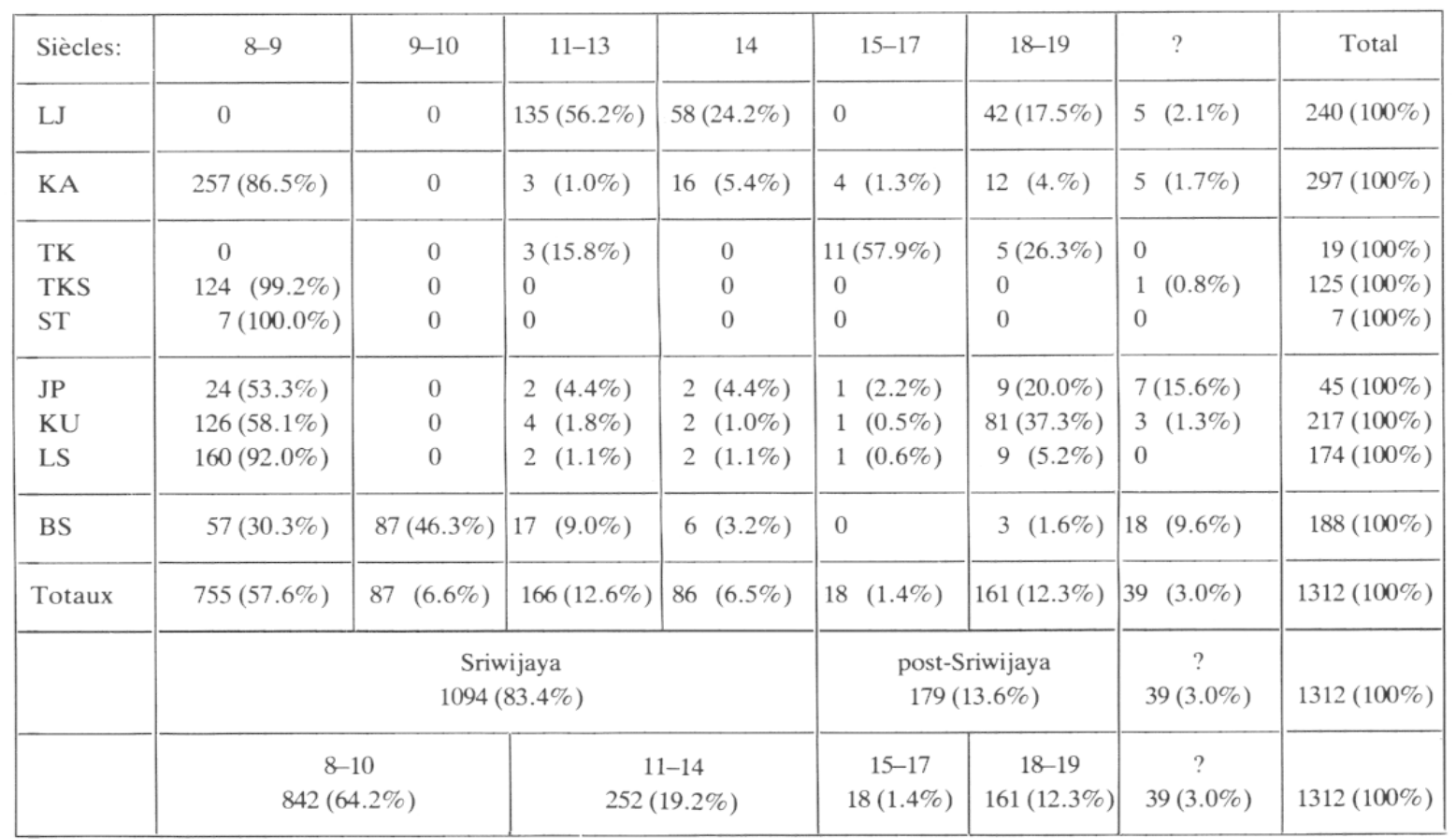

$\mathrm{BS}=$ Bukit Seguntang $\mathrm{JP}=$ Jalan Pam $\quad \mathrm{KA}=$ Karang Anyar $\mathrm{KU}=$ Kambang Unglen $\quad$ LJ $=$ Lorong Jambu LS $=$ Ladang Sirap $\quad$ ST $=$ Sungei Tapak $\quad$ TK $=$ Talang Kikim $\quad$ TKS $=$ Talang Kikim (seberang) 
Sur un corpus total de 1312 tessons trouvés en surface, donc déjà bien significatif, une majorité écrasante de près de $83 \%$ se dégage en faveur des céramiques produites pendant la période qui va du $8 \mathrm{e}$ au $14 \mathrm{e}$ siècles. Si l'on retient une périodisation différente, qui isole pour Sriwijaya l'époque antérieure au 11e siècle, c'est encore la période la plus ancienne qui se dégage clairement, avec $64 \%$ des tessons (la nette prépondérance du site très limité géographiquement de Lorong Jambu pour la période qui va du $11 \mathrm{e}$ au $14 \mathrm{e}$ siècle fausse le pourcentage qui lui est associé).

On a donc bien ici la preuve que pendant les sept derniers siècles de vie de l'Etat de Sriwijaya, entre le $8 \mathrm{e}$ et le $14 \mathrm{e}$ siècles, un centre dont la fonction reste encore à définir faisait un usage régulier de céramiques d'importation. Pour la période qui précède les $8 \mathrm{e}$ et $9 \mathrm{e}$ siècles, l'absence de céramiques chinoises n'est en rien surprenant et on ne peut en aucun cas en conclure que les liens économiques n'existaient pas avec la Chine: les céramiques de la famille vert-olive comptent en effet parmi les premières céramiques à avoir été produites en Chine méridionale en quantités notables pour l'exportation (les céramiques chinoises des périodes antérieures ne sont pas inconnues en Insulinde, mais elles restent des pièces

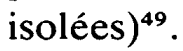

On doit aussi constater ici que, pour la première période (8e-9e siècles), l'assemblage de céramiques est étonnamment homogène: seule la famille vert-olive est représentée parmi les pièces antérieures à la deuxième moitié du $9 \mathrm{e}$ siècle. Aucune céramique contemporaine de meilleure qualité, tels les bols à glaçure blanche, dits de Samara, ou les pièces peintes de la famille Chang-sha n'a encore été trouvée à Palembang (alors qu'avec l'apparition des pièces de type Yue au 10e siècle, la qualité est désormais présente). Cette absence est d'autant plus frappante que les sites sriwijayens du sud de la Thailande ont livré ces différentes pièces en nombre important, en association avec celles de la famille vert-olive, et qu'elles se retrouvent aussi sur les sites du Moyen-Orient. Dans le même ordre d'idées, on doit constater la quasi-absence des céramiques persanes à glaçure bleue, qui font elles aussi partie des assemblages ci-dessus, en petites quantités il est vrai sur les sites de l'Asie du Sud-Est: deux tessons seulement ont été trouvés sur le site de Kambang Unglen (ill.) ${ }^{\text {so }}$. Les pièces de la famille vert-olive ayant des chances d'avoir commencé à être exportées à une période légèrement antérieure aux autres pièces (dès au moins $740 \mathrm{AD}$ ), on pourrait probablement spéculer déjà sur la fonction spécifique ou peut-être sur l'antériorité du site de Palembang par rapport aux autres sites associés à Sriwijaya. Mais la connaissance que l'on a de la période de fonctionnement des fours du Guangdong qui produisaient les céramiques concernées n'est pas à mon sens encore assez précise pour ce faire, et c'est tout autant à une étude comparative de tous les sites pertinents qu'il faudrait pouvoir se livrer ici (des fours de production jusqu'à l'Afrique de l'Est), ce qui dépasserait le cadre de cet article. Je me contenterai donc de signaler ce problème.

L'occupation de Palembang Ouest étant ainsi établie sans ambiguïté pour la période sriwijayenne, la question du lieu d'origine de la statuaire et des inscriptions ne se pose plus: l'hypothèse de la «redéposition» avancée par Bronson dans le seul but d'expliquer l'absence supposée de sites d'époque sriwijayenne ne présente plus aucun intérêt. Une telle «collection» par un souverain postérieur, quand on sait la dispersion des vestiges sur le terrain, était de

49 Adhyatman 1981: 160 sq.; Medley 1981; Watson 1984.

so Whitehouse 1973; Khemchati Thepchai 1983, 1983 a. 
toutes les façons bien peu vraisemblable, et ce d'autant plus que les statues et les inscriptions trouvées dans l'ouest paraissent souvent avoir été brisées volontairement.

On trouve donc réunis en une même zone, à Palembang Ouest:-de nombreuses inscriptions royales datées de la fin du $7^{\mathrm{e}}$ siècle (fussent-elles souvent fragmentaires); - un nombre conséquent de statues monumentales en pierre (fussent-elles en mauvais état), dont beaucoup paraissent bien être proches de modèles indiens et contemporaines de ces inscriptions ${ }^{51}$; - de nombreuses céramiques d'importation que l'on s'accorde pour dater, de façon encore imprécise, des $8 \mathrm{e}$ et $9 \mathrm{e}$ siècles. Cette triple présence en un même lieu me semble indiquer, sans plus d'ambiguïté, que ces sites étaient non seulement occupés, mais qu'ils l'étaient par une communauté religieuse en contact régulier avec l'Inde, ou par la cour d'un souverain dont les relations commerciales et religieuses s'étendaient au moins de la Chine à l'Inde (l'un n'excluant pas l'autre); si l'on ajoute à ces constatations, fondées sur les seuls vestiges archéologiques trouvés sur le terrain, tous les solides arguments philologiques et historiques en faveur de Palembang avancés par les «vétérans» et leurs successeurs, force nous est de constater que le souverain de Sriwijaya reste de très loin le meilleur, si ce n'est le seul candidat à ce poste, pour la période qui va du $7 \mathrm{e}$ au $11 \mathrm{e}-12 \mathrm{e}$ siècles. Pour reprendre les mots de Wolters, on peut «identifier l'ensemble de la zone de Bukit Seguntang [le Palembang Ouest de cet article] à cette partie de Sumatra qui constituait le cœur-même (the heartland) de Sriwijaya» ${ }^{52}$.

Pour la période postérieure au déplacement de la capitale vers Jambi - dont les sources historiques nous apprennent qu'il s'est produit quelque part entre les années 1070 et 1160 -, il semble qu'il y ait repli assez net sur un seul site, celui de Lorong Jambu avec ses quantités notables de céramiques Song et Yuan de belle qualité. On sait bien, toujours par ces sources, que les activités commerciales du port de Palembang n'ont pas cessé après le transfert de la capitale à Jambi. L'occupation du site de Lorong Jambu continue même jusqu'au 14e siècle; elle parait cesser brutalement à l'arrivée des Ming au pouvoir, pour ne reprendre, comme beaucoup de sites de l'ouest de Palembang, qu'avec le $18 \mathrm{e}$ ou le $19 \mathrm{e}$ siècle $^{53}$.

Ces conclusions étant admises, il reste à tenter d'expliquer une caractéristiques marquante des sites de l'ouest de Palembang: si nous sommes dans une zone occupée par la première capitale de Sriwijaya, comment se fait-il que les quelques fouilles effectuées y aient livré peu de céramiques, à tel point que, sur les sites-mêmes de la fouille, les trouvailles de surface sont plus nombreuses? Rappelons d'abord que les fouilles qui ont été effectuées sont de très faible ampleur, et que l'on ne peut encore tirer des conclusions solides de constatations ponctuelles. La question de la rareté des vestiges - tessons ou briques - trouvés in situ me parait facile à expliquer: la couche productive est presque partout dans la région très mince (une cinquantaine de centimètres de profondeur en moyenne). Peu d'entre ces lieux n'ont pas un jour ou l'autre été plantés de manioc: or cette plante a des tubercules profonds (jusqu'a $40 \mathrm{~cm}$ ) que l'on arrache à la récolte, ce qui retourne le sol; dans cette région, elle est cultivée sur billons, pour lesquels la terre est retournée assez profondément. On doit ajouter à ce phénomène celui de l'érosion des pentes de la colline de Bukit Seguntang: une couche productive aussi mince n'a

s1 Bosch 1925: 584-588; Krom 1931.

52 Wolters 1986: 4. Cet article constitue par ailleurs la dernière en date des relectures des sources chinoises concernant Sriwijaya, et en particulier du texte de I-jing. Il tient compte de toutes les dernières découvertes et renouvelle ainsi substantiellement la lecture que l'on pouvait faire de ces textes.

53 Wolters 1966, 1970: chapitre 1. 
pas manqué d'être lavée vers la partie basse des pentes. Les paysans ont systématiquement réutilisé les briques, et la stratigraphie s'en trouve régulièrement bouleversée. Il reste en fait peu de chances de trouver encore à Palembang Ouest des sites intacts.

On peut aussi tenter d'expliquer la relative rareté des vestiges domestiques. C'est ce à quoi s'est déjà attaché $\mathrm{O}$. W. Wolters ${ }^{54}$. Il est certain que l'image qui se dégage de l'ensemble des sources décrivant le site de Sriwijaya ou la ville de Palembang, de I-jing au 7e siècle aux témoignages du $19 \mathrm{e}$ siècle, est celle d'un paysage sur lequel bien peu accrocherait le regard, à l'exception des stupas, dont le site paraissait bien être truffé. Le gros de la population vivait sur des maisons flottant sur des radeaux (rakit) et dans des maisons sur pilotis bordant les voies d'eau: toutes les traces d'occupation, en admettant qu'elles n'aient pas été entièrement faites de matériaux périssables, sont aujourd'hui emportées ou enfouies au fond du fleuve. Les maisons construites sur les berges l'étaient en bois ou bambou; Sevenhoven, en 1825, remarque encore: «Il n'y a pas de bâtiments en pierre à Palembang hors les kedaton, la grande mosquée et les sépultures des princes et de leurs familles» et il ajoute qu'on n'y remarque «aucune particularité, telle des anciens monuments, etc.» ${ }^{55}$. Les monuments de Sriwijaya, à fortiori, pouvaient avoir été construit surtout de matériaux périssables, à l'exception des stupas et peut-être de quelques plate-formes en briques surélevées sur lesquelles des pavillons en bois étaient dressées. Les enceintes d'un complexe royal se conformaient selon toute vraisemblance à ce que les Malais désignaient par kota: des fossés remplis d'eau, des murs en terre, des barricades en troncs dressés ou une dense haie de bambous. On se souviendra ici que le nom local du site de Karang Anyar est précisément Kota Haur, «l'enceinte aux bambous». Les habitants de ces lieux, comme leurs descendants, pouvaient fabriquer en matériaux périssables l'essentiel de leur outillage domestique et réserver les céramiques, encore rares au $8 \mathrm{e}-9 \mathrm{e}$ siècles, à des usages rituels. Pour retrouver les traces d'un tel mode d'habitat ancien à Palembang, il faudrait pouvoir utiliser dans les fouilles des techniques minutieuses, empruntées aux préhistoriens.

\section{UN ENSEMble de Stres INTEGRes?}

Avant d'aborder à part, pour conclure, le problème particulier du complexe hydraulique de Palembang Ouest, dont le point focal est Karang Anyar, un site en lui-même bien défini dans l'espace, je tenterai ici de survoler brièvement les autres sites de Palembang Ouest. En effet aucun autre des sites décrits dans cet article ne possède encore de caractéristiques assez précises pour que ses fonctions puissent être définies avec certitude. Quelques éléments nous permettent néanmoins de proposer dès aujourd'hui certaines hypothèses de travail.

La colline de Bukit Seguntang a retenu jusqu'à nos jours son rôle de site religieux et il est donc vraisemblable qu'elle a toujours joué ce rôle, en raison surtout de sa topographie unique dans la région. Les sites bouddhiques sont souvent ainsi situés sur des reliefs et il est probable que les grandes statues trouvées sur ses flancs provenaient de son sommet. Quelques stupas devaient aussi orner ce dernier, qui ne pouvaient être de bien grande taille, à en juger du moins par les témoignages du $19 \mathrm{e}$ siècle et par les rares vestiges qu'ils ont laissé. Qui dit site rituel dit communauté de religieux: celle-ci devait être logée quelque part à flanc de colline. Bien des sites sont possibles, parmi lesquels Tanjung Rawa, qui a livré les restes de ce qui

s4 Wolters 1979: 17-19.

ss Sevenhoven 1825: 57 . Ces trois exemples de monuments en dur sont connus et postérieurs au 16e siècle. 
parait bien être un (ou des) stupa(s), et que l'environnement s'y prête bien (ce hameau était en 1979 l'un des rares points densément habités sur les flancs de la colline). La bonne qualité des céramiques qui y apparaissent en quantités notables aux $9 \mathrm{e}$ et $10 \mathrm{e}$ siècles cadre bien avec un usage rituel. Dès le 11e siècle, leur nombre diminue, mais l'occupation de Bukit Seguntang n'en apparait pas moins comme la plus longue et régulière de tous les sites décrits. Si l'on est vraiment en présence d'un site rituel, cela me parait faire sens: une communauté religieuse est en principe moins sujette qu'un site directement lié au pouvoir aux aléas de la politique et de l'économie de marché. Comme pour la plupart des sites de Palembang Ouest, seule la période des Ming n'a ici laissé aucun vestige.

Des sites situés entre Bukit Seguntang et Karang Anyar, seul celui de Kambang Unglen présente des caractéristiques bien marquées: on sait qu'il était un centre de production des perles de verre. La fonction précise du plancher en briques que l'on y a dégagé reste incertaine, mais sa simplicité-même pourrait indiquer qu'il s'agit du sol sommairement pavé d'un atelier.

La quantité impressionnante de céramiques (dont une forte proportion de tessons appartenant à de grosses jarres) trouvées à Talang Kikim (seberang), en milieu aujourd'hui marécageux mais à proximité immédiate du cours navigable de la Sungei Lamidaro, fait penser à un debarcadère. Il pourrait s'agir d'un centre de transbordement, au-delà duquel seules des embarcations plus petites auraient donné accès, par l'ouest, aux divers sites situés entre Karang Anyar et Bukit Seguntang, en utilisant le cours d'eau canalisé de Sungei Tapak. Il aurait aussi donné accès au flanc ouest de Bukit Seguntang (par Tanjung Rawa?) et, peut-être, en amont, au site encore à découvrir du jardin célébré par l'inscription de Talang Tuo $^{56}$.

Si l'on accepte, de façon conjecturale, que le site construit de Karang Anyar est bien contemporain des céramiques qu'il a livrées, il faudra alors aussi admettre qu'il n'a été occupé que brièvement; la séquence de céramiques chinoises est homogène et, hors quelques tessons isolés, s'interrompt pratiquement dans le courant du 9e siècle.

Il reste à essayer de comprendre le site de Lorong Jambu, si voisin et si différent à la fois de celui de Karang Anyar, par sa taille d'abord, par sa structure, mais surtout par son assemblage de céramiques (le seul élément que l'on puisse en confiance comparer terme à terme). Le site n'a livré aucun tesson antérieur au 11e siècle, et s'interrompt aussitôt passée l'époque des Yuan en Chine. La belle qualité des céramiques Song (surtout des bols) qui y ont été trouvées parait bien indiquer que le site était occupé par les hautes couches de la société, peut-être une cour, ou peut-être aussi était-il un lieu de culte. On pourrait poser par hypothèse que ce site a succédé à Karang Anyar, mais il faudrait pouvoir alors expliquer l'absence de pièces des Cinq Dynasties ou du début des Song qui pourraient faire la transition avec le site voisin.

Cette même lacune est d'ailleurs remarquable pour l'ensemble des sites de Palembang Ouest, à l'exception de Bukit Seguntang, qui a livré nombre de belles pièces de type Yue (voir le tableau ci-dessus). Elle me parait difficilement expliquable dans l'état présent des connaissances. Une deuxième lacune, moins absolue, est celle qui apparait avec la fin des Yuan, dans le deuxième moitié du 14e siècle: elle pourrait correspondre au coup d'arrêt subit que la nouvelle dynastie des Ming impose de façon draconnienne au commerce extérieur de l'empire jusqu'au début du $15 \mathrm{e}$ siècle, et dont on sait que les réseaux commerçants de

s6 Sur le contenu de l'inscription de Talang Tuo, voir infra et note 73. 
l'archipel insulindien eurent à souffrir, Sriwijaya en premier, qui ne s'en remit pas. Mais comment expliquer l'absence de tessons des $15 \mathrm{e}$ et $16 \mathrm{e}$ siècles, lorsque le commerce reprend, en mineure il est vrai à Palembang, avec les grandes expéditions de Zheng He? Le site du hameau de Talang Kikim est seul à paraître alors rester actif (mais l'échantillon de 19 tessons seulement est peu significatif). L'est de Palembang, avec les sites de Geding Suro et de Air Bersih, parait avoir livré nombre de pièces des Ming et il s'est probablement alors produit un déménagement massif vers les sites situés en aval du centre moderne de la ville (mais on a vu que le seul tableau publié classant les céramiques de la campagne de fouilles de 1974 n'était pas vraiment digne de confiance et il vaut mieux en attendant réserver son diagnostic).

\section{Le Complexe Hydrauluque de Palembang Outest}

Le fait étant acquis que l'ouest de Palembang était à tout le moins l'un des centres d'activité du souverain de Sriwijaya, il reste à examiner la relation entre ce qu'il est difficile de ne pas appeler une «capitale» et les sites hydrauliques, indéniablement construits de main d'homme, dont on a fait plus haut la description. En somme, peut-on prouver à ce stade des recherches qu'ils sont contemporains? Les canaux et les réservoirs de Karang Anyar et des environs ont-ils pu être construits par ces souverains de Sriwijaya dont Coedès disait, pour expliquer la quasi-absence de vestiges archéologiques, qu'ils étaient peut-être trop occupés à faire du commerce? La réponse doit être ici très nette: rien n'est encore prouvé. Hors la superposition en un même lieu, non pertinente en soi, aucune corrélation objective n'a été établie entre, d'une part, ces structures non datées et d'autre part les autres éléments datés, céramiques, inscriptions et statues.

Par définition, les seuls vestiges de surface, qui ont servi jusqu'ici à mon argumentation, ne peuvent établir cette relation objective. Les fouilles restent à ce jour très insuffisantes, même si elles ont commencé à produire des résultats tangibles à Kambang Unglen. Mais on a vu qu'on ne peut y trouver la preuve que le plancher de briques constitute un terminus a quo, au-dessous duquel les céramiques chinoises ne seraient plus présentes. Inversement, leur absence totale dans le seul carré de fouille ayant liviré une surface de briques intacte n'est pas non plus significative en raison de l'état du site dans son ensemble ( $c f$. supra). Seules des fouilles soigneuses et extensives permettront d'établir ou de nier que les sites construits sont contemporains des vestiges datables: tout, ou presque, est encore à faire dans ce domaine.

Cependant, quelle que soit la date précise du complexe hydraulique, il est un certain nombre de points qui peuvent être d'emblée analysés ici, pour mieux en comprendre la fonction. De façon concrète d'abord, ce complexe de canaux et de réservoirs avait-il pour fonction de draîner des terres souvent inondées, de régulariser le niveau d'eau dans les réservoirs, de faciliter la circulation, ou bien doit-on évoquer une combinaison d'un ou plusieurs de ces facteurs? Le plan très particulier des sites de Karang Anyar pouvait-il en outre avoir une fonction symbolique? On connait en Asie du Sud-est d'autres exemples d'aménagements hydrauliques où les fonctions utilitaires sont combinées à des fonctions rituelles ${ }^{57}$.

\section{Les fonctions pratiques}

On ne pourra répondre aux premières questions sans avoir d'abord effectué un relevé topographique minutieux du réseau qui permette d'établir les subtiles dénivellations entre les

57 Wheatley discute à plusieurs reprises de ces systèmes hydrauliques (1983, voir l'index s.v. «hydraulic»). 
différents éléments du complexe de sites. Il faudra tenir compte du fait que les lieux sont affectés par des différences saisonnières, mensuelles et quotidiennes du niveau de l'eau: accumulation des eaux durant la saison des pluies en amont du goulet d'étranglement qui se forme à la hauteur de Karang Anyar; variations de niveau entre marées de vives et de mortes eaux; variations amenées par un phénomène de marée diurne. Si les sites hydrauliques de Karang Anyar, situés à la limite extrême des terres émergées de la pénéplaine, ont bien été occupés de façon permanente, ces variations complexes rendaient sans aucun doute nécessaire un système de régulation, quelle que soit la date de sa construction. L'opposition haut/bas (et par conséquent sec/humide) est bien mise en évidence dès l'époque de rédaction du Sejarah Melayu: l'une des versions du texte propose pour Palembang l'étymologie perlembang, c'est à dire les «terres basses», par opposition à Bukit Seguntang ${ }^{58}$. Le seul fait que le canal de Suak Bujang coupe les sites principaux de Karang Anyar des zones amont à leur nord, et pouvait ainsi draîner vers la Musi les eaux d'écoulement, constitue aussi une première indication en ce sens. Mais l'essentiel du travail topographique reste encore ici à faire.

Il semble que l'on puisse éliminer l'agriculture des usages auxquels était destiné le réseau hydraulique de Palembang Ouest. La culture du riz en dépression marécageuse (lebak) ne s'est developpé que très récemment. Seules les levées naturelles qui bordent la Musi et ses affluents étaient traditionnellement cultivées sur brûlis.

On a vu que le goulet d'étranglement à travers lequel passe la Musi, précisément à la hauteur de Karang Anyar, affecte de façon considérable le niveau de l'eau et l'environnement du lebak dans laquelle coule la Sungei Lamidaro: il sert en quelque sorte de déversoir au trop plein des crues du fleuve. Le versant ouest de Bukit Seguntang, les sites de Talang Kikim et des environs, les berges et les cours de la Tapak et de la Rambutan (qu'ils soient ou non reliés par un canal) ne pouvaient que s'en trouver affectés.

Le canal de Suak Bujang s'ouvre juste en amont de ce rétrécissement du cours de la Musilà où le courant s'accélère et doit affecter la navigation - pour déboucher, après avoir desservi tout une série de sites, de l'autre côté du méandre du fleuve. Pour des embarcations de taille réduite (il fait aujourd'hui $10 \mathrm{~m}$ de large seulement), il pouvait permettre un passage aisé et raccourci en évitant une zone difficile à naviguer, et donner en plus un accès facile à ces sites pour des embarcations venant de l'amont comme de l'aval: le transport des personnes (et on pense bien sûr aux processions royales) et des biens de consommation à l'intérieur d'un ensemble de sites utilisés par une cour royale ou un complexe religieux cadrerait fort bien avec de telles fonctions (ce qui n'exclut pas celle de régulation du niveau de l'eau).

Le transport par voie d'eau était encore au $19 \mathrm{e}$ siècle et pendant la première moitié du $20 \mathrm{e}$ le moyen de déplacement le plus courant à Palembang. Les descriptions d'époque de la ville en font toutes état, au point qu'on a pu qualifier la ville de «Venise de l'Orient»" ${ }^{59}$. De la ville construite sur la rive gauche, plus basse que la rive droite, un observateur britannique notait au début des années 1810 «qu'elle est intersectée par plusieurs petits bras de la rivière, qui forment un certain nombre d'îles, dont on dit qu'il y en a entre vingt et trente»; ce qui lui valait l'appellation de la «ville aux vingt îles» ${ }^{60}$.

58 Voir les variantes de ce passage du Sejarah Melayu données par Westenenk 1923:214-215 et l'interprétation que donne de limbang le dictionnaire malais de Wilkinson.

59 Lire en particulier les descriptions de Court 1821 (p. 105: «houses are built in such a way that communication is always by water»).

60 Thorn 1815: 157. 
Constatant «l'extraordinaire accès aux communications riverines» de cet «environnement sillonné de cours d'eau», Wolters a suggéré avec raison que les archéologues, plutôt que de chercher les signes conventionnels du matériel «urbain», tentent plutôt d'identifier pour Sriwijaya des traces de réseaux reliant divers complexes de sites entre eux; il a aussi proposé l'idée de «distance-pagaie» (paddle-distance) pour donner la mesure de ces réseaux ${ }^{61}$. Il est clair, lorsqu'on lit les premières descriptions modernes de la ville, que ce type de signes était présent au 19e siècle. Et Ma Huan, au début du 15e siècle, dit à propos de Palembang, dont il déclare sans ambage qu'il s'agissait auparavant de Sriwijaya (San-fo-qi), «qu'en cet endroit l'eau abonde, alors que la terre (ferme) est rare ${ }^{62}$. Il est indéniable aussi que le complexe qui s'insère dans le triangle limité par les cours de la Musi au sud, de la Kedukan Bukit/Tatang à l'est et de la Lamidaro à l'ouest pourrait se comprendre comme un réseau de sites aux fonctions diverses et reliés entre eux par voie d'eau.

Peut-on prouver que cet environnement était bien celui de la ville principale de Sriwijaya? Une notation cryptique de Zhao Rugua, en 1225, à propos du souverain de Sriwijaya, prend ici tout son poids: «Quand le roi sort, il s'assied dans un bateau» ${ }^{63}$. Et l'on ne peut que citer ici les auteurs arabes familiers des routes commerciales de l'Asie orientale, et Abu Zaid le premier (916 AD), souvent répété par les auteurs postérieurs: un ancien roi de Sriwijaya avait un palais faisant face à un large estuaire qui communiquait avec la mer (que notre auteur compare au Tigre à Basra). L'eau de cet estuaire formait un étang attenant au palais du roi. Ce palais avait une salle qui dominait l'étang, dans laquelle le roi donnait audience. Les marées, dit-il plus loin, étaient ressenties toutes les douze heures, ce qui correspond exactement au caractère diurne des marées de Palembang ${ }^{64}$. L'image du Tigre à Basra convient en outre bien pour la Musi à Palembang, et comment ne pas être tenté de voir dans l'étang qui jouxte le palais au bord du fleuve l'un des réservoirs du site A de Karang Anyar, dominé par une salle d'audience?

\section{Les fonctions symboliques}

Avant de revenir aux sources historiques qui pourraient nous aider à identifier le «palais» du souverain de Sriwijaya, je me permettrai ici avec Abu Zaid une disgression qui n'a pas la prétention de convaincre qui que ce soit de sa valeur heuristique. Il raconte, comme d'autres auteurs arabes de l'époque, que le Mahārāja de Sriwijaya faisait chaque jour déposer en sa présence un lingot d'or dans l'étang attenant à son palais. Durant le reflux, l'eau qui se retirait décourvait les briques, qui jetaient un grand éclat sous les rayons du soleil. A sa mort, le trésor du souverain était partagé entre les membres de sa cour, et ce qui en restait était donné aux pauvres du royaume ${ }^{65}$. Il est curieux de constater que dans l'épisode légendaire du Sejarah Melayu déjà cité les références à l'or sont nombreuses et que, sur place, elles sont

61 Wolters 1979: 17-18, 21, 26-28.

${ }^{62}$ Mills (ed) 1970: 99.

${ }^{63}$ Hirth \& Rockhill 1911: 60. Le texte à été écrit en 1225, mais il est pour l'essentiel une compilation de sources antérieures et cette remarque pourrait fort bien concerner un souverain régnant à Palembang.

64 Tibbetts 1979: 33-34. Ferrand 1913-15, I: 83-84. Voir les références ci-dessus pour les marées; voir aussi Wyrtki 1961. Cet argument ne pourrait malheureusement pas être utilisé pour départager Palembang et Chaiya, sur le Golfe du Siam, comme siège de la capitale de Sriwijaya: le baie de Bandon connait aussi ce phénomène assez localisé de marées diurnes. Jambi, par contre, est situé dans une zone de marées semi-diurnes et l'on a là un élément de plus pour éliminer sa candidature à l'epoque où Abu Zaid écrivait.

65 Tibbetts 1979: 27, 31, 33-34; Ferrand 1913-14, I: 84. Sauvaget 1954: 301. 
aujourd'hui encore une constante du lieu: la recherche mystique d'objets en or aperçus dans des rêves, concrétisée par des fouilles, est un thème qui est revenu régulièrement lorsque nous interrogions les paysans familiers des environs de Karang Anyar (et qui explique bien des trous creusés par ceux qui habitent les environs de ces sites). L'île de Pulau Cempaka, en particulier, est considérée aujourd'hui comme trop «chargée» (angker) pour être habitée. Le Sejarah Melayu mentionne la crète en diamant d'un naga souterrain dans les environs de Bukit Seguntang, et c'est une jarre pleine de diamants que la propriétaire de l'île a un jour aperçue après avoir suivi un parcours mystique. La stèle de Telaga Batu fait elle aussi grand cas de la protection d'un «trésor d'or et de biens» que renfermait la «cité» (kedatuan) du souverain ${ }^{66}$. La convergence de tous ces témoignages d'époques et d'origines diverses pourrait bien sûr n'être qu'une simple coïncidence.

Sans pour autant quitter la partie dite «légendaire» du Sejarah Melayu (toujours dans le passage des origines des souverains de Melaka), on doit ici revenir à des aspects plus topographiques de la question du palais du souverain. Dans sa description du domaine de l'ancêtre Demang Lebar Daun à Andelas/Palembang, on a déjà vu que Bukit Seguntang et la Sungei Tatang, deux toponymes bien ancrés encore dans la toponymie de Palembang Ouest, étaient placés au cœur-même du territoire. Si l'auteur du texte ne décrit pas alors le palais de Demang Lebar Daun lui-même, c'est celui d'un de ses ancêtres indiens, Raja Shulan, qui a droit au morceau de bravoure littéraire: au milieu de toutes ses splendeurs, il comprenait un lac (tasek), avec une île en son milieu, plantée de toutes sortes d'arbres fruitiers ${ }^{67}$. La référence textuelle est à Vijayanagar, ville qui reste encore en Insulinde, alors en pleine phase d'expansion de l'Islam, une source d'inspiration littéraire et rituelle indienne ${ }^{68}$. Mais si l'on devait chercher une source d'inspiration indienne plus ancienne pour une ville avec des réservoirs, c'est bien sûr vers la ville bengali de Nalanda qu'il faudrait alors se tourner, lieu de destination et d'origine de bien des pélerins bouddhistes de passage à Sriwijaya, avec, dans les mots de l'un d'entre eux, ses «profonds étangs resplendissants chargés de lotus bleus». On a déjà prouvé que ce centre de diffusion du bouddhisme Mahāyāna avait joué un rôle essentiel en Insulinde, y affectant du $7 \mathrm{e}$ au $9 \mathrm{e}$ siècles les développements de la religion d'Etat, mais influençant aussi les styles iconographiques. Tout porte à croire que ce centre a pu affecter aussi les conceptions architecturales des souverains insulindiens, et donc ceux de Sriwijaya les premiers, qui y ont même fait construire pour leur compte un monastère à la fin du $9 \mathrm{e}$ siècle ${ }^{69}$.

${ }^{66}$ Casparis 1956: 39; Wolters 1970: 13-14. Balasubrahmaniam (1935) avait pour sa part noté la ressemblance entre les légendes des lingots d'or immergés telles qu'elles sont rapportées par les auteurs médiévaux arabes et une référence, isolée il est vrai, à des trésors enfouis sous l'eau, dans un texte littéraire tamoul du début du ler millénaire AD. Peut-être est-ce l'occasion de signaler ici que l'une des étymologies populaires proposées sur place pour le nom de Palembang est justement pelimbang, limbang désignant l'action de laver les sables aurifères à la battée; le lieu où était pratiquée cette collecte était la rive gauche de la Musi, dans les environs immédiats de Karang Anyar, à l'embouchure d'un petit bras de rivière nommé Sungei Palembang. Reconnaissant que les noms de lieux indonésiens sont souvent transmis de grande antiquité, Wolters propose par ailleurs de reconnaître dans la transcription chinoise du nom d'un cours d'eau se jetant dans le fleuve, cité dans le Xin Tang shu (début du 9e siècle), la première mention du toponyme Palembang (1986: 14-15).

67 Winstedt 1938: 50, 54.

68 Teeuw, Robson et al. 1969: 22 sq.

69 Bosch 1925: 525; lire aussi l'introduction de Bernet Kempers (1933) et les nombreuses références qui y sont citées. 
Quelle qu'en soit l'origine exacte, la référence du Sejarah Melayu à une île construite au milieu d'un étang, associée à un palais royal, nous ramène à une conception architecturale courante en Insulinde, celle du balai kambang, ou «pavillon flottant». On peut l'observer au jourd'hui encore en bien des palais de Java et de Bali, et il y est toujours associé à la royauté et à la méditation, donc à la résidence ou à un lieu de villégiature du souverain ${ }^{70}$. Le site de la capitale javanaise de Majapahit, au $14^{\mathrm{e}}$ siècle, en a livré deux excellents exemples, au centre du grand bassin segaran (aujourd'hui détruit), et dans les bains de Candi Tikus. Le véritable «pavillon flottant» ne semble pas apparaître en Indonésie dans les représentations iconographiques, tels les reliefs de la grande terrasse du temple de Panataran, avant ce même $14^{\mathrm{e}}$ siècle, mais Bosch voit déjà dans les bains datés du 10e-11e siècle à Jalatunda le premier monument javanais à incorporer cet élément architectural ${ }^{71}$. Si l'on pouvait plus tard apporter la preuve concrète que le site de Karang Anyar était bien contemporain des céramiques qu'il a livrées il présenterait donc un exemple de balai kambang antérieur à ceux de Java. La fonction symbolique du «pavillon flottant» prendrait ici tout son sens et l'association de ce site avec une résidence princière, le kedatuan de l'inscription de Telaga Batu, serait difficilement récusable.

On m'a aussi parfois objecté qu'en ensemble hydraulique de cette complexité était bien peu vraisemblable à Sumatra à si haute époque. Mais, dans un même ordre d'idées, Coedès dit bien que si les sources épigraphiques ne l'avaient pas prouvé sans ambiguïté, qui eut cru que Sumatra allait livrer les plus anciens témoignages datés concernant l'existence du Mahâyâna d'Insulinde et d'Indochine? En fait, ces aménagements hydrauliques seraient à peine antérieurs à ceux du pays Khmer, tels les baray construits par Yaçovarman à la fin du $9 \mathrm{e}$ siècle. Les travaux hydrauliques du Funan antidateraient de plusieurs siècles ceux de Karang Anyar et ceux, tous proches de Palembang, entrepris par Purnavarman à Tugu (près de Jakarta), tels qu'ils sont rapportés dans une inscription du 5 e siècle, prouvent bien que ces techniques étaient connues et pratiquées en Insulinde deux siècles au moins avant Sriwijaya ${ }^{72}$.

J'ai gardé pour la fin le seul argument historique qui, sans pour autant constituer la preuve tant recherchée, me parait apporter à cette discussion plus que de simples présomptions. A quelques cinq kilomètres au nord-ouest de Bukit Seguntang, au lieu dit Talang Tuo (le «vieux talang»), a été découverte une inscription datée de 684 AD qui y célébrait la création par le souverain de Sriwijaya d'un jardin planté d'arbres divers et de bambous haur, pour le plaisir temporel et spirituel de «tous les êtres». Mais le texte ajoute que ce roi construisit «aussi les autres jardins (parlak) avec les barrages (tavad), les étangs (taläga) et toutes les bonnes œuvres (...)» $»^{73}$. Le terme «jardin» lui-même ne manque pas ici d'intérêt, car c'est bien de jardins qu'il s'agit toujours lorsqu'on a un balai kambang, servant tout autant au plaisir des sens qu'à celui de l'esprit, puisque ce sont des lieux de méditation pour les souverains ${ }^{74}$. Mais, plus encore, c'est la mention des «barrages» et des «étangs» qui doit retenir notre attention.

70 Lombard 1969.

71 J. Dumarçay, communication personnelle; Bosch \& de Haan 1965: 213.

72 Noorduyn \& Verstappen 1972. Voir Wheatley (1983: 136 sq.) sur les fonctions des travaux hydrauliques du Fu-nan.

${ }^{73}$ Coedès 1930: 40. Le lieu de découverte de l'inscription n'a pu encore être retrouvé. S'il est en dehors du cœur archéologique de Palembang Ouest, il n'en reste pas moins dans la même zone, et c'est vraisemblablement le long du cours de la Lamidaro qu'il faut le rechercher.

${ }^{74}$ Lombard 1969. 
Pour les premiers, le texte a le terme vieux malais tavad, malais moderne tebat, qui indique l'action de «barrer un cours d'eau pour créer un réservoir». Le terme taläga est pour sa part d'origine indienne, et on le retrouve en malais moderne sous la forme teläga qui désigne en général un petit lac ou un étang ${ }^{75}$. Ce souverain a donc construit, pour que chacun puisse atteindre à la félicité, plusieurs jardins avec des étangs, des réservoirs ou des cours d'eau contenus par des barrages. Il en a fait état dans une inscription trouvée dans la zone-même de Palembang Ouest, qui est à peine antérieure aux céramiques les plus anciennes trouvées dans le complexe de Karang Anyar, un site dont on sait qu'il pourrait fort bien rentrer dans la catégorie des «jardins» d'Insulinde, avec leurs réservoirs et leurs barrages. La toponymie locale associe d'ailleurs les bambous haur (ceux-là même qui apparaissent dans l'inscription de Talang Tuo) et les arbres cempaka au site A, et les jacquiers (nangka) au site B, proposant ainsi une autre lecture du paysage en forme de «jardin». Rien ne prouve bien sûr que Karang Anyar est bien cet autre jardin que mentionne l'inscription, mais du moins est-il certain que le souverain de Sriwijaya a construit de tels monuments hydrauliques. Un site de cet ampleur cadrerait d'ailleurs bien avec la richesse et la puissance du Mahārāja de Sriwijaya.

N'ayant pu trouver encore sur le terrain ou dans les textes la preuve que le complexe de Karang Anyar datait de l'époque de Sriwijaya, j'ai tenté au contraire de prouver qu'il avait été construit par des souverains de périodes postérieures (puisqu'il apparait qu'un tel site, par sa taille aussi bien que par le symbolisme qui lui est très vraisemblablement attaché, ne peut être qu'une création royale).

Malheureusement, avec la disparition de Sriwijaya, Palembang se trouve réléguée au rang de port secondaire dans les réseaux maritimes d'Insulinde et rares sont les sources qui en font mention en détail. Après la conquête par Java à la fin du $14 \mathrm{e}$ siècle, la ville parait se transformer surtout en un repaire de pirates, et les relations du passage des grandes expéditions des Ming dans le premier quart du 15e siècle nous entretiennent uniquement de querelles entre chefs de la communauté chinoise. Au début du 16e, les Portugais décrivent brièvement une ville sans souverain, soumise aux principautés musulmanes de la côte nord de Java. Nous avons vu que le Sejarah Melayu était particulièrement fiable pour sa topographie du cours de la Sungei Tatang et de la région de Bukit Seguntang, un site récupéré - à une date indéterminée - comme lieu saint de la tradition musulmane. Il ne dit pourtant mot de Karang Anyar, pourtant à proximité de ces lieux. Il y a donc peu de chances que ce site puisse dater d'une période voisine de la date de compilation de ce texte (16e-17e siècles, avec des ajouts plus tardifs pour certaines versions). Il était alors soit oublié - et le très petit nombre de céramiques postérieures au 9e siècle trouvées sur le site pourrait alors s'expliquer -, soit pas encore construit. Mais pendant toute cette période de flottement, comment imaginer qu'un prince ait eu assez de pouvoir économique ou politique pour mobiliser des ressources suffisantes à la construction d'un complexe de la taille de Karang Anyar?

La fin du 16e siècle voit la naissance d'un sultanat qui, sous la suzeraineté javanaise, semble gagner en importance. C'est vraisemblablement de cette époque que datent les sites de

75 Le texte d'Abu Zaid mentionné ci-dessus utilise le mot thalaj pour désigner l'estuaire qu'il compare au Tigre. On y reconnait le même mot d'origine indienne (Ferrand 1922: 57); l'auteur arabe, qui transcrit un terme étranger, l'a probablement utilisé par erreur pour cet estuaire, alors qu'il aurait normalement désigné le «lac» sur lequel donne le palais du roi. 
Geding Suro à l'est de Palembang. Les Hollandais ouvrent sur la rive droite une factorerie au 17 e siècle, qui suit son bonhomme de chemin jusqu'aux années 1810 . Hors des archives de la VOC, que je n'ai pas eu le loisir de consulter, et d'un certain nombre de textes en malais et en javanais non encore édités ou même transcrits, il n'est pratiquement pas de sources aisément accessibles pour cette époque ${ }^{76}$. Il faut attendre les premières décades du 19ème siècle, lorsque Britanniques et Hollandais choisissent d'en découdre dans la ville, en y attisant des querelles dynastiques, pour à nouveau avoir une abondante littérature descriptive et quelques textes malais contemporains des évènements ${ }^{77}$. On est donc en terrain plus solide lorsqu'on aborde cette période finale de l'histoire du Sultanat de Palembang. On y apprend entre autres que le Sultan, comme ses congénères javanais de l'époque, dont il est proche culturellement et politiquement, est amateur de jardins, de réservoirs et semble-t-il, d'îles. Les matériaux qu'il a récupérés après avoir rasé la factorerie hollandaise ont servi aussitôt «à la construction d'un nouveau harem, qui jouxte le palais intérieur; mais les bâtiments n'en sont pas encore finis. Un grand réservoir d'eau, avec des embarcations de loisir, occupe le centre de cet endroit, et il est entouré de nombreuses maisons individuelles, pour les femmes de la cour» ${ }^{78}$. Nous sommes là sur le site-même du keraton, au cour de la ville moderne. En amont de Palembang, nous raconte encore Thorn, «le fleuve se divise en deux larges branches; celui de gauche [la Sungei Ogan] mène à une villégiature du Sultan, qui consiste en plusieurs bungalows et jardins, admirablement répartis sur un ensemble de petits îles, nommées, en référence à leur grand nombre, les ‘Pulo Sariboo' [Pulau Seribu], ou les ‘Milles Iles`.» Là encore le Sultan avait fait transporter depuis la factorerie hollandaise nombre de matériaux de construction ${ }^{79}$. Un Sultan maître d'œuvre donc, amateur de monuments hydrauliques, qui pourrait bien avoir construit un complexe tel celui de Karang Anyar? Si c'était le cas, pourquoi les sources consultées, loquaces lorsqu'il s'agit de décrire les travaux entrepris par le dernier Sultan, n'en disent-ils mot? Et il faudrait dans ce cas encore expliquer la quasiabsence dans ce site de céramiques d'époques Ming tardive et Qing. Un monument aussi important, si proche de nous dans le temps, aurait-il laissé aussi peu de traces d'occupation? Une seule explication possible: il aurait été construit à la fin du sultanat, peu avant son abolition suite à l'intervention européenne du début du $19 \mathrm{e}$ siècle, et les Sultans n'auraient pas eu le temps d'en faire usage. Ce n'est pas exclu, mais cela aussi reste à prouver de façon convaincante. Un texte malais retraçant les épisodes du conflit entre Sultans, Hollandais et Britanniques cite à deux reprises le toponyme de Karang Anyar: à chaque fois, le Sultan

${ }^{76}$ Cependant, Barbara Andaya, qui travaille à une histoire de Palembang et a dépouillé systématiquement ces deux catégories de sources, m'assure qu'elle n'y a rien trouvé qui indiquerait une quelconque activité de bâtisseurs dans l'ouest de la ville (communication personnelle, 1987). John Bastin, qui a consacré une étude aux Britanniques à Palembang, m'a assuré pour sa part ne pas se souvenir d'avoir vu de telles références dans les documents de l'East India Company.

77 Voir entre autres Thorn 1815; Court 1821; Sevenhoven 1825; Praetorius 1843; Sturler 1843; Alkemade 1883; Woelders 1975. A l'India Office Library, lors d'un passage malheureusement trop bref, je n'ai moi-même rien pu trouver dans les archives, documents cartographiques ou autres, qui indique que le Sultan ait rien construit de particulier à Karang Anyar.

78 Thorn 1815: 158-159 et pl. XVII pour le plan du keraton.

79 Une carte non datée au 1/25.000 dont je dispose (qui date probablement des années 1960) porte en effet bien une petite Sungei Pulau Seribu débouchant à quelques deux kilomètres en amont de l'Ogan, sur la rive gauche. Sur la rive droite de l'Ogan, face à ce toponyme, débouche un canal long de quelques $3 \mathrm{~km}$, dont l'autre extrêmité rejoint la Musi, précisément devant le keraton. Il porte le nom de Sungei Kedukan Anyar, ou «Rivière nouvellement creusée». On retrouve donc ici, pour un canal apparemment tardif, le terme kedukan. 
réfugié loin en amont de la Musi, vient rencontrer le responsable des forces d'occupation hollandaises, stationnées dans son ancien keraton; il fait donc halte à la limite du territoire occupé, au lieu-dit Karang Anyar. Le texte n'accompagne ce toponyme d'aucun autre qualificatif, d'aucune autre précision. En aurait-il été ainsi si le souverain y avait fait halte dans une de ses résidences? C'est peu probable vu la propension des textes du monde malais à surcharger d'ornements littéraires à valeur symbolique toute référence aux attributs de la royautéso.

Le grand point d'interrogation doit donc rester celui de la date du complexe hydraulique de Palembang Ouest. Nous nous trouvons confrontés à un faisceau imposant de présomptions, dont l'une au moins n'est pas loin d'être décisive, et qui toutes attestent que les sites que l'on doit s'attendre à trouver à Srivijaya/Palembang ressemblent à s'y méprendre à ceux que l'on y a découvert ces dernières années. Me faisant l'avocat du diable, je n'ai pu fournir aucune objection solidement fondée à l'ancienneté du site. Ces fortes présomptions nous dispensentelles pour autant de preuves? Certes pas, à moins de prendre le risque d'être plus tard accusés d'avoir aussi été les victimes d'une illusion d'optique. La balle est donc dans les mains des archéologues qui fouilleront sérieusement les sites de Palembang.

Jakarta, Paris 1984

Jakarta 1988

\section{Addenda}

Peu avant la mise sous presse de cet article, le 26 février 1988, Mme. Satyawati Suleiman est décédée des suites d'une longue maladie. C'est à la mémoire de celle qui s'est tant dépensée pour faire revivre les études srivijayennes que je dédie cette contribution.

80 Woelders 1975: 180, 376. Une autre objection peut être facilement rejetée: la carte de 1821 donnant l'ordre de bataille de l'attaque hollandaise contre Palembang, indique un «jardin du Sultan» (tuijn van den Sultans), situé à l'intérieur des terres, en amont du palais. La carte n'étant pas topographiquement exacte, ce jardin se trouve placé face à l'embouchure de la Ogan, donc tout près, en apparence, de Karang Anyar (en fait le méandre de la Musi dans lequel le site est situé n'est pas représenté sur la carte). On a voulu y voir la preuve que c'était une représentation de ce site. Mais ce jardin est clairement sur cette carte voisin du «logement du Pangeran Adipati» et celui-ci, on le sait bien par ailleurs, jouxtait le keraton (et a donné son nom à ce quartier de la ville, le kadipaten). La carte a été publiée par de Clercq 1877 et par Woelders 1975. Cette objection a été émise dans le rapport de Budi Utomo et Nurhadi (1985, où la date de 1877 est attribuée par erreur à cette carte). 


\section{BIBLIOGRAPHIE}

\section{Adhyatman, $\mathbf{S}$.}

1981 Keramik Kuno yang ditemukan di Indonesia/Ancient Ceramics found in Indonesia. Jakarta: The Ceramic Society of Indonesia, 1981.

1983 Notes on Early Olive Green Wares found in Indonesia. - Jakarta: The Ceramic Society, 1983.

Alkemade, J. A. van Rijn van

1883 «De Hoofdplaats Palembang», TAG , 7, 1883: 51-69.

Ambary, H. MuariF

1979 "Catatan tentang penelitian beberapa situs 'masa, Srivijaya», in Pra Seminar Penelitian Sriwijaya (Jakarta, 7-8 Desember 1978). - Jakarta, 1979: 7-18.

1981 «Notes on Research on Sites from the Srivijaya Period», in Studies on Srivijaya. - Jakarta, Puslit Arkenas, 1981: 1-12.

1982 «Recent Archaeological Research in Sumatra», In Final Report, SPAFA Consultative Workshop on Archaeological and Environmental Studies on Srivijaya. - Bangkok: SPAFA, 1982: Appendix 3b.

Balasubrahmaniam, S. R.

1935 «The lake of bricks of gold», $T B G, 75,1935:$ 618-620.

BOECHARI

1979 «An Old Malay Inscription at Palas Pasemah (South Lampong)», in Pra Seminar Penelitian Sriwijaya (Jakarta, 7-8 Desember 1978). - Jakarta: Puslit Arkenas, 1979: 19-42.

1981 «Report on Research on Srivijaya», in Studies on Srivijaya. - Jakarta: Puslit Arkenas, 1981: $79-84$.

1986 «New Investigations on the Kedukan Bukit Inscription», in Untuk Bapak Guru. Persembahan para murid untuk memperingati (...) Prof. Dr. A.J. Bernet Kempers. - Jakarta: Pusat Penelitian Arkeologi Nasional, 1986, 33-56.

Bosch, F. D. K.

1925 «Een Oorkonde van het Groote Klooster te Nâlandâ», $T B G, 65$, 1925: 509-588.

1929 «Oudheidkundig verslag over het derde en vierde kwartaal 1929», OV, 1929 (3-4): 129-167.

1930 «Verslag van een reis door Sumatra», OV, 1930: 133-157.

Bosch, F. D. K. \& DE HAAN, B.

1965 «The Old Javanese bathing place Jalatunda», BKI, 121(2), 1965: 189-232.

Bronson, B.

1975 «A Lost Kingdom Mislaid: A Short Report on the Search for Srivijaya», Field Museum of Natural History Bulletin, 46(4), 1975: 16-20.

1977 «Exchange at the Upstream and Downstream Ends: Notes Towards a Functional Model of the Coastal State in Southeast Asia», In Karl L. Hutterer (ed), Economic Exchange and Social Interaction in Southeast Asia: Perspectives from Prehistory, History and Ethnography.Ann Arbor, 1977: 39-52. 
BRONSON, B.

1979 «The Archaeology of Sumatra and the Problem of Srivijaya», in R. B. Smith \& W. Watson, Early South East Asia. - New York, Kuala Lumpur: OUP, 1979, 395-405.

Bronson, B. \& Wisseman, J.

1974 Archeological Research in Sumatra 1974: a Preliminary Report. - Unpublished Report, 1974.

1976 «Palembang as Srivijaya: the Lateness of Early Cities in Southern Southeast Asia», AP, 19(2), 1976: 220-239.

BRown, R. L.

1987 «A Note on the Recently Discovered Ganeśa Image from Palembang, Sumatra», Indonesia, 43, 1987: 95-100.

Budi UTOMo, Bambang

1985 «Karanganyar as a Srivijayan Site: New Evidence for the Study of Settlement Patterns of the Srivijayan Period», in Final Report, SPAFA Consultative Workshop on Archaeological and Environmental Studies on Srivijaya. - Bangkok: SPAFA, 1985, 273-291.

1987 Laporan penelitian arkeologi: Palembang, Sumatra Selatan. - Jakarta: Puslit Arkenas, 1987 (rapport inédit, 33p.).

1987a Hasil peninjauan ke situs Geding Suro (Kotamadya Palembang). - Jakarta: Puslit Arkenas, 1987 (rapport inédit, 11p.).

BUdi UTOMO, BAMBANG \& NURHADI RANGKUTI

1985 Laporan penelitian arkeologi: Palembang, Sumatra Selatan. -Jakarta: Puslit Arkenas, 1985 (rapport inédit, 69p.).

CASParis, J. G. De

1956 Prasasti Indonesia. II: Selected Inscriptions from the 7th to the 9th Century AD. - Bandung, 1956.

1982 «Some Notes on the Epigraphic Heritage of Sriwijaya», In Final Report, SPAFA Consultative Workshop on Archaeological and Environmental Studies of Srivijaya. - Bangkok: SPAFA, 1982: Appendix 4h.

1985 «Srivijaya and Malayu», In Final Report, SPAFA Consultative Workshop on Archaeological and Environmental Studies on Srivijaya. - Bangkok: SPAFA, 1985: 245-255.

CERAMIC SOCIETY OF INDONESIA

1977 Tempayan di Indonesia. - Jakarta: The Ceramic Society of Indonesia, 1977.

Chand Chirayu Rajan

1974 «Background to the Srivijaya Story», JSS, 62(1), 1974: 174-211; 62(2), 1974: 285-324.

Chavannes, E.

1894 Mémoire composé à l'époque de la grande dynastie T'ang sur les religieux éminents qui allèrent chercher la loi dans les pays d'Occident, par I-Tsing. - Paris, 1894.

Clerce, F. S. A. De

1877 «De Hoofdplaats Palembang», TAG, 2, 1877: 174-175.

CoEDEs, G.

1918 «Le Royaume de Çrivijaya», BEFEO, XVIII(6), 1918: 1-36

1964 Les Etats hindouisés d'Indochine et d'Indonésie. - Paris, 1964.

1964a «A Possible Interpretation of the Inscription of Kedukan Bukit (Palembang)», in J. Bastin \& R. Roolvink (eds), Malayan and Indonesian Studies. -Oxford, 1964: 42-47.

CoUrt, M. H.

1821 An Exposition of the Relations of the British Government with the Sultaun and State of Palembang (...), with Descriptive Accounts of Palembang and the Island of Banca. London, 1821. 
FERRAND, G.

1913-14 Relations de voyages et textes géographiques arabes, persans et turks relatifs à l'ExtrêmeOrient, du VIIIe au XVIIle siècles. - Paris, 1913-14, 2 vols.

1922 «L'empire sumatranais de Çrivijya», JA, 1922: 1-104, 161-246.

1932 «Quatre textes épigraphiques malayo-sanskrits de Sumatra et de Banka», JA, 221, 1932: 271-326.

GraAf, H. J. de \& Pigeaud, Th. G. Th.

1974 De Eerste Moslimse Vorstendommen op Java. - s'Gravenhage: VKI 69, 1974.

GrosLIER, B. -Ph.

1979 «La cité hydraulique angkorienne: exploitation ou surexploitation du sol?» BEFEO, 66, 1979: 161-202.

HARRISSON, $T$.

1964 «Monochrome Glass Beads from Malaysia and Elsewhere», Man, 64, 1964: 37-41.

1965 «Dusun Jars: from Mayfair and Friesland through Cairo to Sabah», SMJ, 12(25-26), 1965: 69-74.

1966 «A Small ‘Dusun-type, Jar in the Sarawak Museum», SMJ, 14(28-29), 1966: 156-157.

HASSAN SHUHAIMI, NIK

1978 «The Mitred Avalokiteśvara from Palembang: its Significance on the Origin and Development of Srivijayan Art», Akademika, 13, 1978.

1979 «The Bukit Seguntang Buddha: A Reconsideration of its Date», JMBRAS, 52(2), 1979: $40-49$.

HIRTH, F. \& ROCKHILL, W. W.

1911 Chau Ju-kua: His Work on the Chinese and Arab Trade in the Twelth and Thirteenth Centuries, Entitled Chu-fan-chi. - St. Petersbourg, 1911.

JACKSON, J. C.

1973 «Post-Independence Developments and the Indonesian City: Preliminary Observations on the Spatial Structure of Palembang», Sumatra Research Bulletin, 2(2), 1973: 3-11.

KAIDA, YOSHIHIRO

1980 «Physiographic regions in the Komering-Ogan river basin, South Sumatra», in Tsubouchi \& Iljas 1980: 1-19.

\section{KHEMCHATI THEPCHAI}

1983 «The Excavation at Laem Pho: A Srivijaya Entrepôt?», In Final Report, SPAFA Consultative Workshop on Archaeological and Environmental Studies on Srivijaya. - Bangkok: SPAFA, 1983: 153-164.

1983a «Archaeological Site at Ko Khor-Khao, Amphoe Khura Buri, Phangnga Province», In Final Report, SPAFA Consultative Workshop on Archaeological and Environmental Studies on Srivijaya. - Bangkok: SPAFA, 1983: 239-243.

Kempers, A. J. BerNet

1937 The Bronzes of Nālandā and Hindu-Javanese Art. - Leiden, 1937 (proefschrift).

KROM, N. J.

1931 «Antiquities of Palembang», Annual Bibliography of Indian Archaeology for the year 1931: 29-33.

KULKE, $\mathrm{H}$.

sous « 'Kadâtuan Srivijaya - Empire or Kraton of Srivijaya ? A Reassessment of the Epigraphical presse Evidence», in J. Stargardt (ed.), The Asian City and State. - Leiden: sous presse.

LA FAILLE, P. ROO DE

1929 «Uit de Palembangschen Sultanstijd» in Festbundel Uitgegeven door het Bataviaasch Genootschap (...) 1778-1928. - Weltevreden, 1929, vol. II: 316-352. 
LAMB, A.

1965 «Some Glass Beads from the Malay Peninsula», Man, 65, 1965: 36-38.

1966 «Some Observations on Stone and Glass Beads in Early South-east Asia», JMBRAS, 38(2), 1966: 87-124.

LOMBARD, D.

1969 «Jardins a Java», Arts Asiatiques, 20, 1969: 135-183.

MANGUIN, P. - Y.

1982 «The Sumatran Coastline in the Straits of Bangka: New Evidence for its Permanence in Historical Times», SPAFA Digest, 3(2), 1982: 24-29.

1982a «Report on Two New Archaeological Sites», In Final Report, SPAFA Consultative Workshop on Archaeological and Environmental Studies on Srivijaya. - Bangkok, 1982: Appendix 4e.

1984 «Garis pantai Sumatra di Selat Bangka: Sebuah bukti baru tentang keadaan yang permanen pada masa sejarah», Amerta, 8, 1984: 17-24 [traduction de Manguin 1982].

1984a Report on a Survey of Two Archaeological Sites in the Bukit Seguntang Area. - Paris/ Jakarta: EFEO/Puslit Arkenas, 1984 (rapport inédit, 50p.).

1986 Report on a Visit to Archaeological Sites in Palembang with Prof. Wolters, 5-7 November 1986. - Jakarta: EFEO/Puslit Arkenas, 1986 (rapport inédit, 17p.).

1987 Report on the Kampung Samirejo Boat Remains and on a Visit to Srivijayan Sites, Palembang, September 1987. - Jakarta: EFEO/Puslit Arkenas, 1987 (rapport inédit, 31p.).

McKinnon, E. E.

1979 «A Note on the Discovery of Spur-Marked Yueh-Type Sherds at Bukit Seguntang, Palembang», JMBRAS, 52(2), 1979: 50-58.

1985 «Early Polities in Southern Sumatra: Some Preliminary Observations based on Archaeological Evidence», Indonesia, 40, 1985: 1-36.

MCKInNon, E. E. \& Mirner, A. C.

1979 «A Letter from Sumatra: A Visit to Some Early Sumatran Historical Sites», Indonesia Circle, 18, 1978: 2-21.

Medley, M.

1981 Tang Pottery and Porcelain. - London, Boston, 1981.

MrLls, J. V. G. (éd.)

1970 Ma Huan, The Overall Survey of the Ocean's Shores, 1433. - Cambridge: Hakluyt Society, 1970.

NoORduYN, J. \& Verstappen, H. Th.

1972 «Purnavarman's River Works near Tugu», BKI, 128, 1972: 298-307.

PERQuin, P. J.

1928 «Oudheidkundig Onderzoek te Palembang», $O V, 1928(1): 124-128$.

Pisit Charoenwongsa

1985 «A Confusing Picture of Srivijaya History», In Final Report, SPAFA Consultative Workshop on Archaeological and Environmental Studies on Srivijaya. - Bangkok: SPAFA, 1985: 105-112.

Praetorius, C. F. E.

1843 «Eenige Bijzonderheden omtrent Palembang», in C. L. Blume (ed), De Indische Bij. Tijdschrift ter bevording van de kennis der Ned. Volksplantiger en dezzelver belangen. Leyden: Deel I, 1843.

RIDHO, ABU

1982 «Ceramic Collection in the Museum Nasional Jakarta», In Final Report, SPAFA Consultative Workshop on Archaeological and Environmental Studies on Srivijaya. - Bangkok: SPAFA, 1982: Appendix 4c. 
RoXAs-Lim, A.

1985 «A Preliminary Report of Srivijayan-Philippine Relations», In Final Report, SPAFA Consultative Workshop on Archaeological and Environmental Studies on Srivijaya. -

SATARI, SRI SoEJATMI Bangkok: SPAFA, 1985: 189-204.

1985 «Research Activities in Indonesia, Sumatra», In Final Report, SPAFA Consultative Workshop on Archaeological and Environmental Studies on Srivijaya. - Bangkok: SPAFA, 1985: 73-79.

SAuvaget, J. (éd.)

1954 «Les Merveilles de l'Inde», in Memorial Jean Sauvaget. Damas: Institut français de Damas, 1954, tome I: $189-312$.

SCHNITGER, F. M.

1935 Oudheidkundige vondsten in Palembang. - Palembang, [1935].

1935a Oudheidkundige vondsten in Palembang, Bijlage B: Addenda en Corrigenda. - Palembang [1935].

1936 Oudheidkundige vondsten in Palembang. Bijlage C. - Leiden, 1936.

1937 The Archaeology of Hindoo Sumatra. - Leiden, 1937.

1939 Forgotten Kingdoms in Sumatra. - Leiden, 1939 (1964, 2e éd.).

Scholz, U.

1983 The Natural Regions of Sumatra and their Agricultural Production Pattern: A Regional Analysis. - Bogor: Central Research Institute for Food Crops, 1983, 2 vols.

SeVEnHOVEn, J. J. van

1825 «Beschrijving van de Hoofdplaats van Palembang», $V B G, 9,1825: 1-126$.

SPAFA

1979 Final Report, Workshop on Research on Srivijaya, Jakarta 1979. -Bangkok: SPAFA, 1979.

1982 Final Report, Consultative Workshop on Archaeological and Environmental Studies on Srivijaya, Jakarta, Palembang and Jambi, 1982. - Bangkok: SPAFA, 1982.

1983 Final Report, Consultative Workshop on Archaeological and Environmental Studies on Srivijaya, Bangkok and South Thailand, 1983. - Bangkok: SPAFA, 1983.

1985 Final Report, Consultative Workshop on Archaeological and Environmental Studies on Srivijaya, Jakarta and Sumatra 1985. - Bangkok: SPAFA, 1985.

STURLER, W. L. de

1843 Proeve eener Beschrijving van het Gebeid van Palembang. - Groningen, 1843.

SUKENDAR, $\mathrm{H}$.

1975 «Catatan sementara tentang temuan manik-manik prasejarah di Kampung Unglen, Lebak Kranji, Palembang», Bulletin Yaperna, 2(6), 1975: 57-69.

Suleiman, Satyawati

1982 «Country Report of Indonesia», In Final Report, SPAFA Consultative Workshop on Archaeological and Environmental Studies on Srivijaya. - Bangkok: SPAFA, 1982: Appendix $3 a$.

1983 «The Role of the Śailendras in Srivijaya», In Final Report, SPAFA Consultative Workshop on Archaeological and Environmental Studies on Srivijaya. - Bangkok: SPAFA, 1983: Appendix 4a.

1985 «The Art of Srivijaya», In Final Report, SPAFA Consultative Workshop on Archaeological and Environmental Studies on Srivijaya. - Bangkok: SPAFA, 1985: 97-104.

SuRASTOPO H. (ed)

1985 Laporan Pemetaan terintegrasi kepurbakalaan Sriwijaya. - Yogyakarta: Bakosurtanal \& Universitas Gadjah Mada, 1985 (rapport inédit). 
SURASTOPO, H. \& SUTIKNo

1985 «Looking for Sriwijaya: A Geomorphological Approach to Locating the Capital of the Ancient Kingdom», in Proceedings of the Regional Symposium on Remote Sensing Applications for Socio-Economic Aspects of the Environment. - Yogyakarta: ESCAP/Gajah Mada University, 1985: 99-100.

TAKAKUSU, $\mathbf{J}$.

1896 A Record of Buddhist Religion as Practised in India and the Malay Archipelago (A.D. 671-695) by I-Tsing. - Oxford, 1896.

TeEuw, A., RoBson, S.O. et.al. (éds)

1969 Siwaratrikalpa of Mpu Tanakun. An Old Javanese Poem, its Indian sources and Balinese illustrations. - The Hague: Biblioteca Indonesica, 3, 1969.

THORN, W.

1815 Memoir of the conquest of Java; with the subsequent operation of the British forces in the Oriental Archipelago. - London, 1815.

TIBBETrS, G. R.

1979 A Study of the Arabic Texts containing Material on South-East Asia. - London, Leiden: Royal Asiatic Society, 1979.

Tim Pemetaan Dan Penelitian Geologi Dan Arkeologi

1984 Laporan pemetaan dan penelitian geologi di Bukit Seguntang dan sekitarnya, Kotamadya Palembang, dan penelitian arkeologi di daerah Kotamadya Palembang, Propinsi Sumatra Selatan. - Jakarta: Pusat Penelitian Arkeologi Nasional, 1984 (rapport inédit).

Tsubouchi, Yoshirmiro \& ILJAs, N. (eds.)

1980 South Sumatra: Man and Agriculture. - Kyoto: Centre for Southeast Asian Studies, 1980.

WATSON, W.

1984 Tang and Liao Ceramics. - London, 1984.

WESTENENK, L. C.

1921 «Uit het Land van Bittertong (Zuid-Soematra)», Djawa, 1(1), 1921: 5-11.

1923 «Boekit Segoentang en Goenoeng Mahaméroe uit de Sedjarah Melajoe», TBG, 68(1), 1923: 212-226.

WhEATLEY, P.

1983 Nägara and Commandery: Origins of the Southeast Asian Urban Traditions. - Chicago: University of Chicago, Department of Geography Research Paper No. 207-208, 1983.

WhITEHOUSE, D.

1973 "Chinese Stoneware from Siraf: the Earliest Finds», In N. Hammond (ed). South Asian Archaeology. - London 1973: 241-255.

WILKINSON, R. J.

1959 A Malay-English Dictionary (Romanised). - London, 1959, 2 vols.

WINSTEDT, R. O.

1938 «The Malay Annals or Sejarah Melayu», JMBRAS, 16(3), 1938: 1-226.

WOELDERS, M. O.

1975 Het Sultanaat Palembang, 1811-1825. -'Gravenhage: VKI 72, 1975.

WOLTERS, O. W.

1966 «A Note on the Capital of Srivijaya during the Eleventh Century», in Ba Shin, J. Boisselier \& A. B. Griswold (eds), Essays offered to G. H. Luce. - Ascona: Artibus Asiae (Supplementum 23), vol. I, p. 225-239.

1967 Early Indonesian commerce: A study of the origins of Srivijaya. - Ithaca, New York: Cornell University Press, 1967.

1970 The Fall of Srivijaya in Malay History. - Kuala Lumpur/Singapore: Oxford University Press, 1970. 
WOLTERS, O. W.

1979 «Studying Srivijaya», JMBRAS, 52(2), 1979: 1-32.

1979a «A Note on Sungsang Village at the Estuary of the Musi River in Southeastern Sumatra: A Reconsideration of the Historical Geography of the Palembang Region», Indonesia, 27, 1979: 33-50.

1984 «Palembang Revisited», Cornell University, Southeast Asia Program Bulletin, 1984: 17-18.

1986 «Restudying Some Chinese Writings on Sriwijaya», Indonesia, 42, 1986: 1-41.

WRIGHT, M.

1983 «Observations on Srivijaya», In Final Report, SPAFA Consultative Workshop on Archaeological and Environmental Studies on Srivijaya. - Bangkok: SPAFA, 1983, 269-276.

WYRTKI, K.

1961 Physical Oceanography of the Southeast Asian Waters. - La Jolla: The University of California, Scripps Institute of Oceanography, 1961.

YAMAMOTO TATSURO

1983 "Reexamination of Historical Texts Concerning Srivijaya", In Final Report, SPAFA Consultative Workshop on Archaeological and Environmental Studies on Srivijaya. Bangkok: SPAFA, 1983, 171-179.

1985 "Transformation of the Chinese Images of South Seas Countries from the 12th to the 14th Centuries", In Final Report, SPAFA Consultative Workshop on Archaeological and Environmental Studies on Srivijaya. - Bangkok: SPAFA, 1985: 205-211.

ZAINIE, C. M. (with T. HARRISSON)

1967 "Early Chinese Stonewares Excavated in Sarawak, 1947-67: A Suggested First Basic Classification", $S M J, 15$ (30-31), 1967: 30-90.

\section{ANNEXE \\ LISTE DES COMMUNICATIONS PRESENTEES AUX QUATRE «SPAFA WORKSHOP ON RESEARCH ON SRIVIJAYA» 1979-1985}

AMBARY, H. MUARIF

1982 «Recent Archaeological Researches in Sumatra», in Final Report, SPAFA Consultative Workshop on Archaeological and Environmental Studies on Srivijaya. - Bangkok: SPAFA, 1982: Appendix 3b.

BANJONG WONGWICHIEN

1983 «The Excavation and Renovation of Wat Lo-Ong, Amphoe Chaiya, Surat Thani», In Final Report, SPAFA Consultative Workshop on Archaeological and Environmental Studies on Srivijaya. - Bangkok: SPAFA, 1983: Appendix 6c.

BOECHARI

1979a «Report on Research on Sriwijaya», In Final Report, SPAFA Workshop on Research on Srivijaya. - Bangkok: SPAFA, 1979: Appendix 3a.

1985 «Ritual Deposits of Candi Gumpung (Muara Jambi)», In Final Report, SPAFA Consultative Workshop on Archaeological and Environmental Studies on Srivijaya. - Bangkok: SPAFA, 1985: 229-243.

BUDI UTOMO, BAMBANG

1985 «Karanganyar as a Srivijayan Site: New Evidence for the Study of Settlement Patterns of the Srivijayan Period», in Final Report, SPAFA Consultative Workshop on Archaeological and Environmental Studies on Srivijaya. - Bangkok: SPAFA, p. 273-291. 
CASPARIS, J. G. DE

1982 «Some Notes on the Epigraphic Heritage of Sriwijaya», In Final Report, SPAFA Consultative Workshop on Archaeological and Environmental Studies on Srivijaya. Bangkok: SPAFA, 1982: Appendix 4h.

1985 «Srivijaya and Malayu», In Final Report, SPAFA Consultative Workshop on Archaeological and Environmental Studies on Srivijaya. - Bangkok: SPAFA, 1985: 245-255.

\section{Chusiri Chamoraman}

1983 «Some Historical International Ports of the Malay Peninsula», In Final Report, SPAFA Consultative Workshop on Archaeological and Environmental Studies on Srivijaya. Bangkok: SPAFA, 1983: Appendix 6b.

1985 «Srivijaya and Contemporary Archaeological Findings at Pattani», In Final Report, SPAFA Consultative Workshop on Archaeological and Environmental Studies on Srivijaya. Bangkok: SPAFA, 1985: 161-166.

\section{DHIDA SARAYA}

1983 «The Development of the Thai Peninsular States with Special Reference to rTambralinga (6th-13th Centuries)», In Final Report, SPAFA Consultative Workshop on Archaeological and Environmental Studies on Srivijaya. - Bangkok: SPAFA, 1983: Appendix 4g.

Diskul, SubHADRAdIS

1979 «A Short History of the Srivijaya Kingdom and Its Art in Southern Thailand», In Final Report, SPAFA Workshop on Research on Srivijaya. - Bangkok: SPAFA, 1979: Appendix $3 \mathrm{~d}$.

Ferdinandus, P. E. J.

1983 «Indonesian Traditional Music Instruments in the Sailendra Period», In Final Report, SPAFA Consultative Workshop on Archaeological and Environmental Studies on Srivijaya. - Bangkok: SPAFA, 1983: Appendix 4d.

1985 «Some Remarks on Musical Instruments History in Southeast Asia Related to the Srivijaya Studies», In Final Report, SPAFA Consultative Workshop on Archaeological and Environmental Studies on Srivijaya. - Bangkok: SPAFA, 1985: 311-322.

Francisco, J. R.

1983 «Notes on the Ethnography of Srivijaya», In Final Report, SPAFA Consultative Workshop on Archaeological and Environmental Studies on Srivijaya. - Bangkok: SPAFA, 1983: Appendix 4e.

1985 «The Iconography of Hindu and Buddhist Images», In Final Report, SPAFA Consultative Workshop on Archaeological and Environmental Studies on Srivijaya. - Bangkok: SPAFA, 1985: 167-188.

FRANCISCO, J. R. \& HAN, B. A.

1979 «Country Report of the Philippines», In Final Report, SPAFA Workshop on Research on Srivijaya. - Bangkok: SPAFA, 1979: Appendix 3c.

HaN, B. A.

1983 «Notes on a Photo-Ethnographic Survey of the Sama of Central Sulu and the Indonesians of Sungsang», In Final Report, SPAFA Consultative Workshop on Archaeological and Environmental Studies on Srivijaya. - Bangkok: SPAFA, 1983: Appendix 4f.

Hassan Shumaimi, Nik \& Othman Bin Mohd. Yatim

1979 «Country Report on Past or On-going Research in Malaysia on Srivijaya», In Final Report, SPAFA Workshop on Research on Srivijaya. - Bangkok: SPAFA, 1979: Appendix 3b.

HASSAN SHUHAIMI, NIK

1985 «Country Report on Past and On-going Research in Malaysia on Srivijaya after 1979», In Final Report, SPAFA Consultative Workshop on Archaeological and Environmental Studies on Srivijaya. - Bangkok: SPAFA, 1985: 323-332. 
KHEMCHATI THEPCHAI

1982 «The Environmental and Archaeological Studies on Srivijaya at Chaiya, Surat Thani Province», In Final Report, SPAFA Consultative Workshop on Archaeological and Environmental Studies on Srivijaya. - Bangkok: SPAFA, 1982: Appendix 3f.

1983 «The Excavation at Laem Pho: A Srivijaya Entrepôt?», In Final Report, SPAFA Consultative Workshop on Archaeological and Environmental Studies on Srivijaya. - Bangkok: SPAFA, 1983: Appendix 4i.

1983a «Archaeological Site at Ko Khor-Khao, Amphoe Khura Buri, Phangnga Province», In Final Report, SPAFA Consultative Workshop on Archaeological and Environmental Studies on Srivijaya. - Bangkok: SPAFA, 1983: Appendix 6d.

KONGKAEW VEERAPRAJAK

1985 «Inscriptions from South Thailand», In Final Report, SPAFA Consultative Workshop on Archaeological and Environmental Studies on Srivijaya. - Bangkok: SPAFA, 1985: 131-160.

MACHI SUHADI

1983 «Seven Old-Malay Inscriptions Found in Java", In Final Report, SPAFA Consultative Workshop on Archaeological and Environmental Studies on Srivijaya. - Bangkok: SPAFA, 1983: Appendix 4b.

1985 «Inscriptions from Muara Jambi», in Final Report, SPAFA Consultative Workshop on Archaeological and Environmental Studies on Srivijaya. - Bangkok: SPAFA, 1985: 257262.

MANGUIN, P. - Y.

1982 "The Sumatran Coastline in the Straits of Bangka: New Evidence for its Permanence in Historical Times», SPAFA Digest, 3(2), 1982: 24-29.

1982 «Report on Two New Archaeological Sites», In Final Report, SPAFA Consultative Workshop on Archaeological and Environmental Studies on Srivijaya. - Bangkok: SPAFA, 1982, Appendix 4e.

1983 «Comments on the Concept of Trans-Peninsular Routes», In Fianal Report, SPAFA Consultative Workshop on Archaeological and Environmental Studies on Srivijaya. Bangkok: SPAFA, 1983: Appendix 7d.

1985 «Research on the Ships of Srivijaya (and of 1st Millenium AD Southeast Asia). A Progress Report», in Final Report, SPAFA Consultative Workshop on Archaeological and Environmental Studies on Srivijaya. - Bangkok: SPAFA, 1985: 291-306.

MCKINNON, E. E.

1982 «A Brief Note on Muara Kumpeh Hilir: an Early Port Site on the Batang Hari?» SPAFA Digest, 3(2), 1982: 37-40.

1984 «New Data for Studying the Early Coastline in the Jambi Area», SPAFA Digest, 5(2), 1984: 4-8.

NOERHADI MAGETSARI

1985 «On the Study of Buddhism of Srivijaya», In Final Report, SPAFA Consultative Workshop on Archaeological and Environmental Studies on Srivijaya. - Bangkok: SPAFA, 1985: 213-214.

Phasook IINDRAWOOTH

1982 «A Study on Local Ceramics of Southern Thailand and Their Relations to Dvaravati and Srivijayan Cultures», In Final Report, SPAFA Consultative Workshop on Archaeological and Environmental Studies on Srivijaya. - Bangkok: SPAFA, 1982: Appendix 3e.

\section{Pisit Charoenwongsa}

1985 «A Confusing Picture of Srivijaya History», In Final Report, SPAFA Consultative Workshop on Archaeological and Environmental Studies on Srivijaya. - Bangkok: SPAFA, 1985: 105-112. 
PORNCHAI SUCHITTA

1983 «An Overview of the Country Papers from Thailand», In Final Report, SPAFA Consultative Workshop on Archaeological and Environmental Studies on Srivijaya. - Bangkok: SPAFA, 1983: Appendix 4j.

Preecha Noonsuk

1983 «The Ancient Settlement of Mok Khalan», In Final Report, SPAFA Consultative Workshop on Archaeological and Environmental Studies on Srivijaya. - Bangkok: SPAFA, 1983: Appendix 6e.

1983a «Sichon: An Ancient Brahmanical Settlement on the Malay Peninsula», In Final Report, SPAFA Consultative Workshop on Archaeological and Environmental Studies on Srivijaya. - Bangkok: SPAFA, 1983: Appendix 4h.

RIDHO, ABU

1982 «Ceramic Collection in the Museum Nasional Jakarta», In Final Report, SPAFA Consultative Workshop on Archaeological and Environmental Studies on Srivijaya. - Bangkok: SPAFA, 1982: Appendix 4c.

RoXAS-LIM, A.

1985 «A Preliminary Report of Srivijayan-Philippine Relations», In Final Report, SPAFA Consultative Workshop on Archaeological and Environmental Studies on Srivijaya. Bangkok SPAFA, 1985: 189-204.

SARTONO, S.

1982 "Gold in Historic Sumatra», In Final Report, SPAFA Consultative Workshop on Archaeological and Environmental Studies on Srivijaya. - Bangkok: SPAFA, 1982: Appendix 4f.

1985 «The Historic Sea Route Around Bangka and Belitung: A Geological Interpretation», In Final Report, SPAFA Consultative Workshop on Archaeological and Environmental Studies on Srivijaya. - Bangkok: SPAFA, 1985: 215-227.

SATARI, SRI SoEJaTmI

1985 «Research Activities in Indonesia, Sumatra», In Final Report, SPAFA Consultative Workshop on Archaeological and Environmental Studies on Srivijaya. - Bangkok: SPAFA, 1985: 73-79.

SHOJI Iто

1983 «Remarks on the Iconography of Bodhisattva Images Found in Chaiya, Southern Thailand», In Final Report, SPAFA Consultative Workshop on Archaeological and Environmental Studies on Srivijaya. - Bangkok: SPAFA, 1983: Appendix 5c.

SOEKarto K. ATMODJo

1985 «Short Notes on the Old Malay Inscriptions in Central Java», In Final Report, SPAFA Consultative Workshop on Archaeological and Environmental Studies on Srivijaya. Bangkok: SPAFA, 1985: 81-95.

SOEKMONO

1985 «The Architecture of Srivijaya: A Review», In Final Report, SPAFA Cosultative Workshop on Archaeological and Environmental Studies on Srivijaya. - Bangkok: SPAFA, 1985: 57-71.

SRISAKRA VALLIBHOTAMA

1982 «A Survey of Ancient Settlements in Southern Thailand», In Final Report, SPAFA Consultative Workshop on Archaeological and Environmental Studies on Srivijaya. - Bangkok: SPAFA, 1982: Appendix 3d.

STARGARDT, J.

1982 «The Satingpra Civilization and Its Relevance to Srivijayan Studies», In Final Report, SPAFA Consultative Workshop on Archaeological and Environmental Studies on Srivijaya. -Bangkok: SPAFA, 1982: Appendix 4b. 
STARGARDT, J.

1983 «Kendi Production at Kok Moh, Songkhla Province, and Srivijayan Trade in the 11th Century», In Final Report, SPAFA Consultative Workshop on Archaeological and environmental Studies on Srivijaya. - Bangkok: SPAFA, 1983: Appendix 5b.

SuKatno, SRI H. ENDANG

1983 «Stupikas and Votive Tablets Found in Indonesia», In Final Report, SPAFA Consultative Workshop on Archaeological and Environmental Studies on Srivijaya. - Bangkok: SPAFA, 1983: Appendix 4c.

1985 «Beads from Muara Jambi», In Final Report, SPAFA Consultative Workshop on Archaeological and Environmental Studies on Srivijaya. - Bangkok: SPAFA, 1985: 307-310.

Suleiman, Satyawati

1982 "Country Report of Indonesia», In Final Report, SPAFA Consultative Workshop on Archaeological and Environmental Studies on Srivijaya. - Bangkok: SPAFA, 1982: Appendix 3a.

1983 «The Role of the Sailendras in Srivijaya», In Final Report, SPAFA Consultative Workshop on Archaeological and Environmental Studies on Srivijaya. - Bangkok: SPAFA, 1983: Appendix 4a.

1985 «The Art of Srivijaya», In Final Report, SPAFA Consultative Workshop on Archaeological and Environmental Studies on Srivijaya. - Bangkok: SPAFA, 1985: 97-104.

\section{TARAPONG SRISUCHART}

1985 «The Early Historic Sites and the Remains in Southern Thailand», In Final Report, SPAFA Consultative Workshop on Archaeological and Environmental Studies on Srivijaya. Bangkok: SPAFA, 1985: 113-130.

TJANDRASASMITA, UKa

1982 «A Brief Information on the Restoration Work of the Temples at Muara Jambi», In Final Report, SPAFA Consultative Workshop on Archaeological and Environmental Studies on Srivijaya. - Bangkok: SPAFA, 1982: Appendix 4g.

VeERAPRAJAK, $\mathrm{K}$.

1985 «Inscriptions from South Thailand», in Final Report, SPAFA Consultative Workshop on Archaeological and Environmental Studies on Srivijaya. - Bangkok: SPAFA, 1985: 105112/SPAFA Digest, 7(1), 1986: 7-21.

\section{YAMAMOTO TATSURO}

1983 «Reexamination of Historical Texts Concerning Srivijaya», In Final Report, SPAFA Consultative Workshop on Archaeological and Environmental Studies on Srivijaya. Bangkok: SPAFA, 1983: Appendix 5a.

1985 «Transformation of the Chinese Images of South Seas Countries from the 12th to the 14th Centuries», In Final Report, SPAFA Consultative Workshop on Archaeological and Environmental Studies on Srivijaya. - Bangkok: SPAFA, 1985: 205-211. 


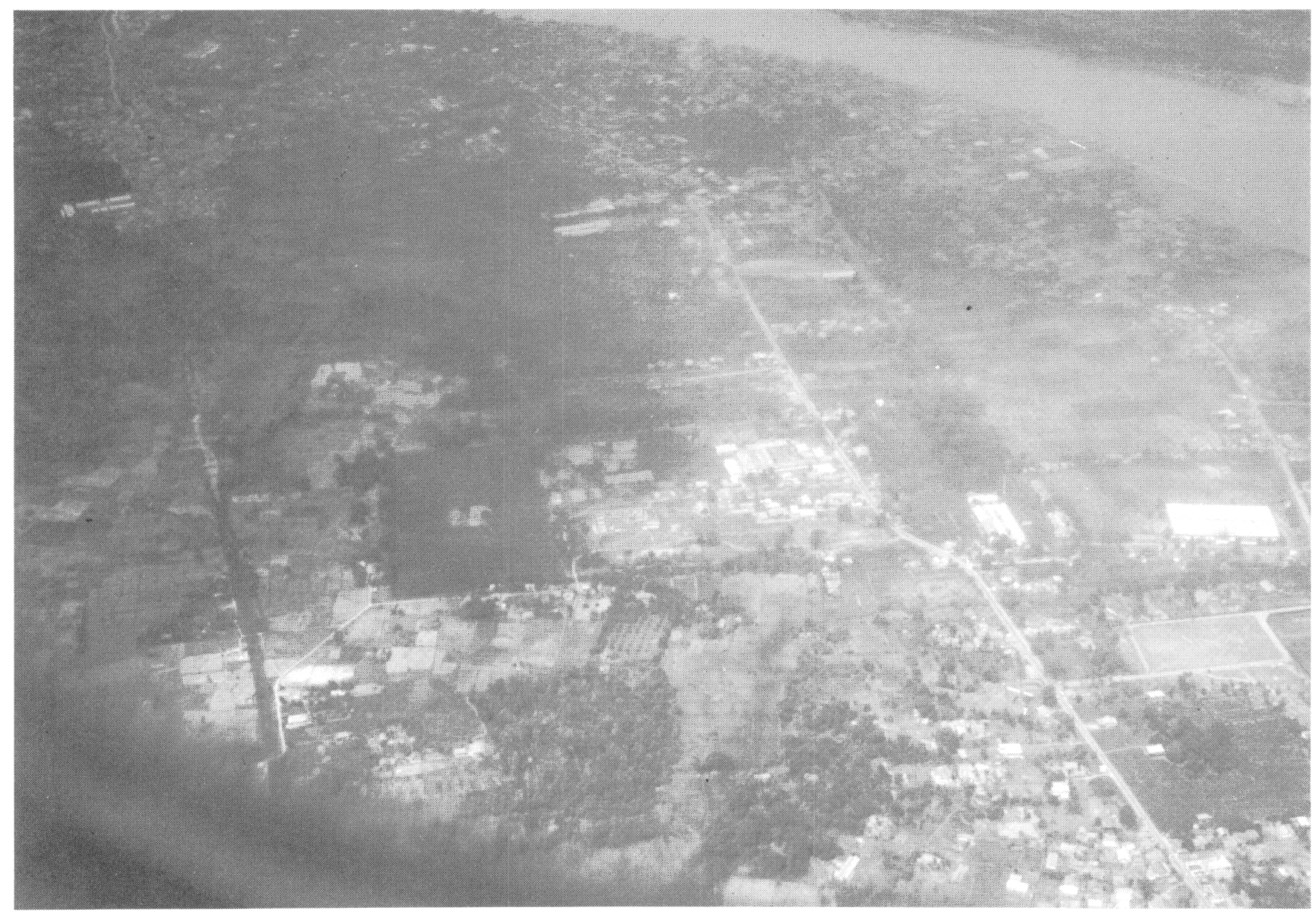

Fig. 1. - Vue aérienne de Karang Anyar en 1985 (vue vers l'est; au centre, le site A). 


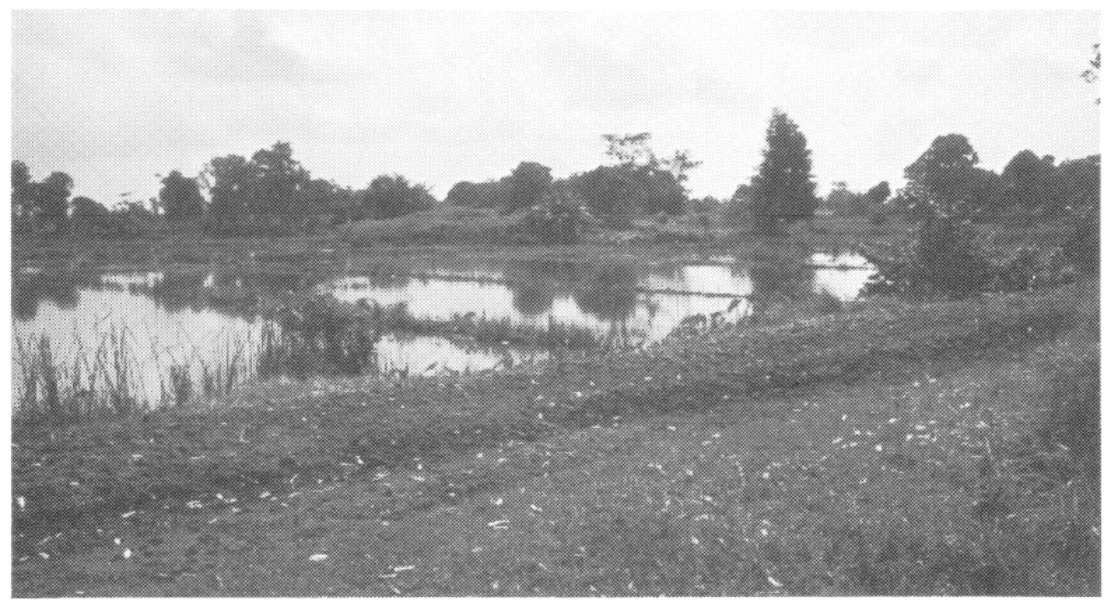

Fig. 2. - Karang Anyar A (réservoir nord, vue de l'île de Cempaka, depuis la terrasse centrale).

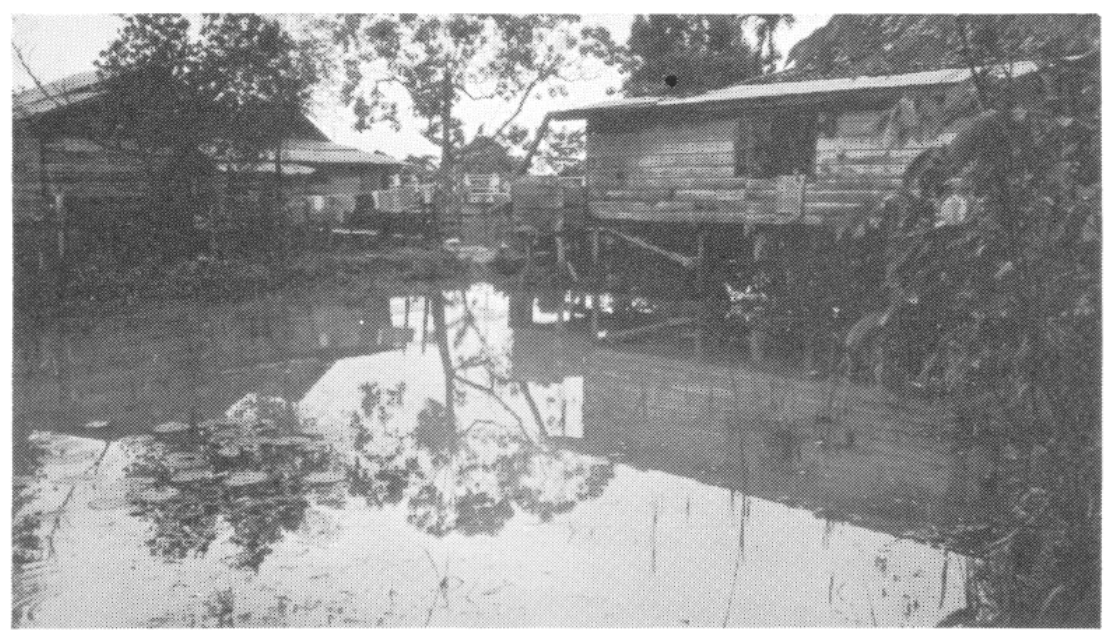

Fig. 3. - Karang Anyar A (canal est, près du coin sud-est).

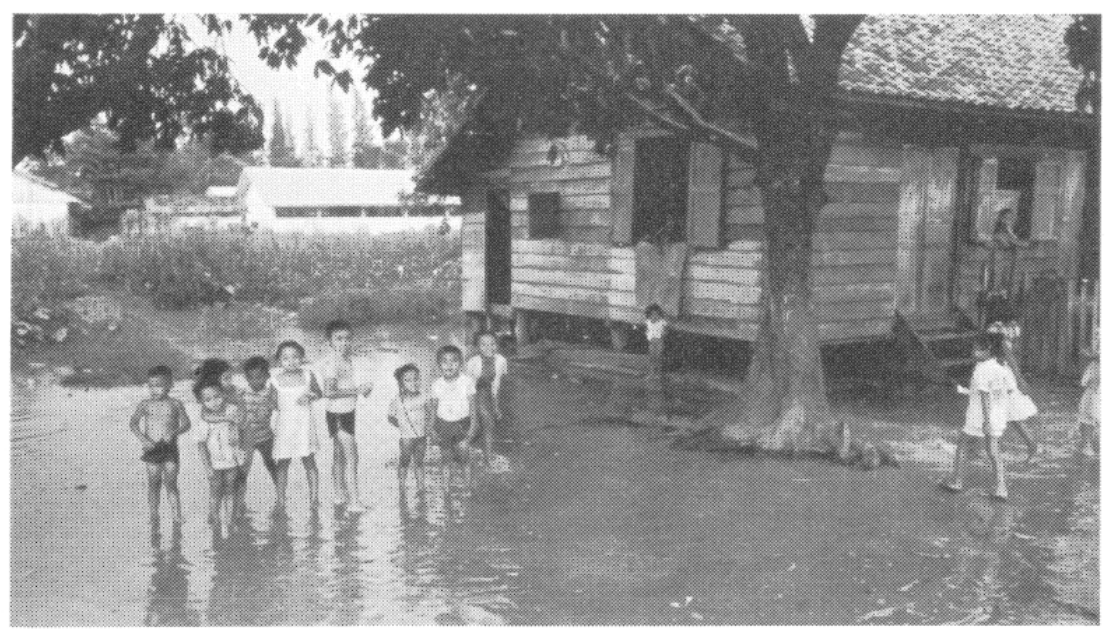

Fig. 4. - Karang Anyar A (sud de la terrasse centraie, inondée par une marée de vives-eaux). 


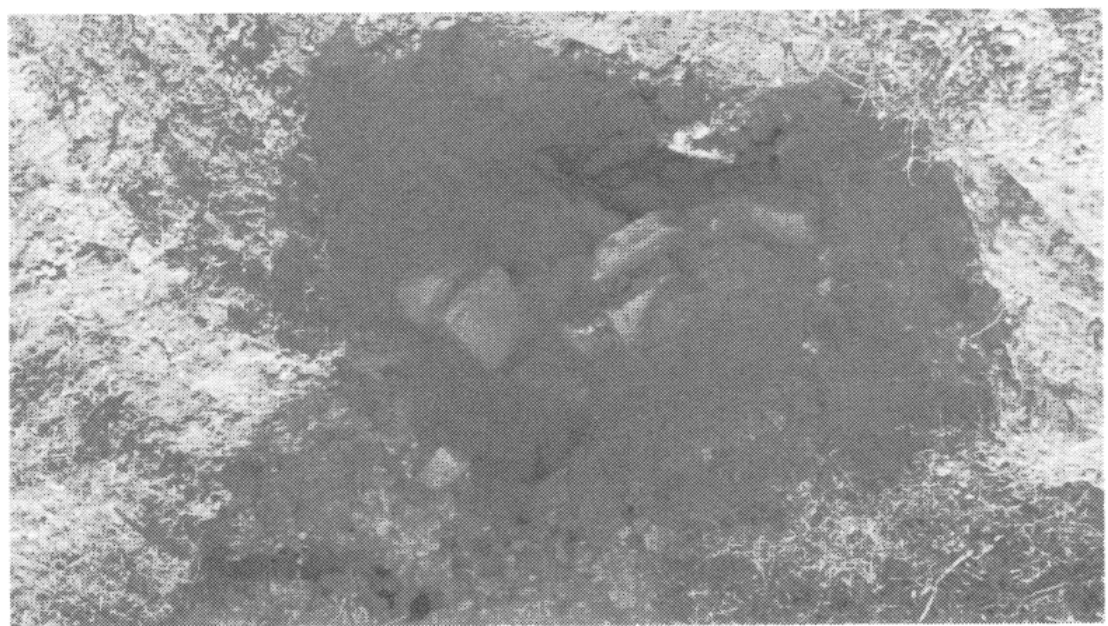

Fig. 5. - Karang Anyar B (île centrale plantée d'arbres, réservoir au premier plan).

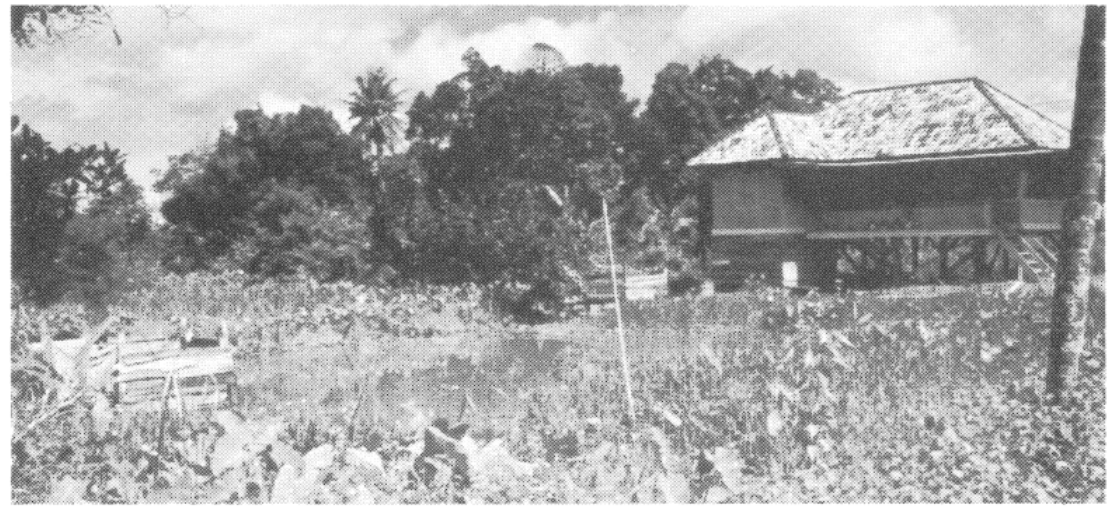

Fig. 6. - Karang Anyar A (terrasse centrale, briques in situ, dans un puits creusé par les paysans; photo E. E. McKinnon).

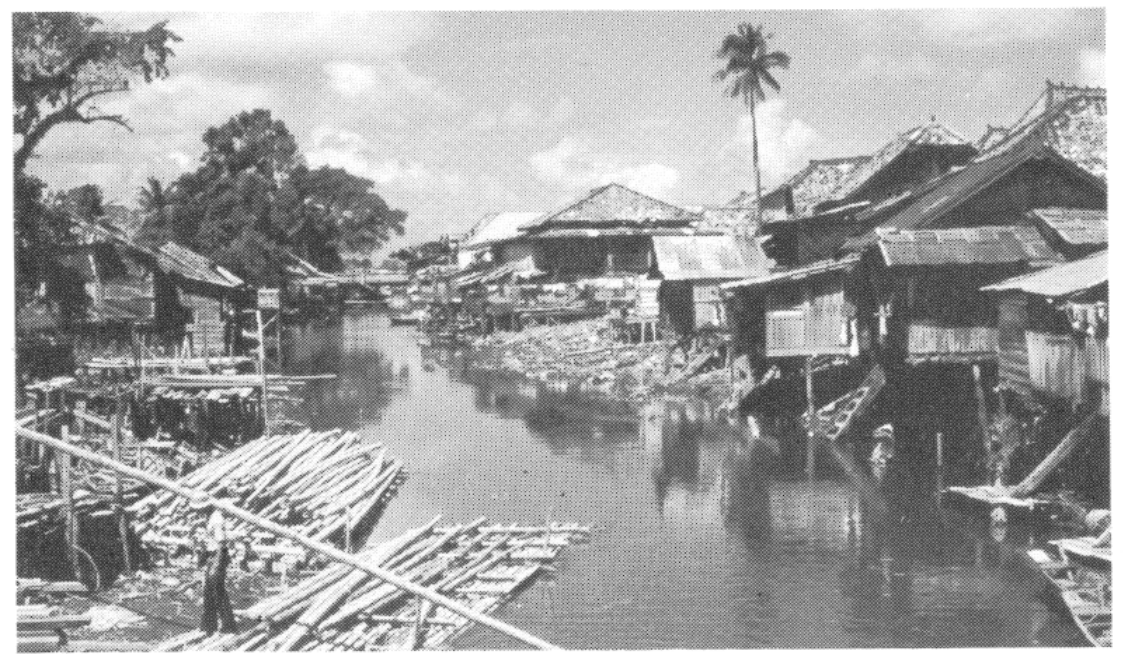

Fig. 7. - Sungei Kedukan Bukit, près de son confluent avec la Sungei Musi. 


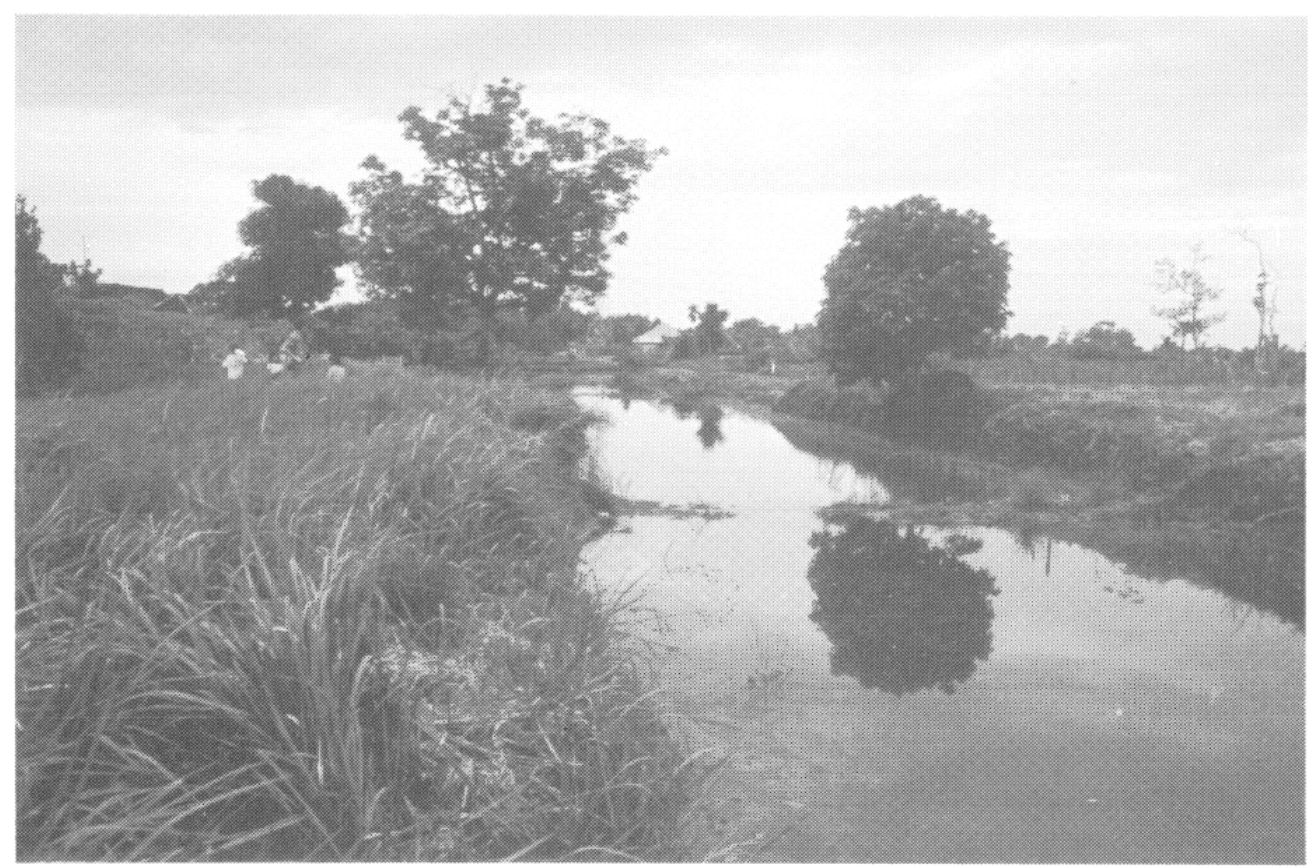

Fig. 8. - Canal de Suak Bujang (au nord de Karang Anyar A).

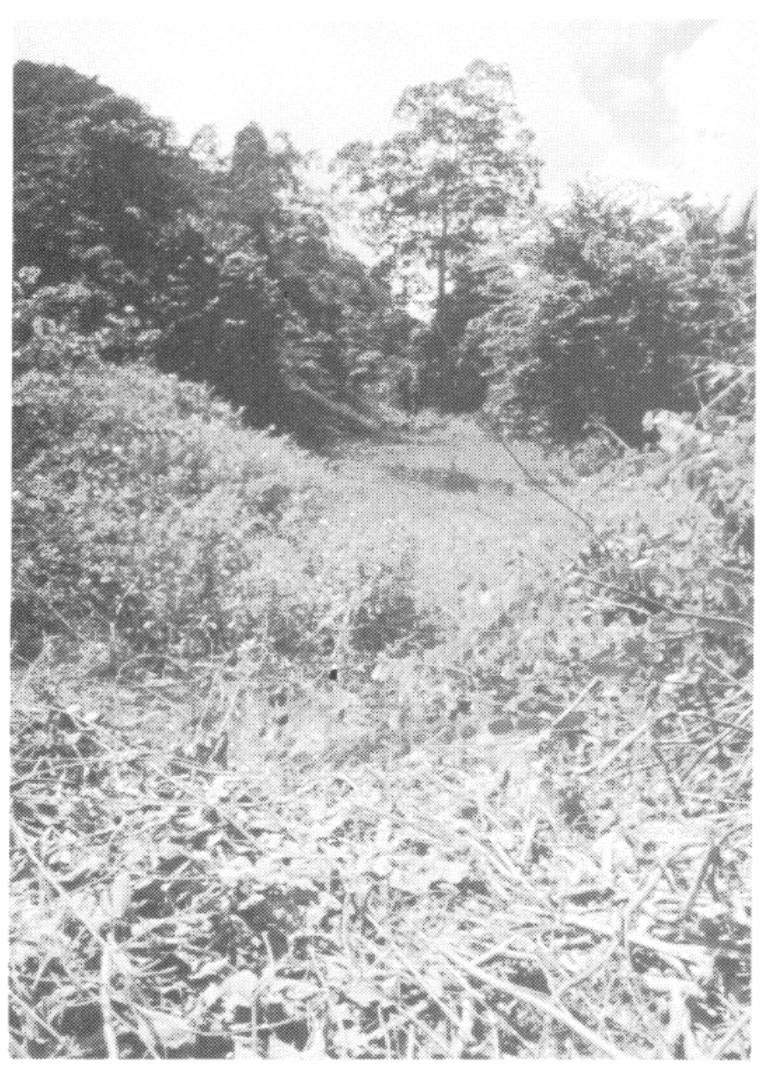

Fig. 9. - Canal de Suak Bujang (près de Ladang Sirap, coupant à travers un talang).

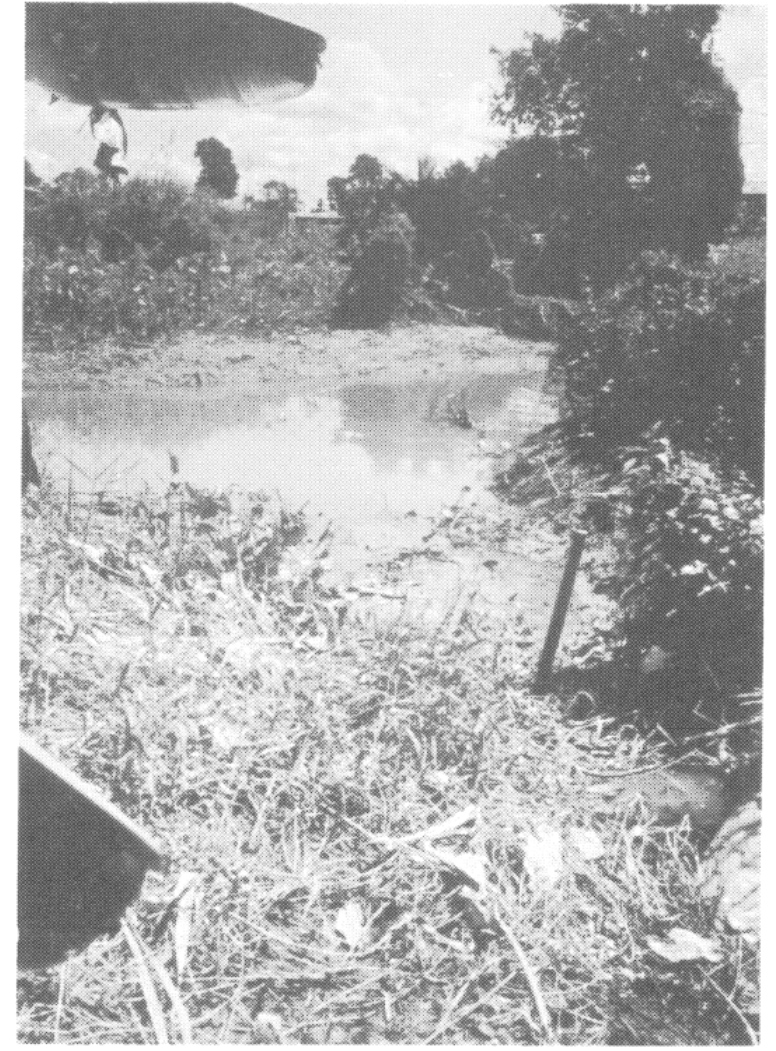

Fig. 10. - Canal de Suak Bujang (confluent avec la Sungei Rambutan). 


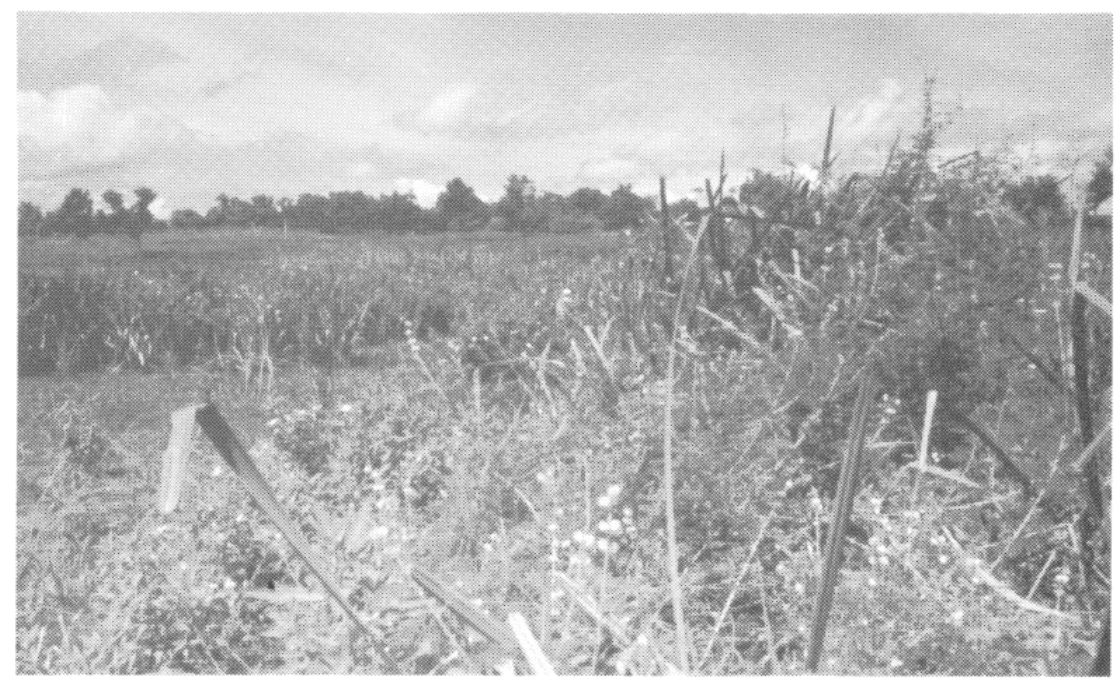

Fig. 11. - Environnement typique de Palembang Ouest : au premier plan, un lebak marécageux; au fond, un talang surélevé et planté d'arbres.

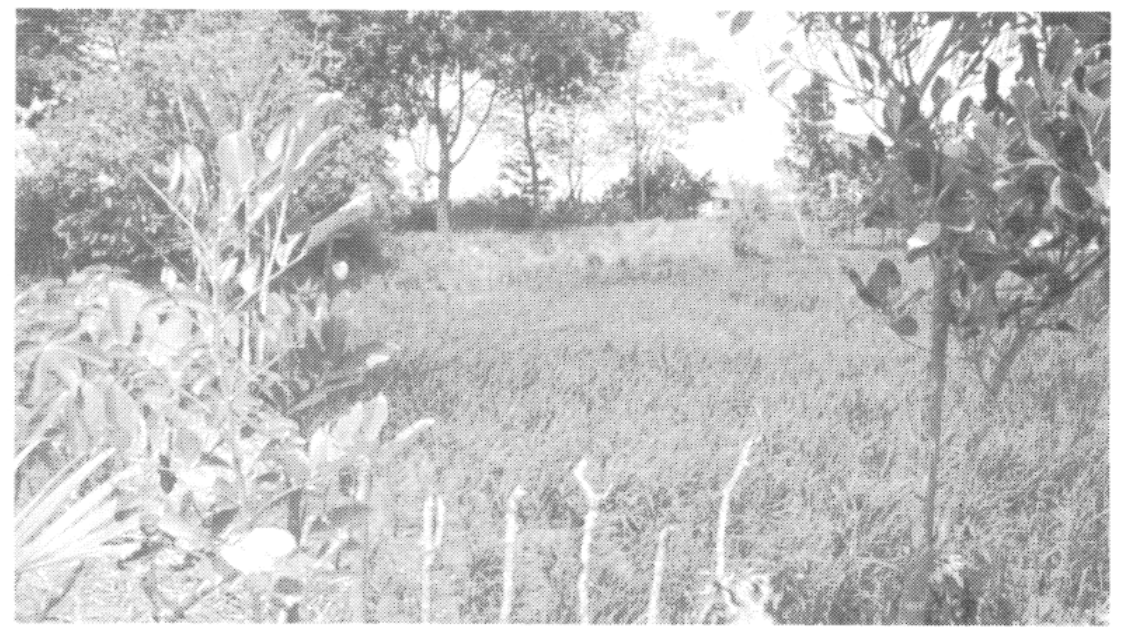

Fig. 12. - Cours (canalisé?) de la Sungei Tapak; à gauche, surélevé, site possible d'un stûpa.

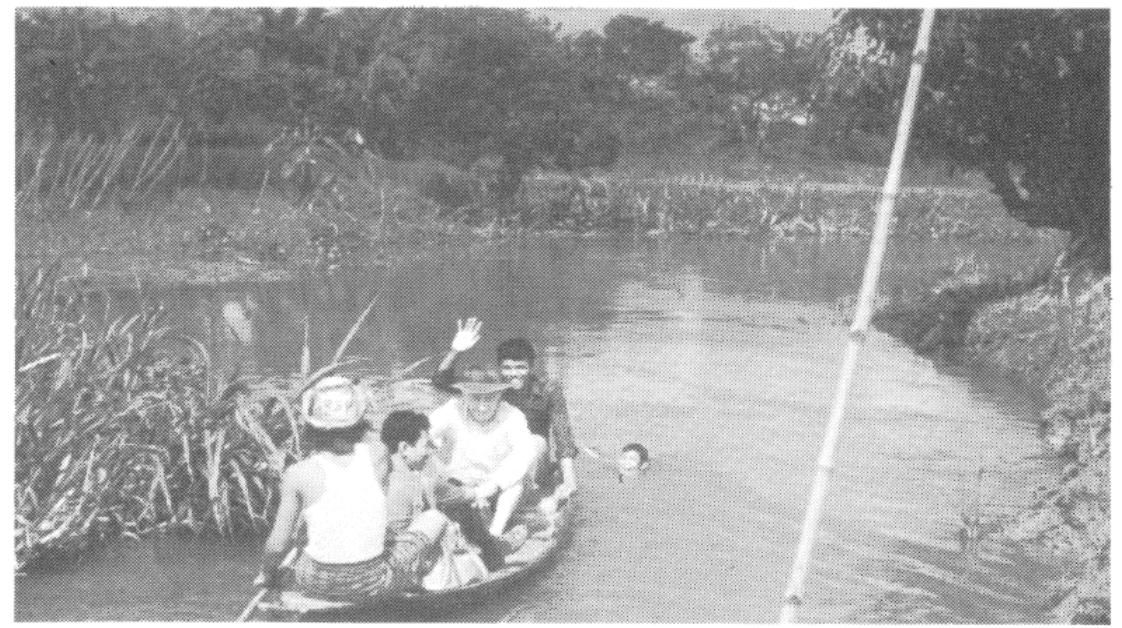

Fig. 13. - Sungei Lamidaro (à la hauteur de Talang Kikim). 
Fig. 14. - Bukit Seguntang (la colline vue du sud, en 1980).
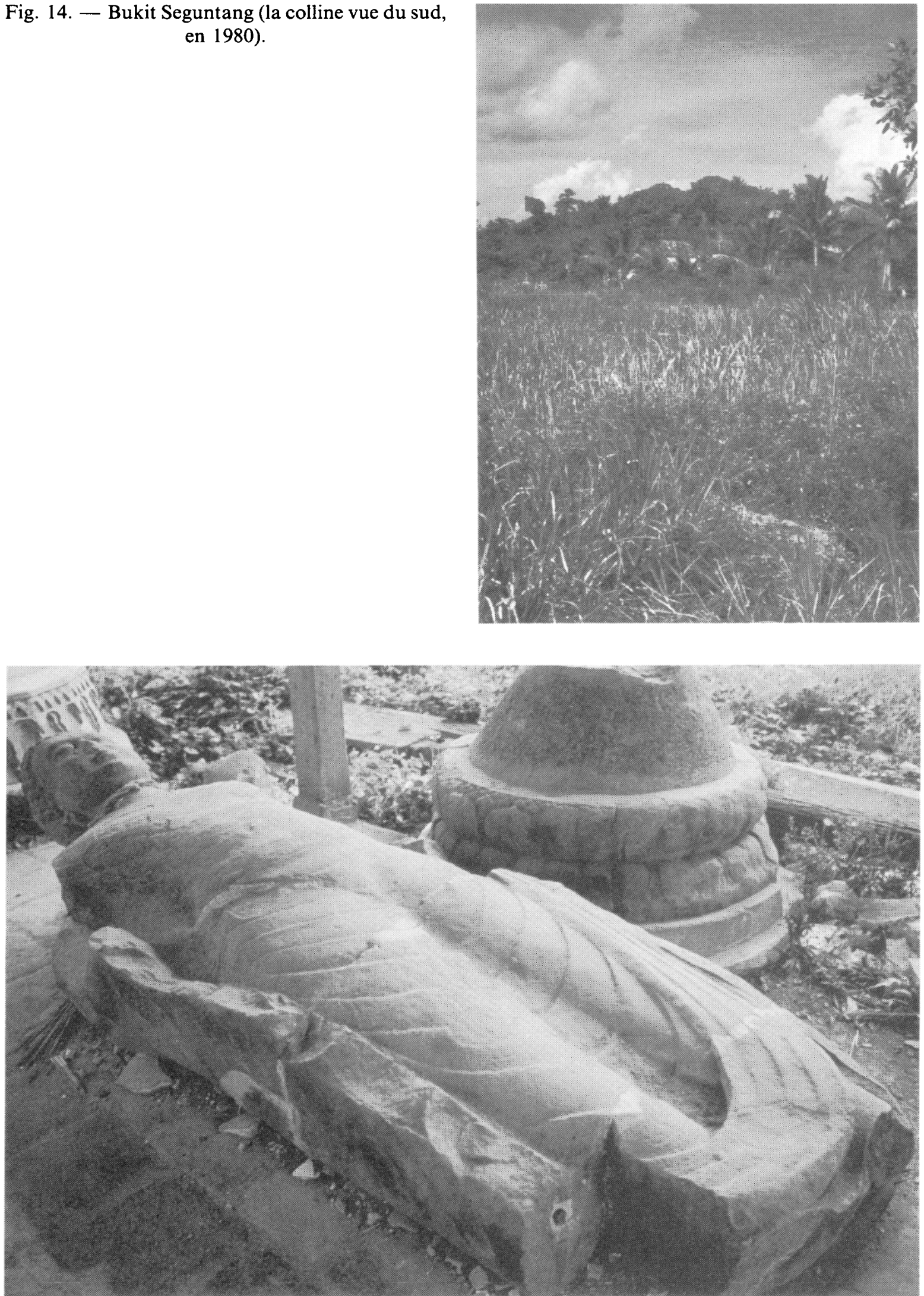

Fig. 15. - Bukit Seguntang: le "grand Buddha», tel que conservé au Musée Badaruddin. 


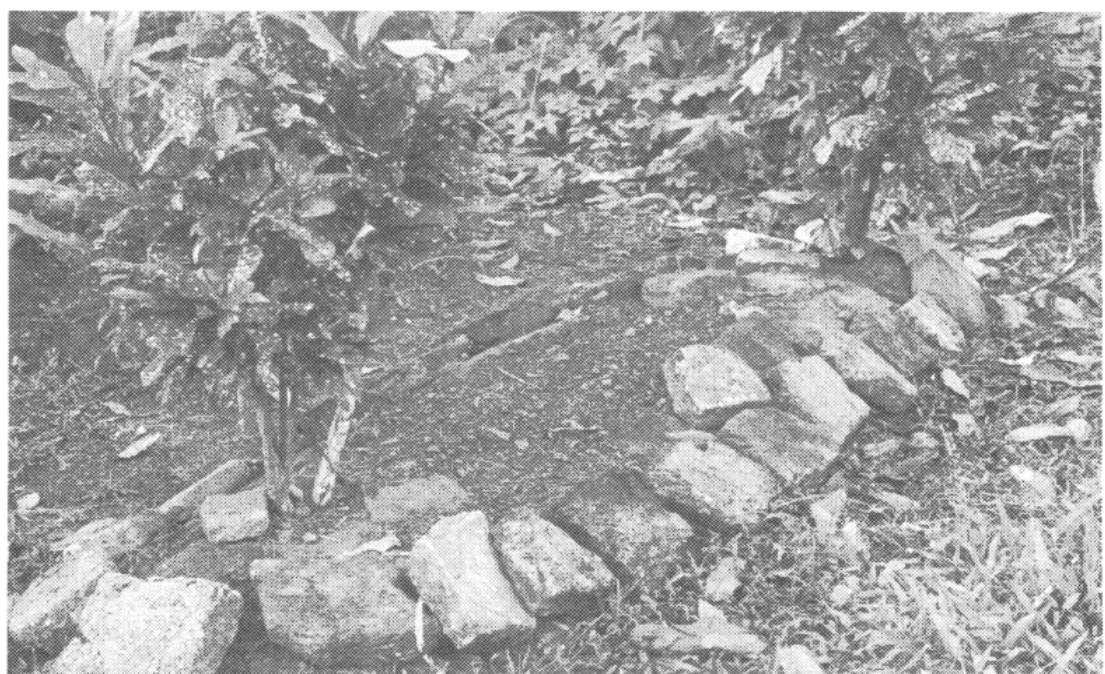

Fig. 16. - Bukit Seguntang: briques anciennes marquant une tombe musulmane.

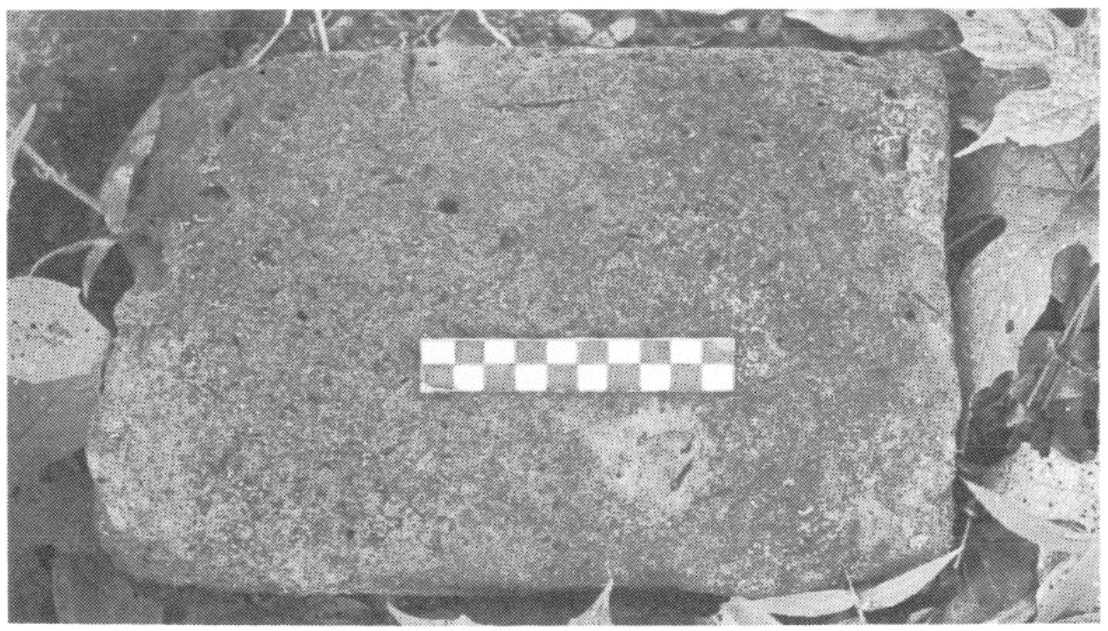

Fig. 17. - Bukit Seguntang: brique ancienne, avec intrusions nombreuses.

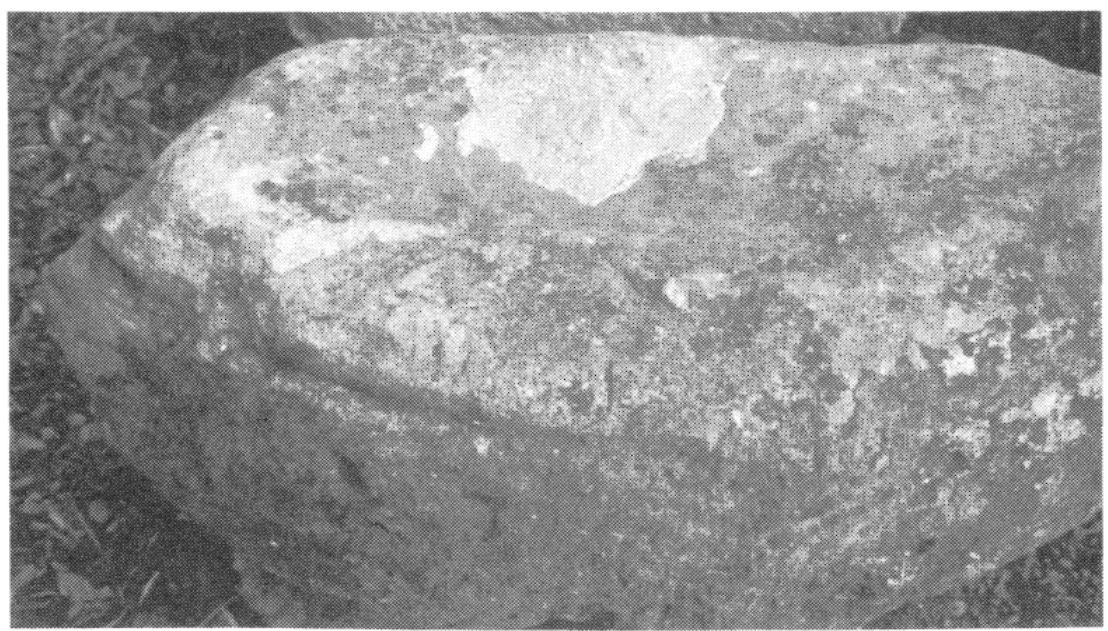

Fig. 18. - Bukit Seguntang: pierre sculptée circulaire (en provenance d'un stûpa?). 


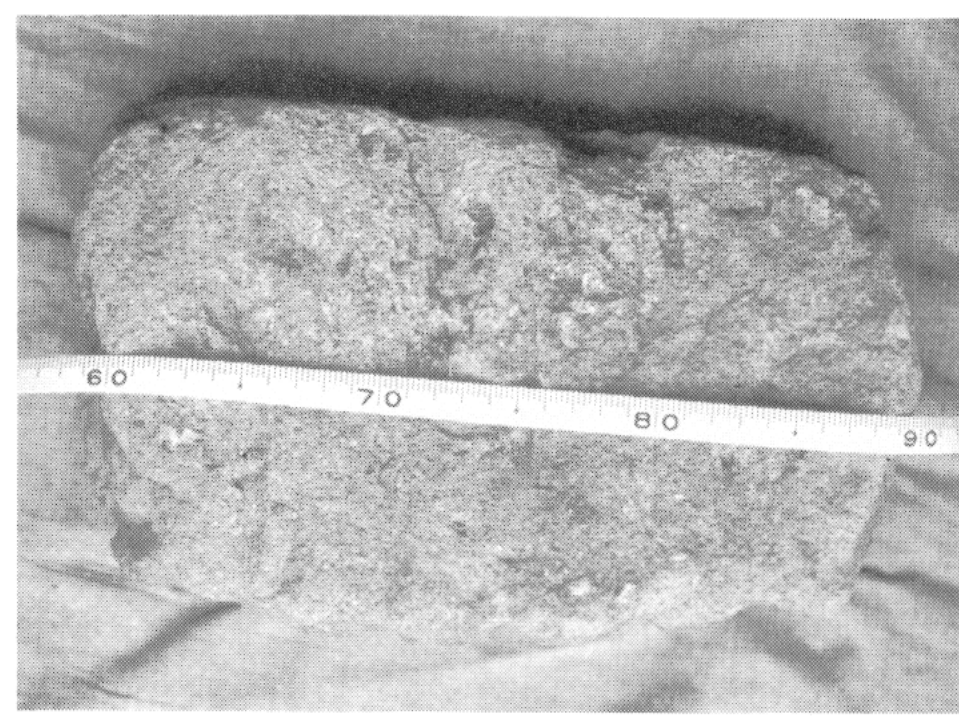

Fig. 19. - Bukit Seguntang (Tanjung Rawa): brique sculptée (plan) (coll. Puslit Arkenas)

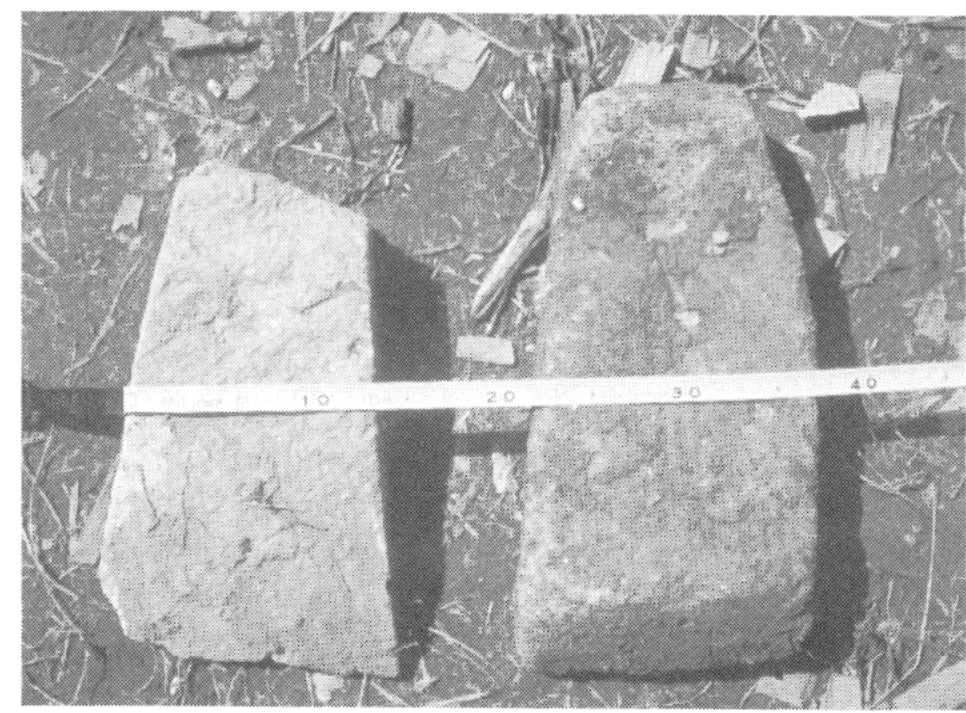

Fig. 21. - Bukit Seguntang (Tanjung Rawa): briques sculptées (plan) (coll. Puslit Arkenas).

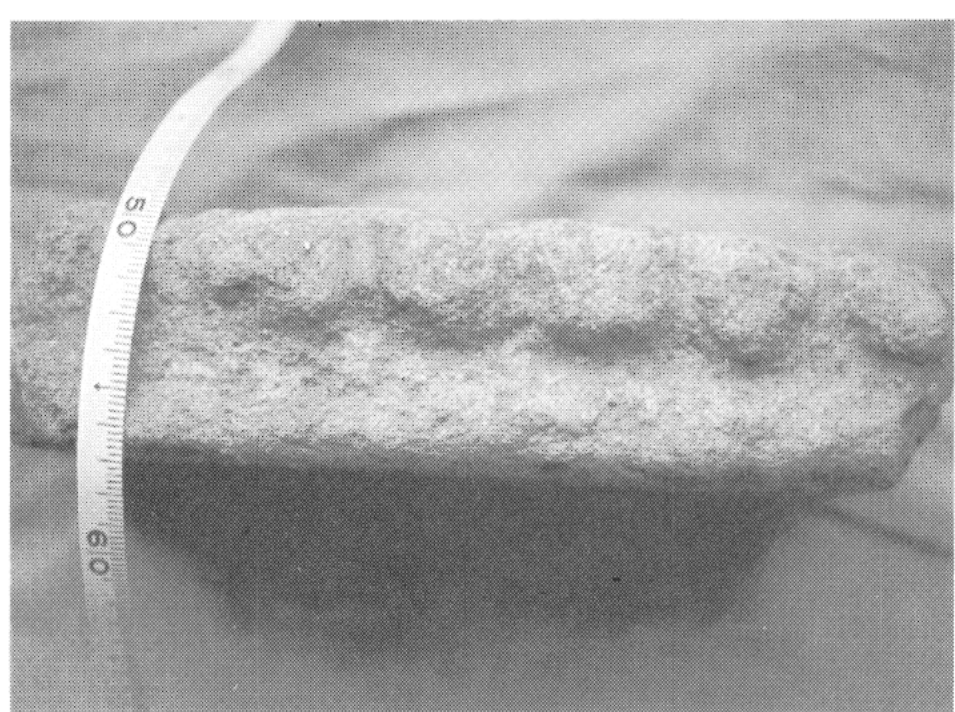

Fig. 20. - Id. fig. 19 (profil).

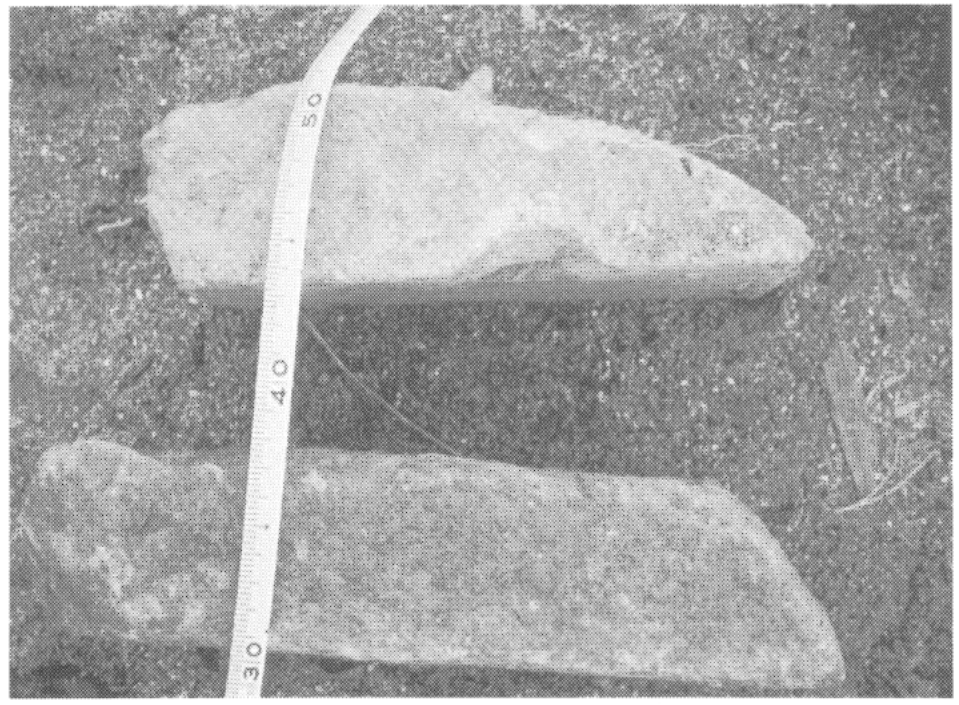

Fig. 22. - Id. fig. 21 (profil). 


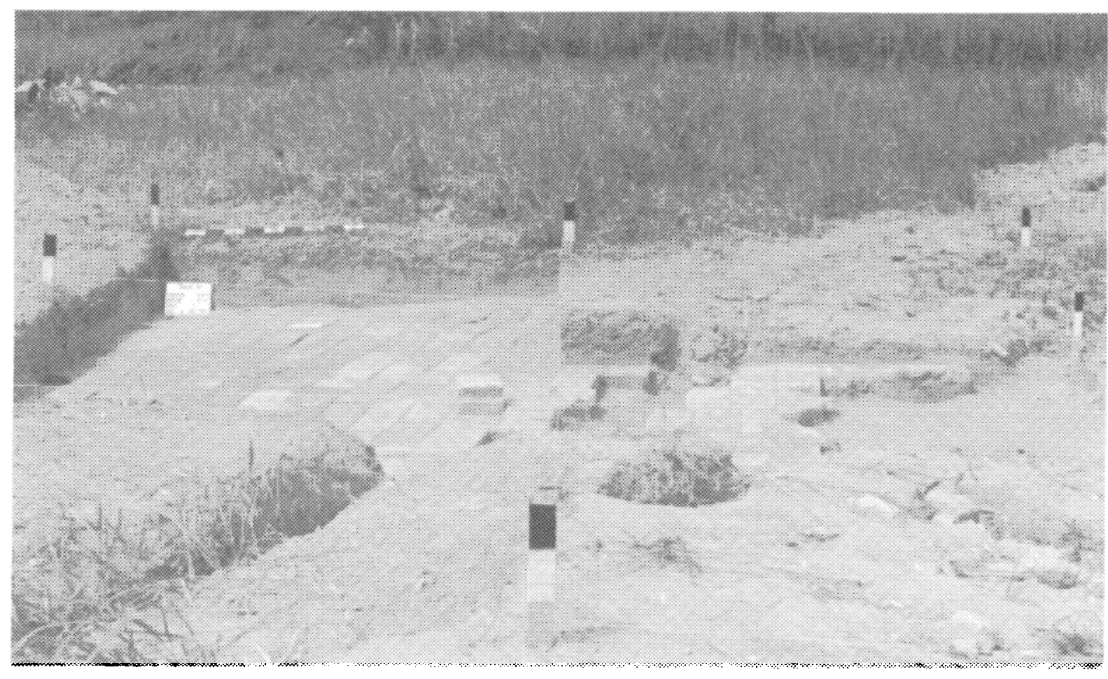

Fig. 23. - Kambang Unglen, fouilles du Puslit Arkenas (7/1987): plancher de briques (photo Puslit Arkenas).

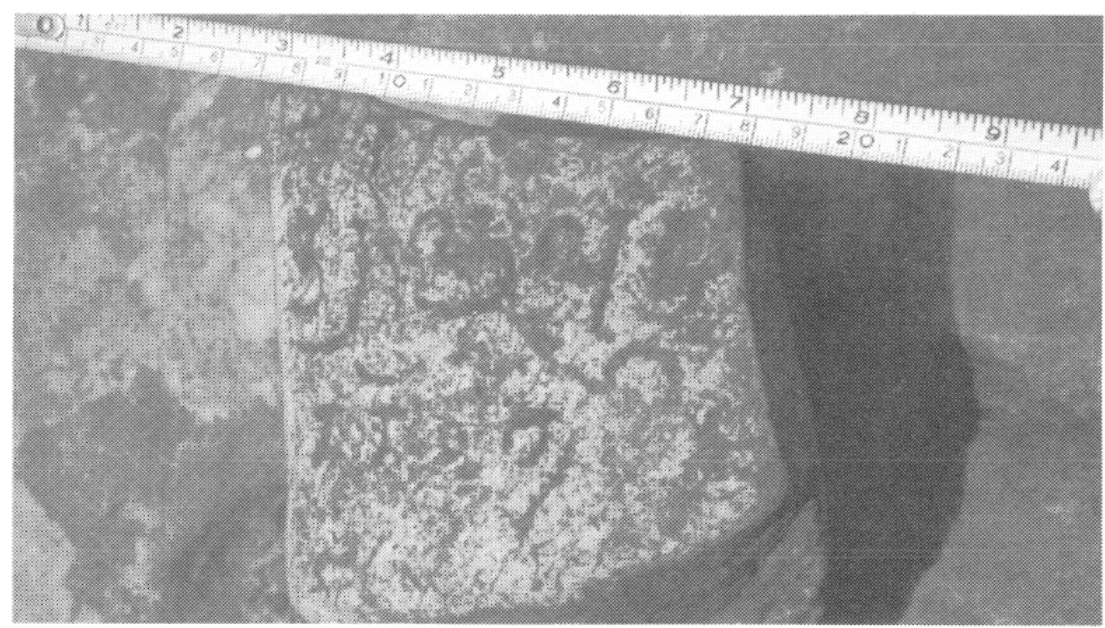

Fig. 24. - Kambang Unglen: fragment d'inscription.

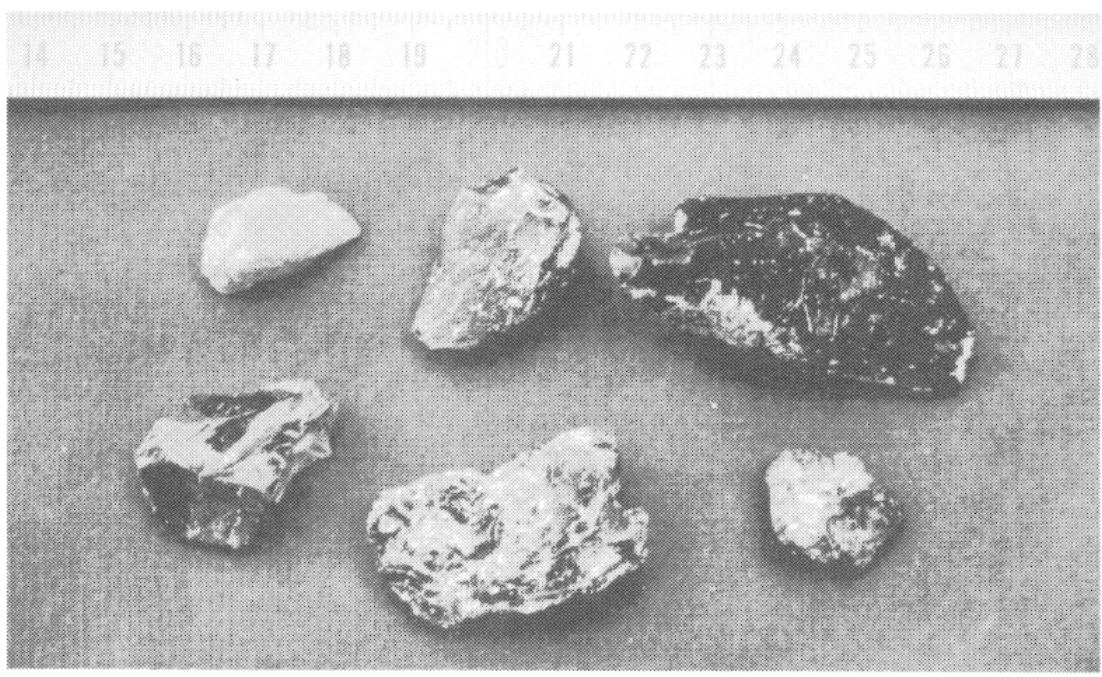

Fig. 25. - Kambang unglen: fragments de verre fondu. 


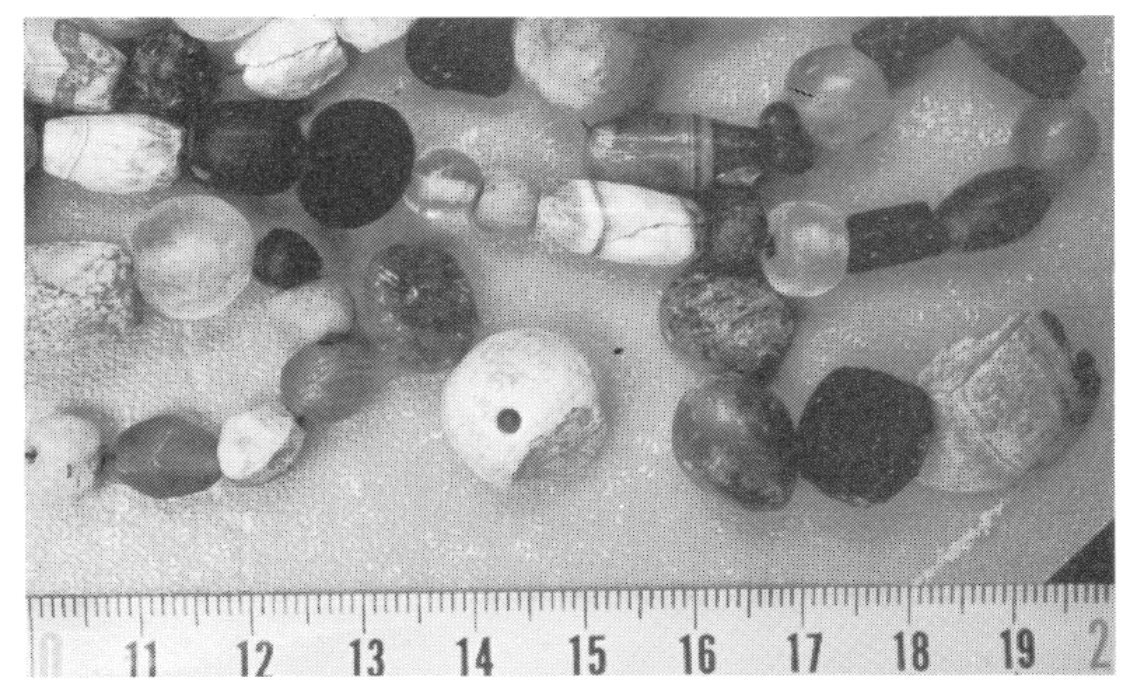

Fig. 26. - Kambang Unglen: perles, matériaux divers.

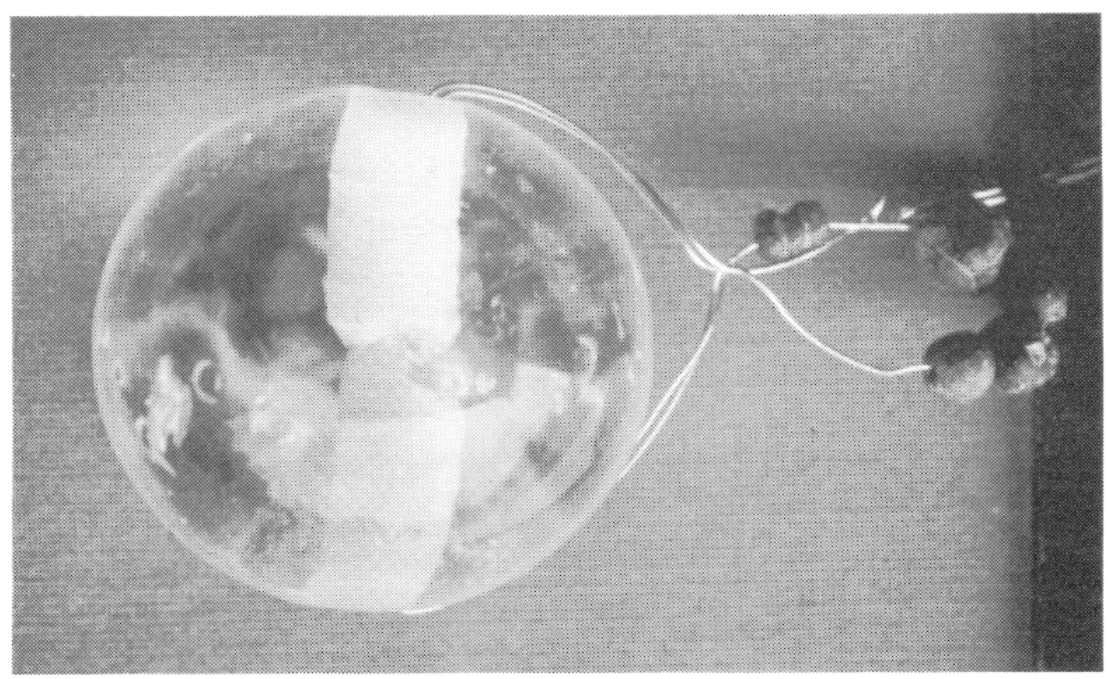

Fig. 27. - Kambang Unglen: grosse perle en quartz (diam: $28 \mathrm{~mm}$ ) (coll. Puslit Arkenas).

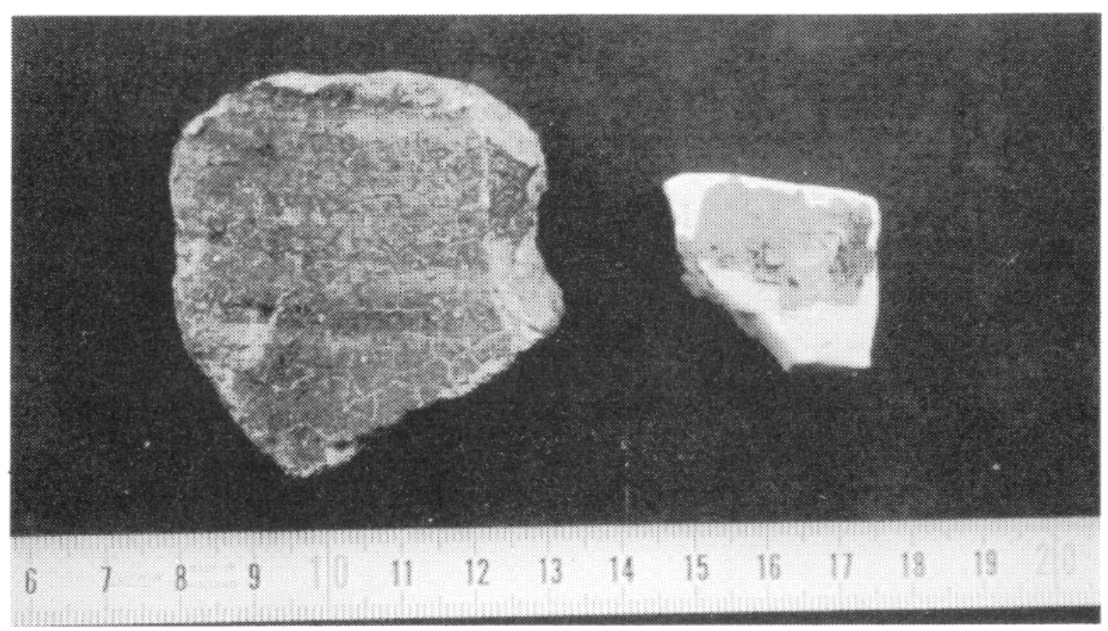

Fig. 28. - Kambang Unglen: céramiques persanes de la fin du $1^{\text {er }}$ millènnaire AD (coll. Puslit Arkenas). 


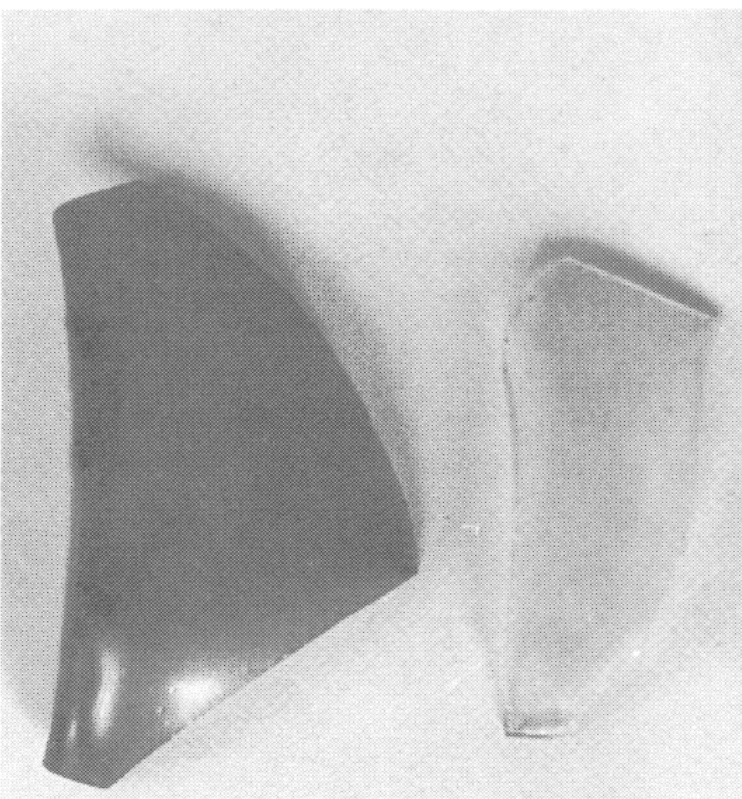

Fig. 29. - Talang Kikim Seberang: fragments de verre (photo E. E. McKinnon).

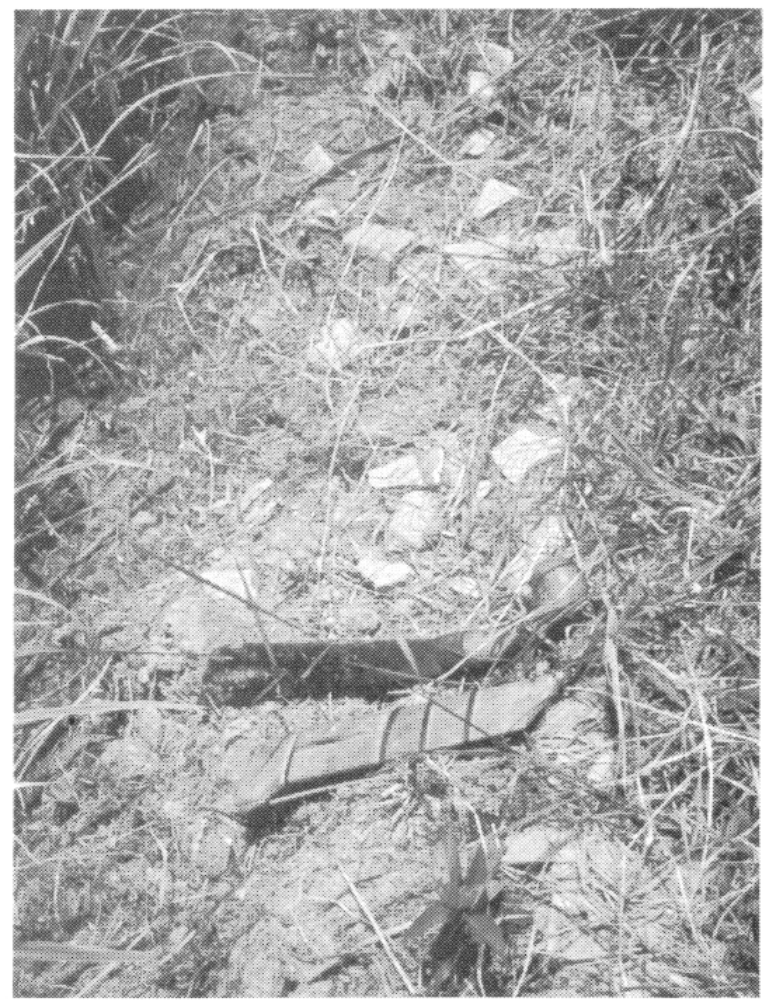

Fig. 30. - Talang Kikim Seberang: amas de tessons de céramique de la famille "vert-olive", formant une diguette de rizière.

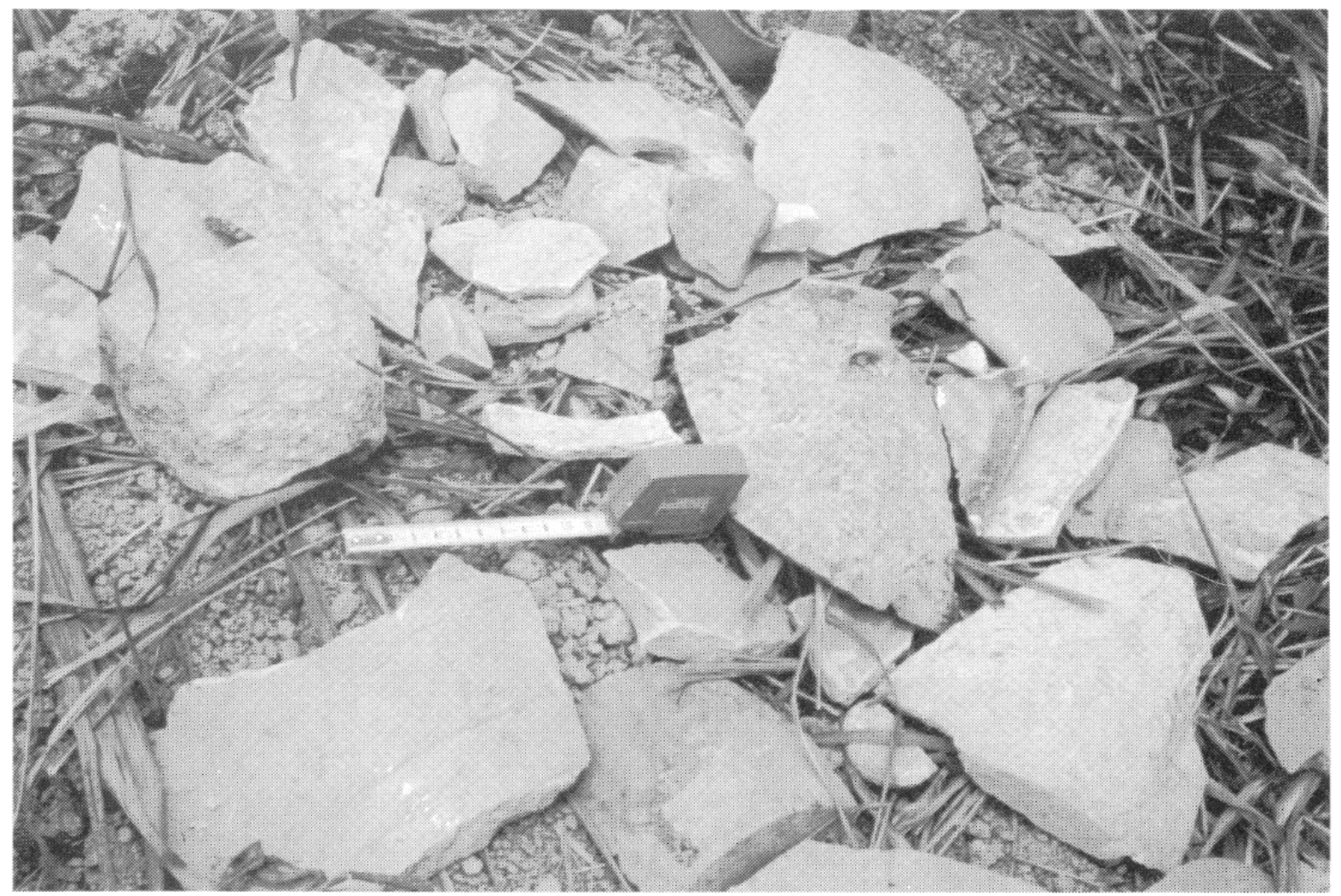

Fig. 31. - Ladang Sirap, tessons de la famille «vert-olive», in situ. 


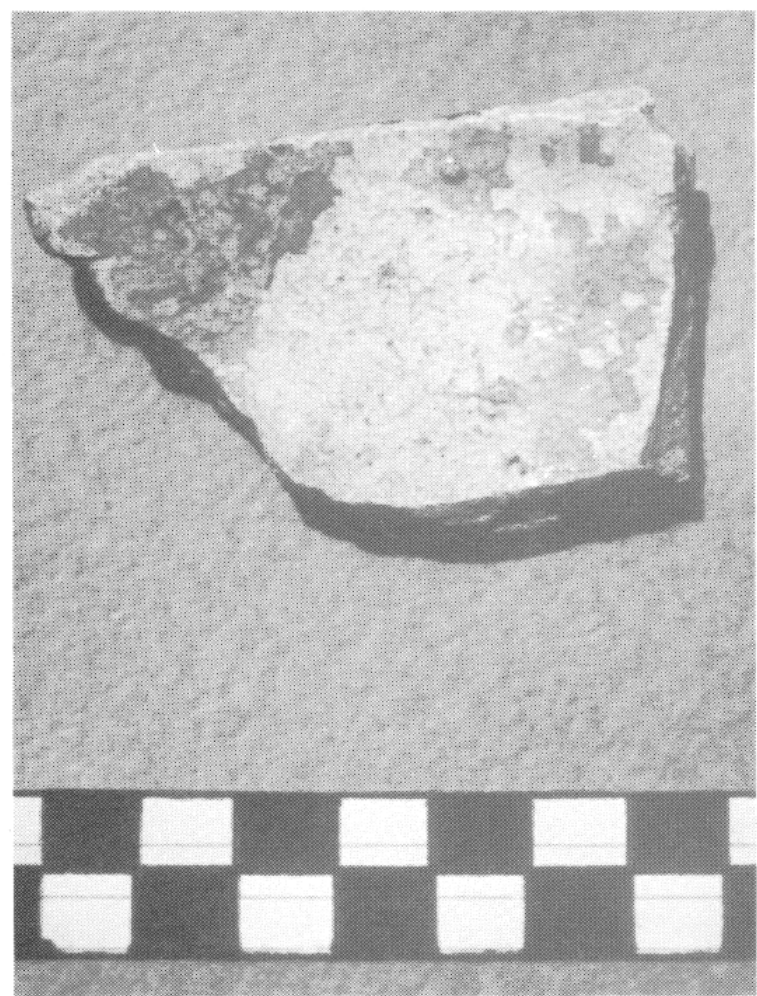

Fig. 32. - Karang Anyar: bol de la famille «vert-olive» (intérieur avec marque de cuisson) (coll. Puslit Arkenas).

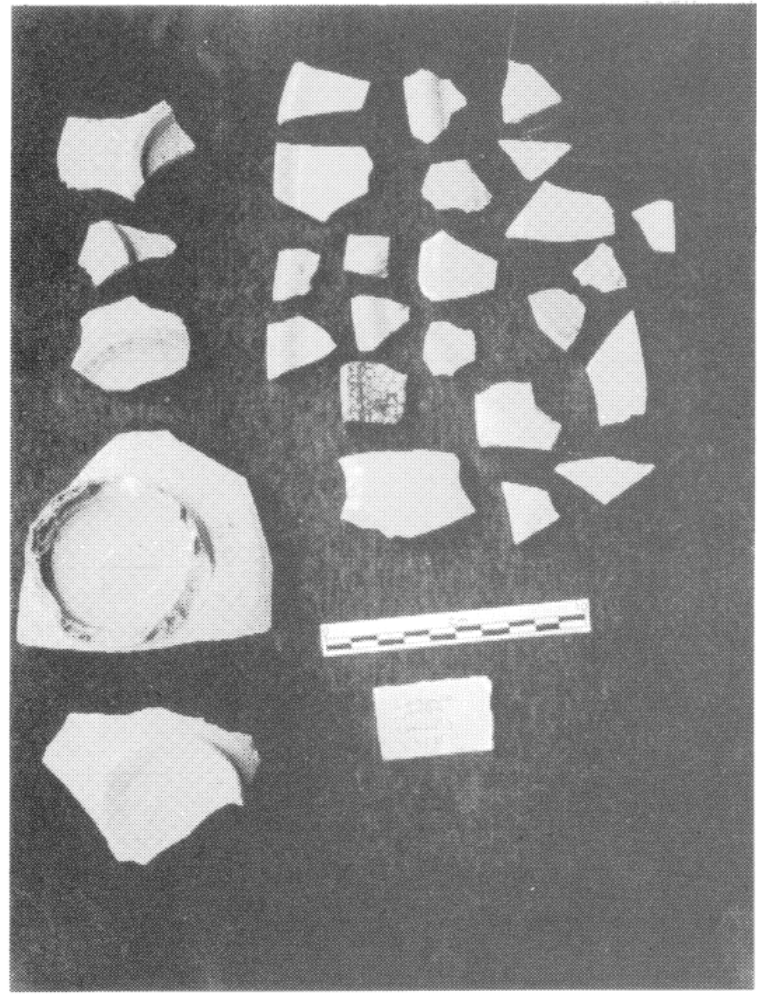

Fig. 34. - Lorong Jambu, tessons d'époque Song (coll. Puslit Arkenas).

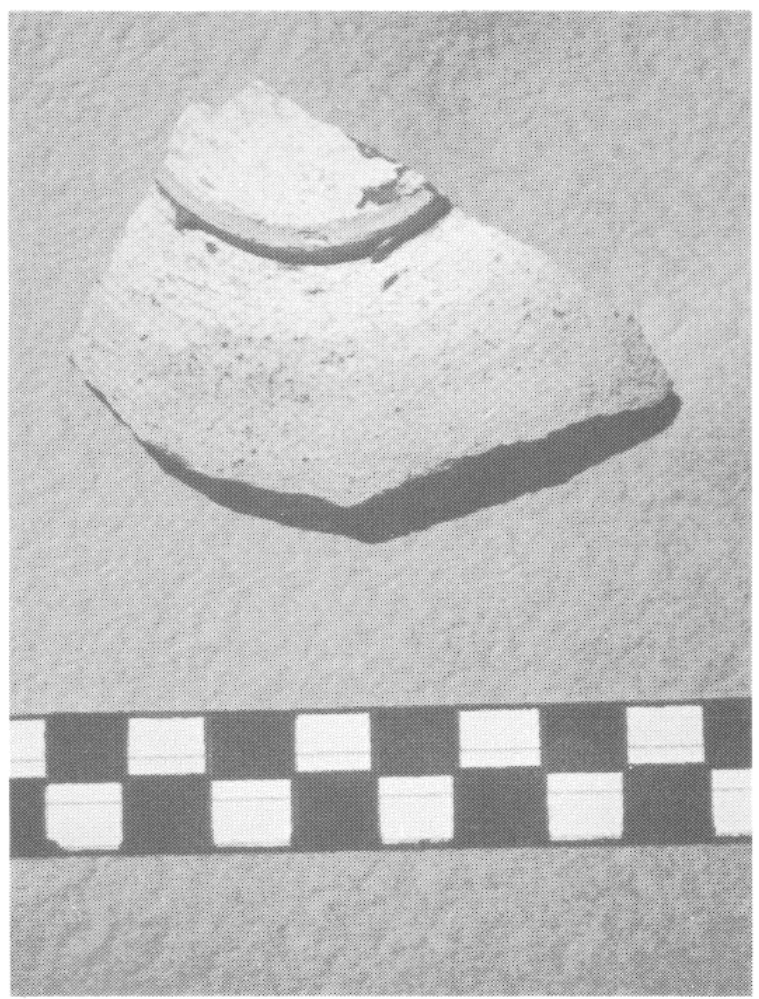

Fig. 33. - Id. fig. 32 (pied).

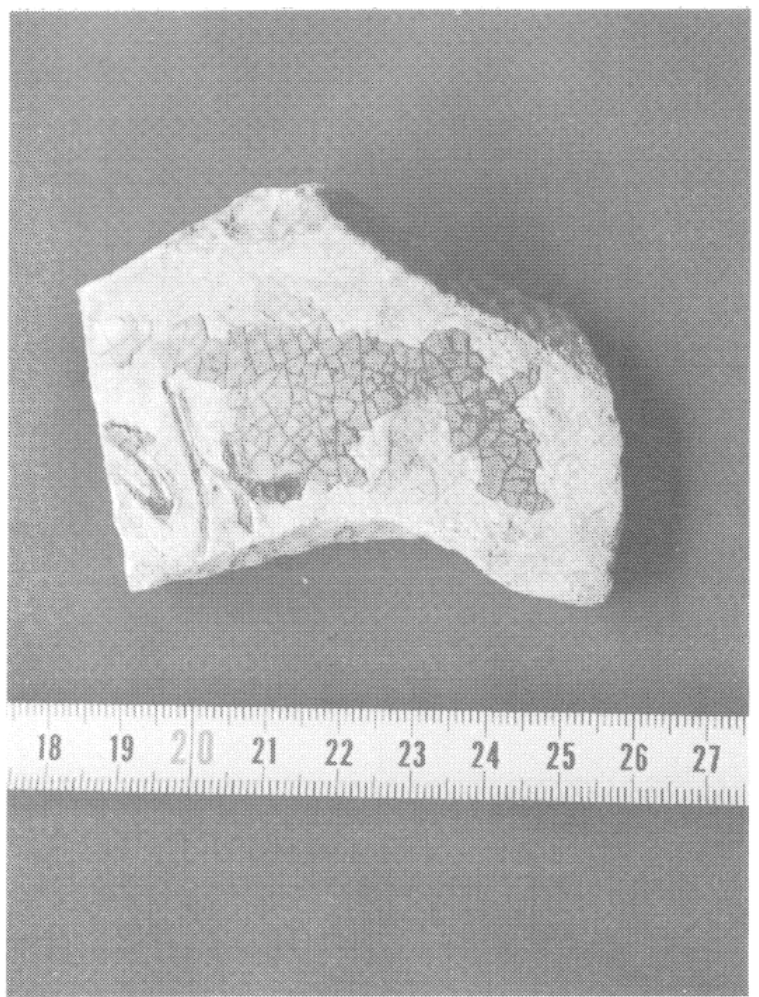

Fig. 35. - Karang Anyar: fragment de jarre de la famille "vert-olive» (avec marque de potier et glaçure craquelée typiques) (coll. Puslit Arkenas). 


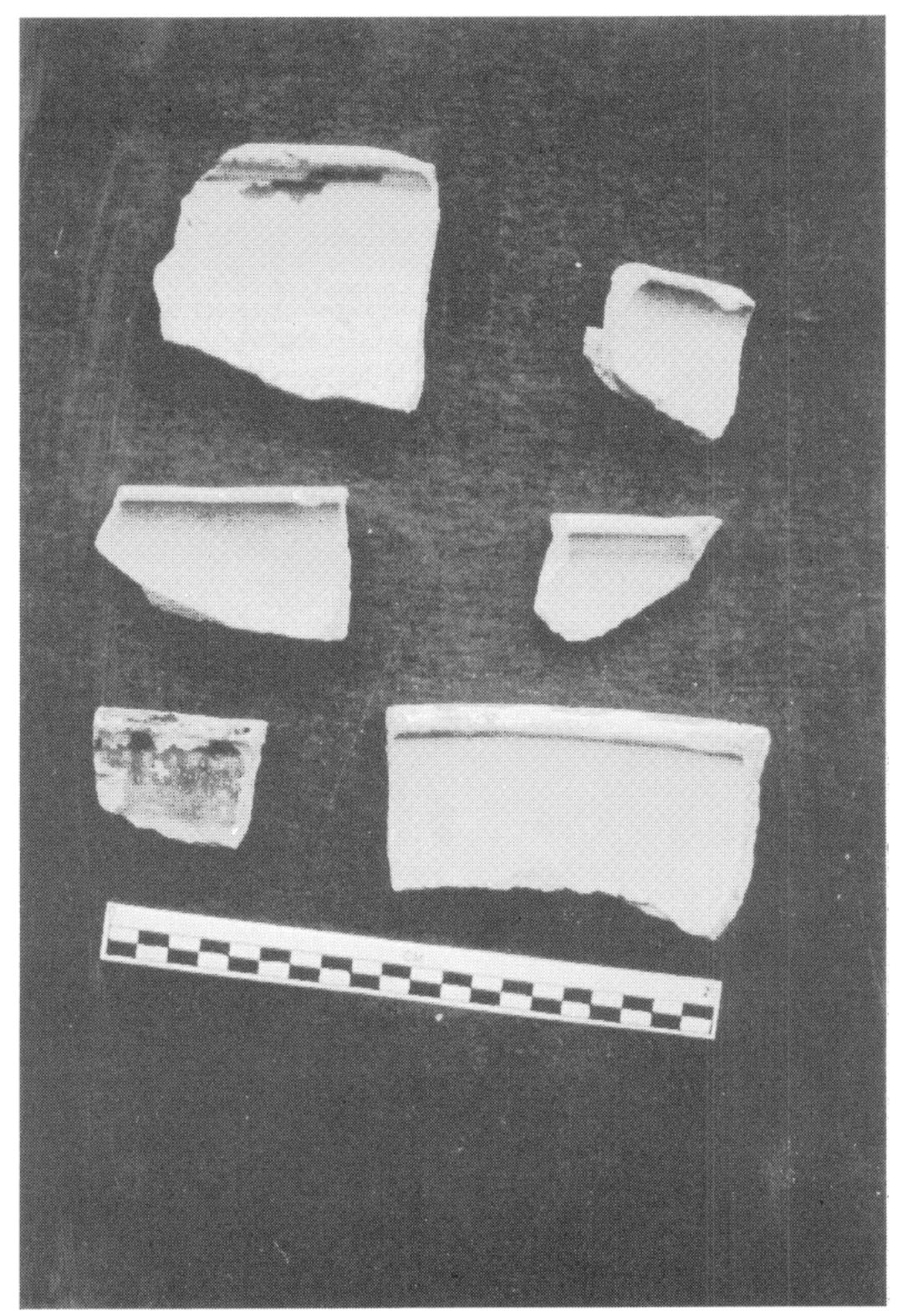

Fig. 36. - Talang Kikim Seberang: bassines de la famille «vert-olive» (intérieurs) (coll. Puslit Arkenas).

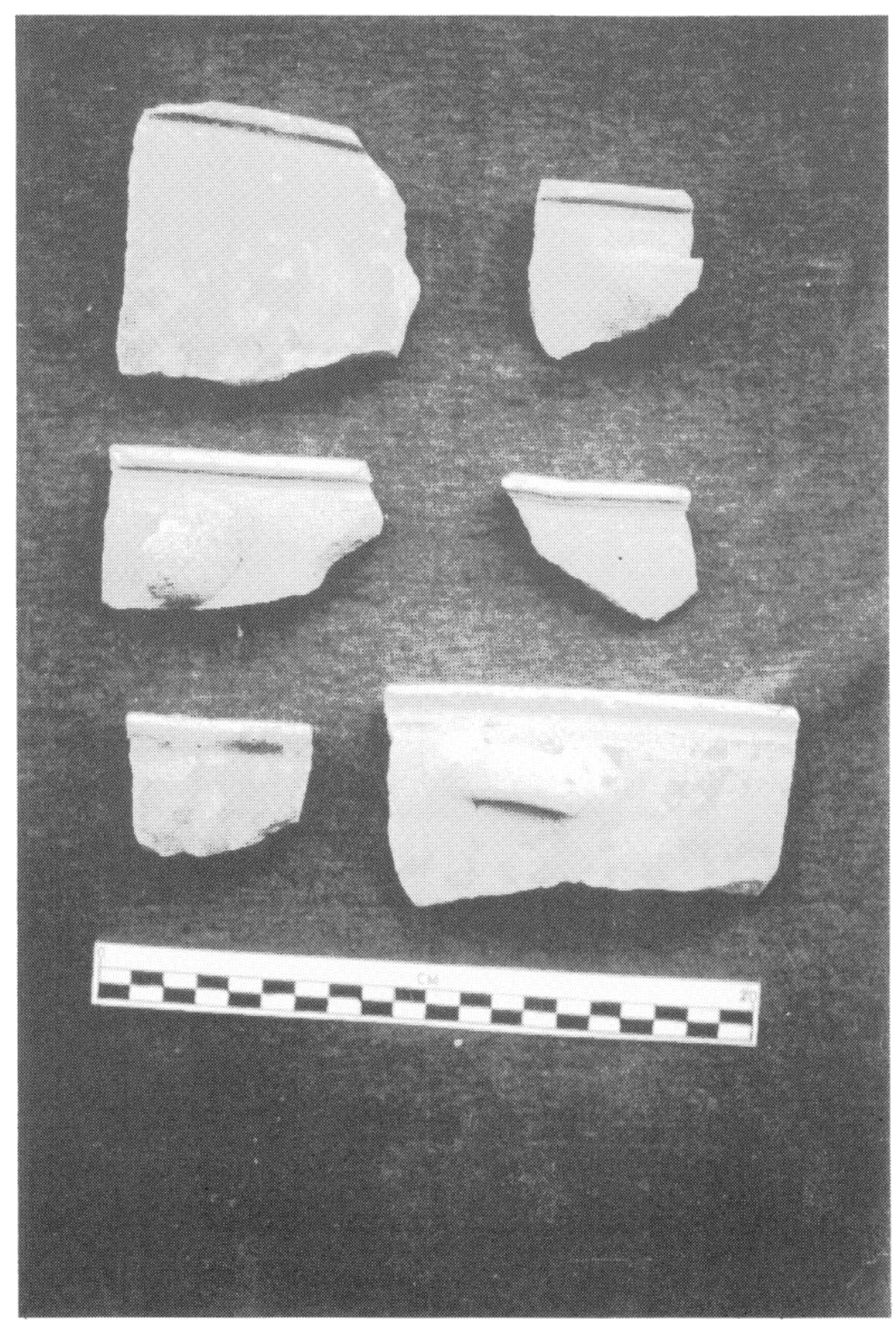

Fig. 37. - Id. fig. 36 (extèrieurs).

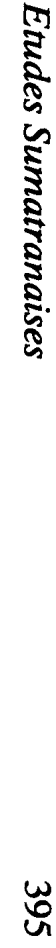




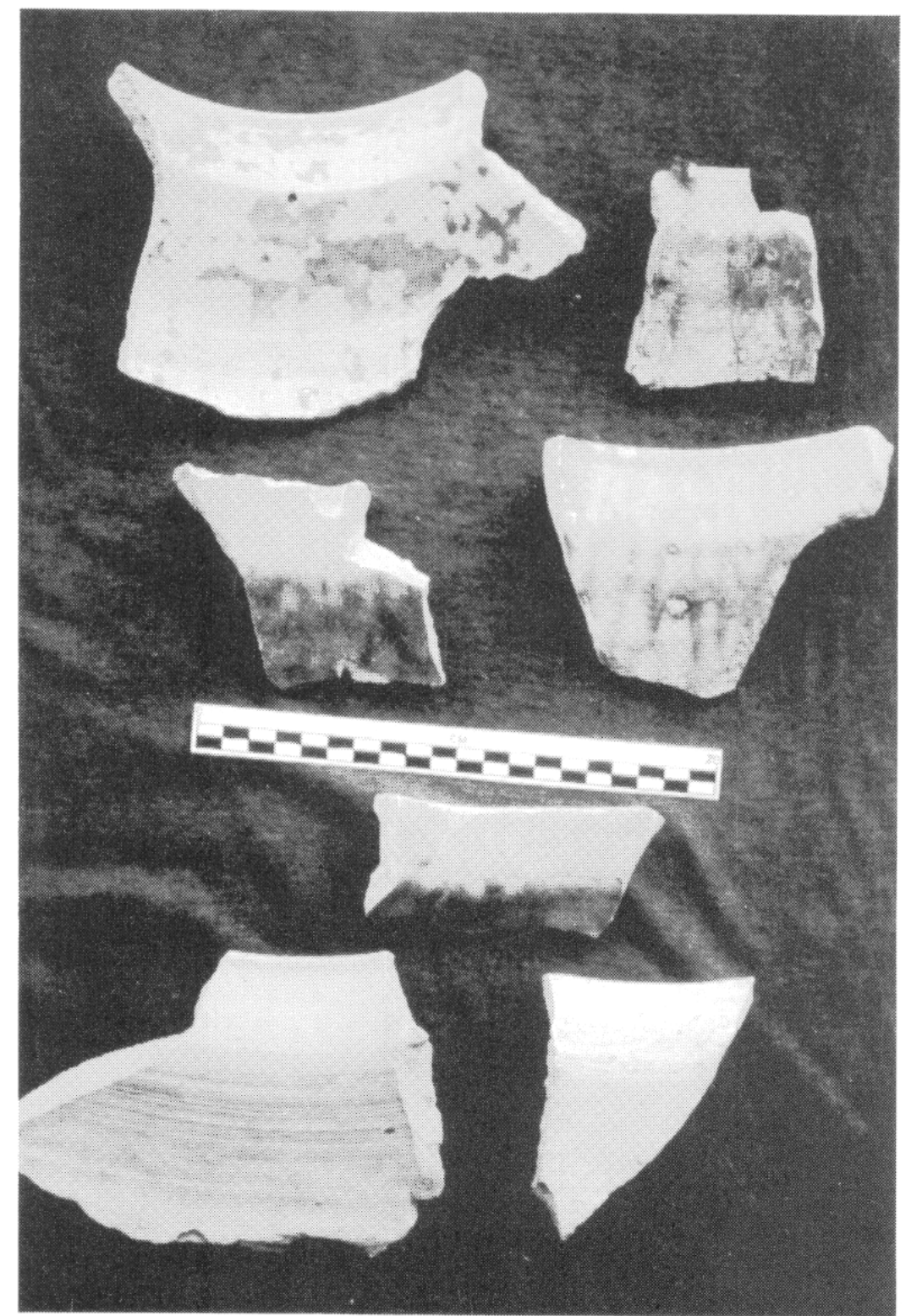

Fig. 38. - Talang Kikim Seberang: jarres de la famille «vert-olive» (intérieurs) (coll. Puslit Arkenas).

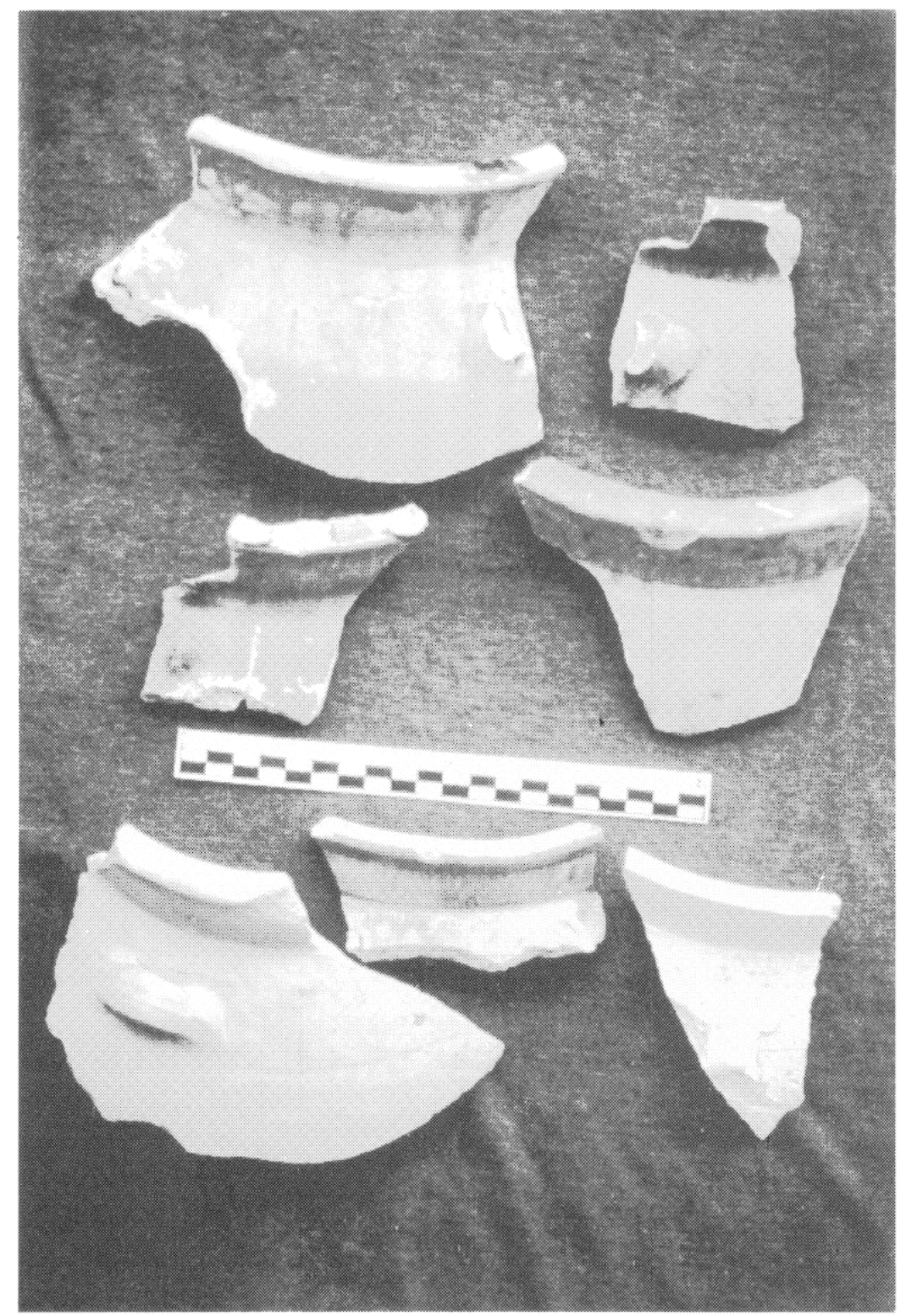

$\underset{\circ}{\omega}$

ำ 


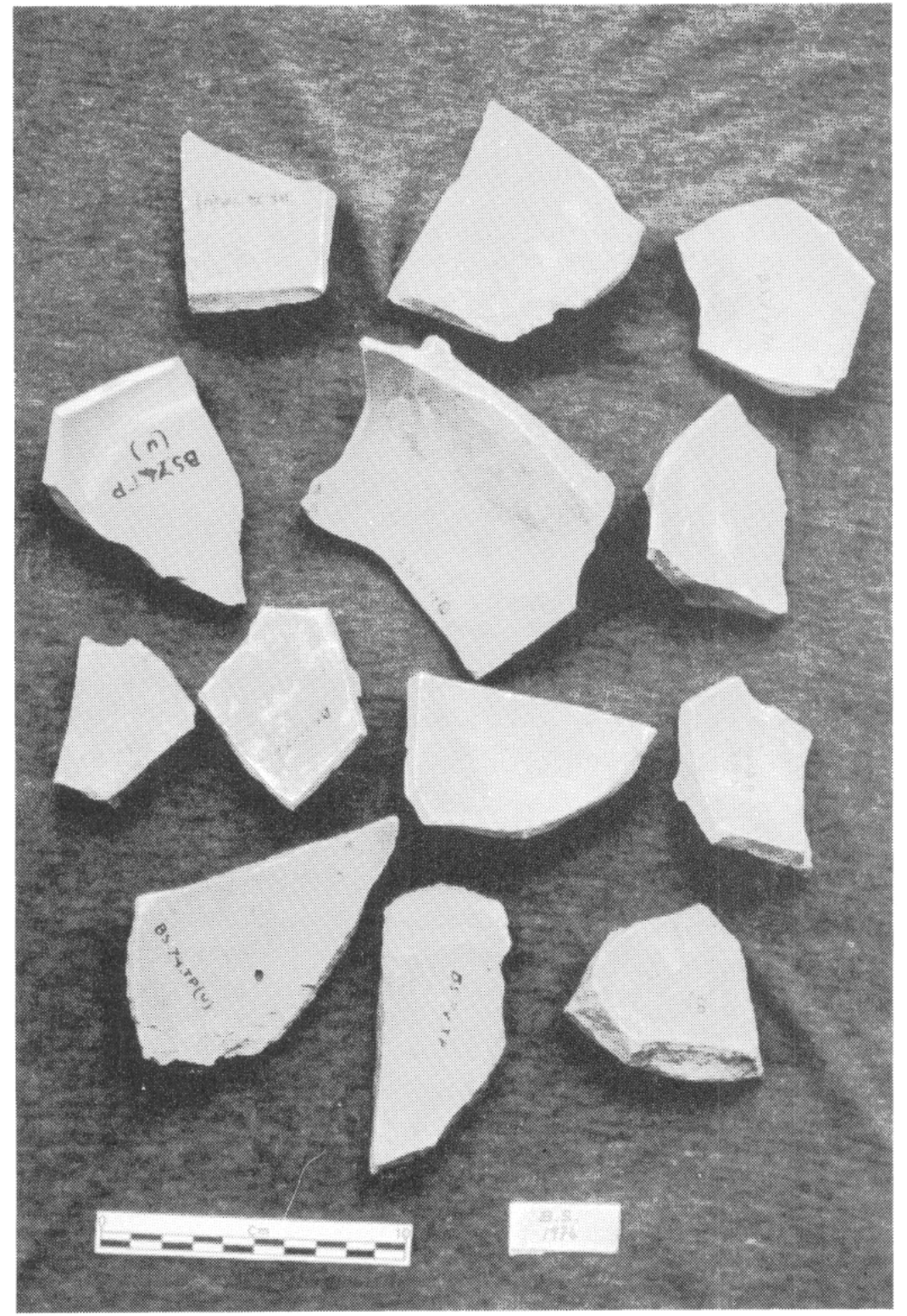

Fig. 40. - Bukit Seguntang: bols de type Yue, intérieurs, avec marques de cuisson (campagne de 1974; coll. Museum Badaruddin).

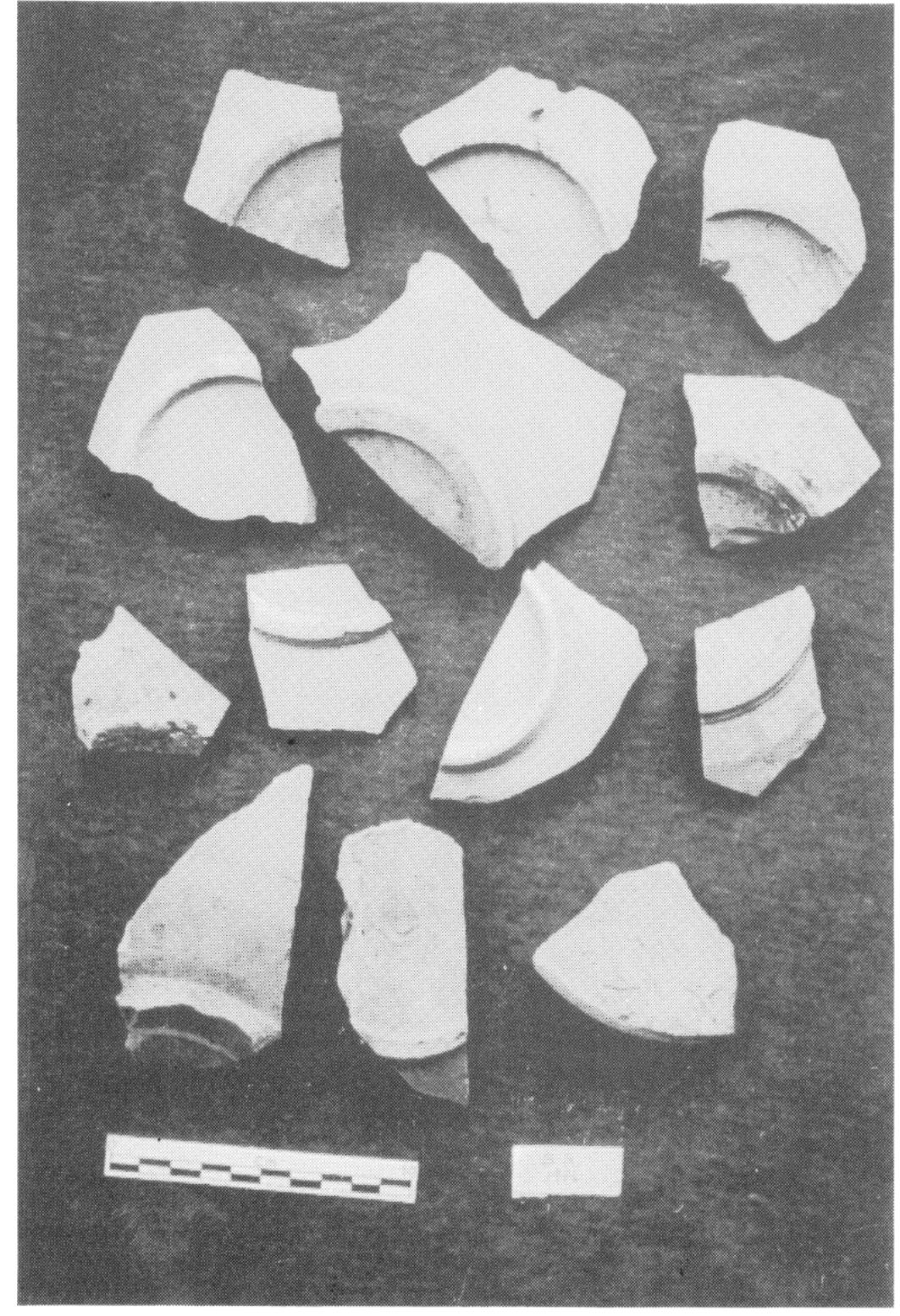

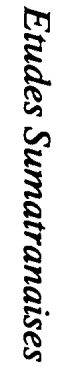

Fig. 41 . - Id. fig. 40 , bases. 


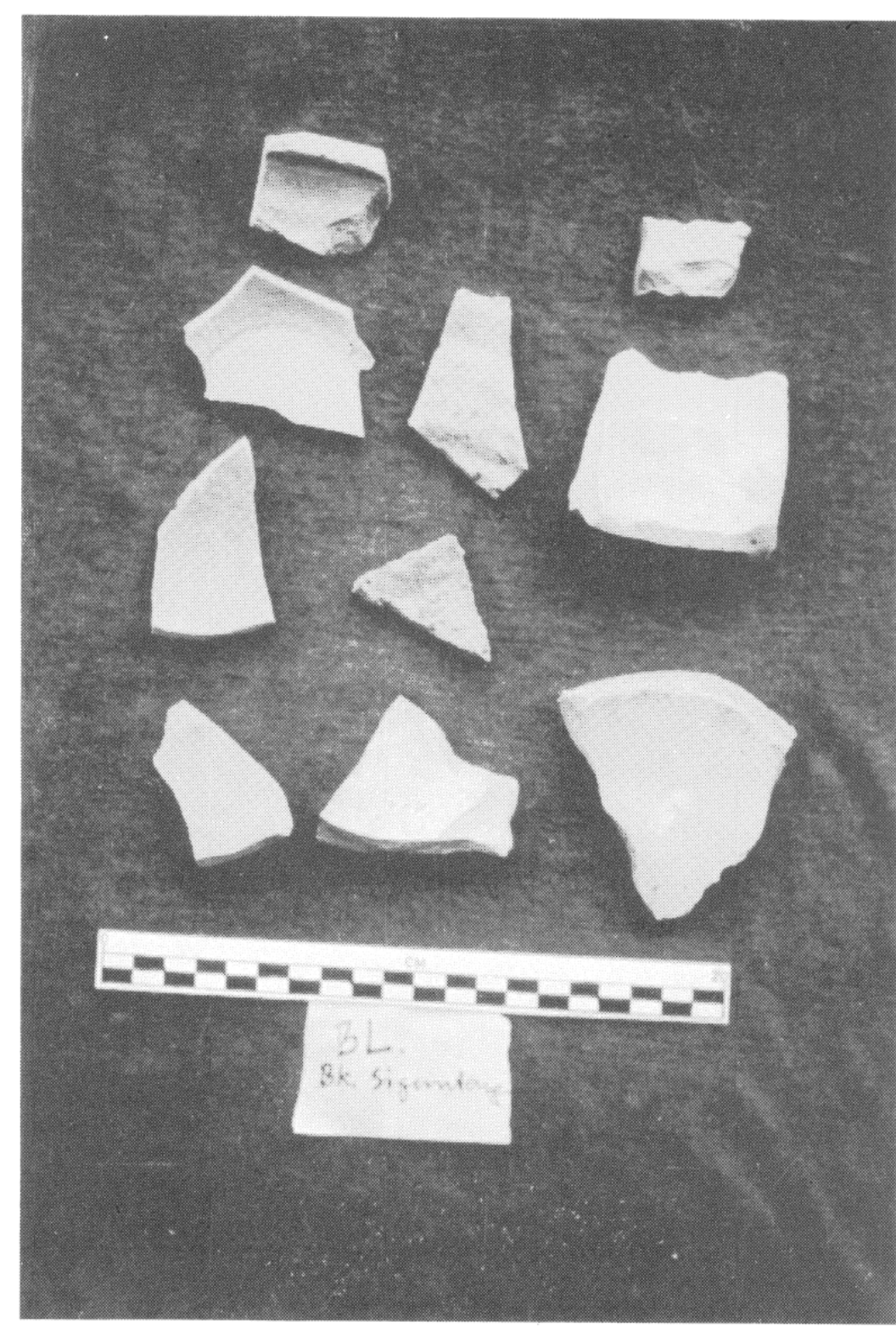

Fig. 42. - Bukit Seguntang: céramiques du type Yue, intérieurs (don bols avec marques de cuisson) (campagne de 1985; coll. Puslit Arkenas).

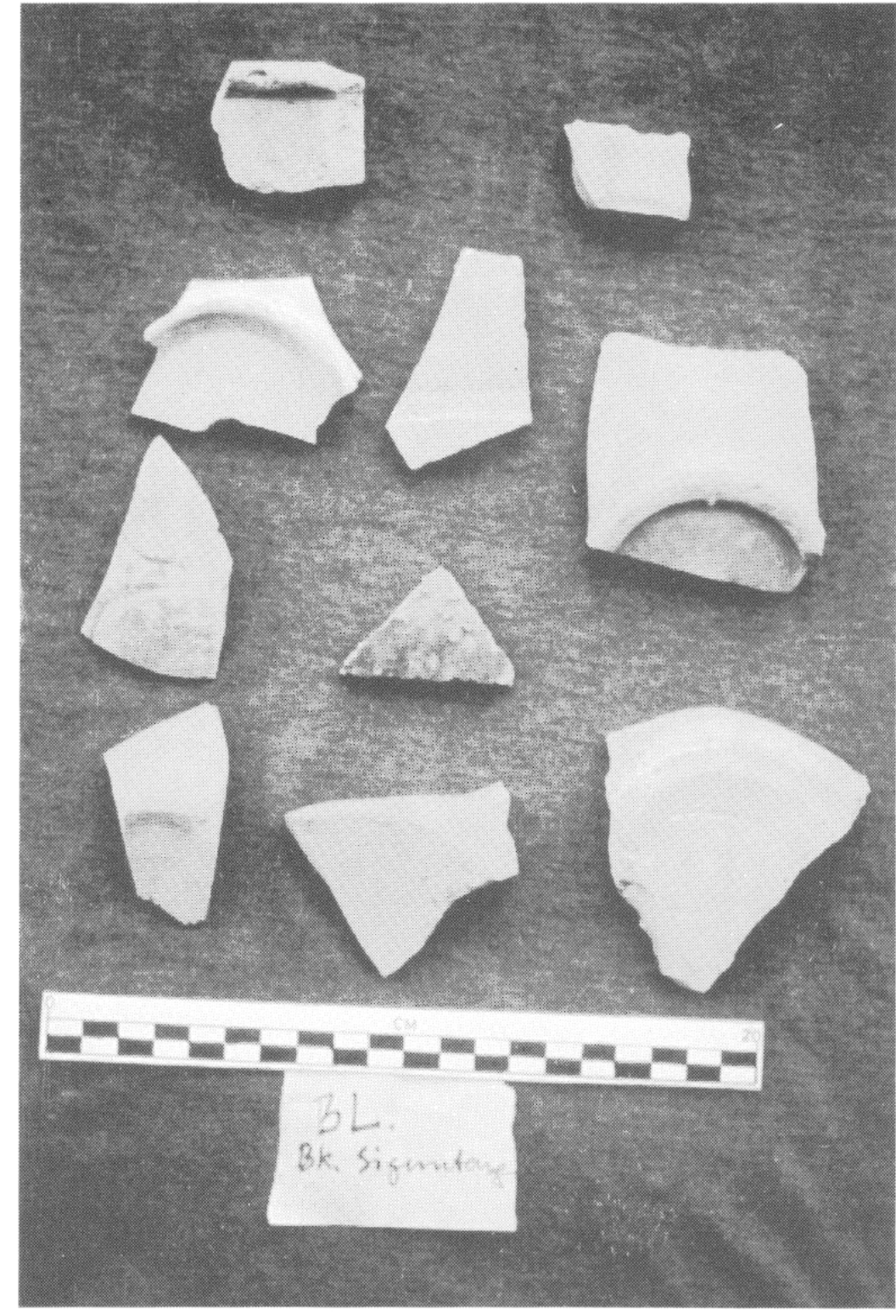

$\underset{\infty}{\infty}$

ำ

Fig. 43. - Id. fig. 42, bases. 


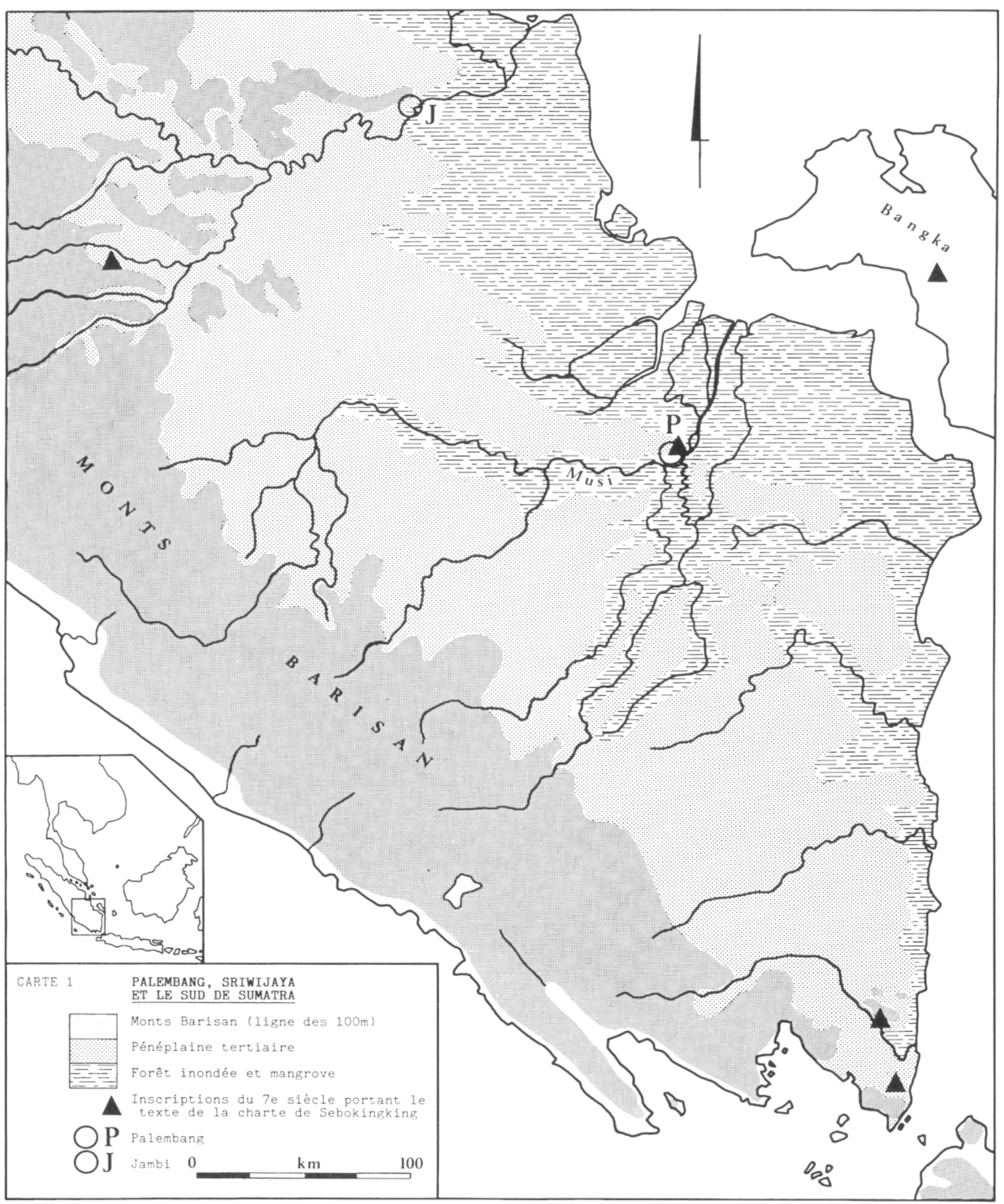




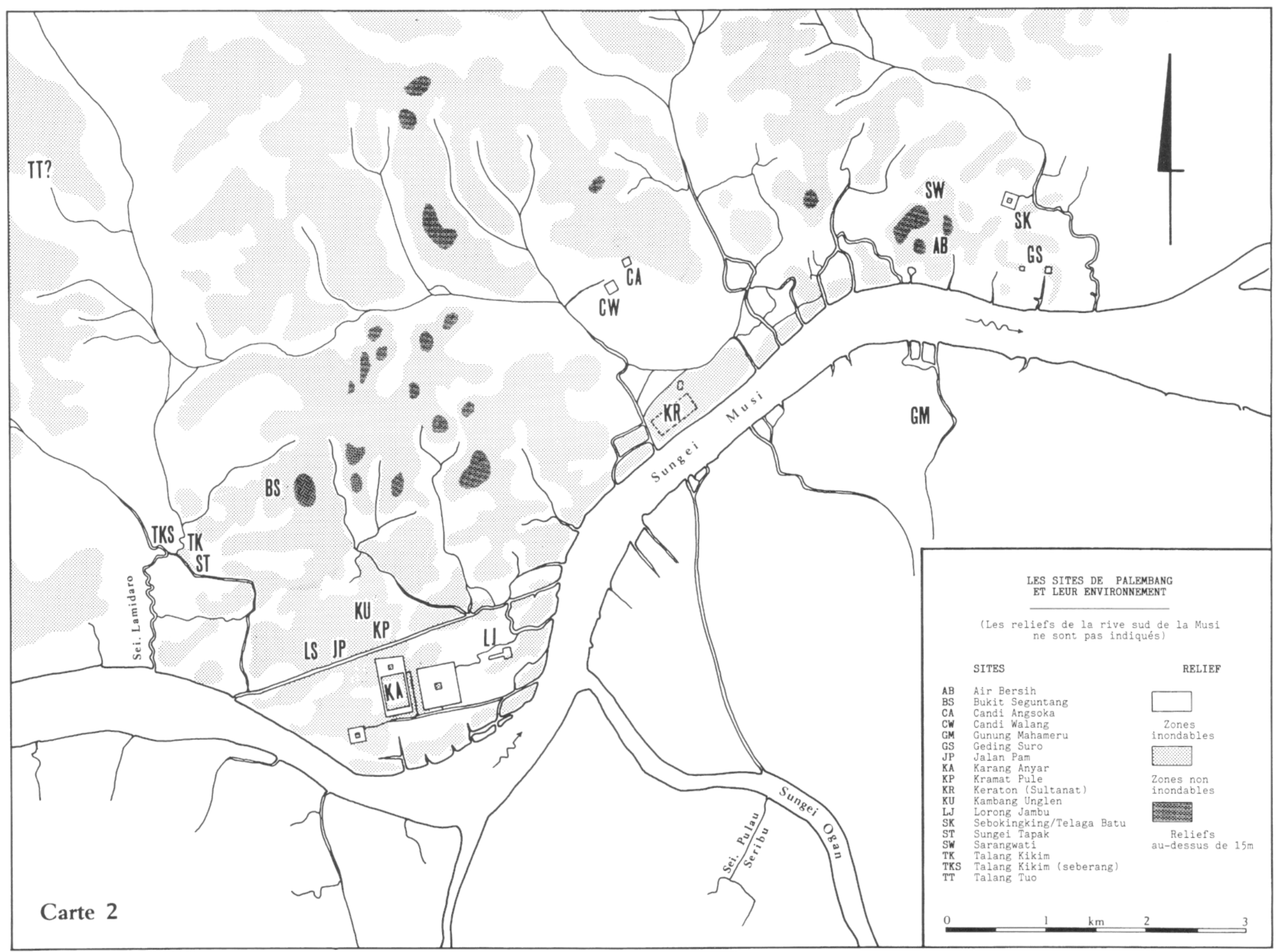




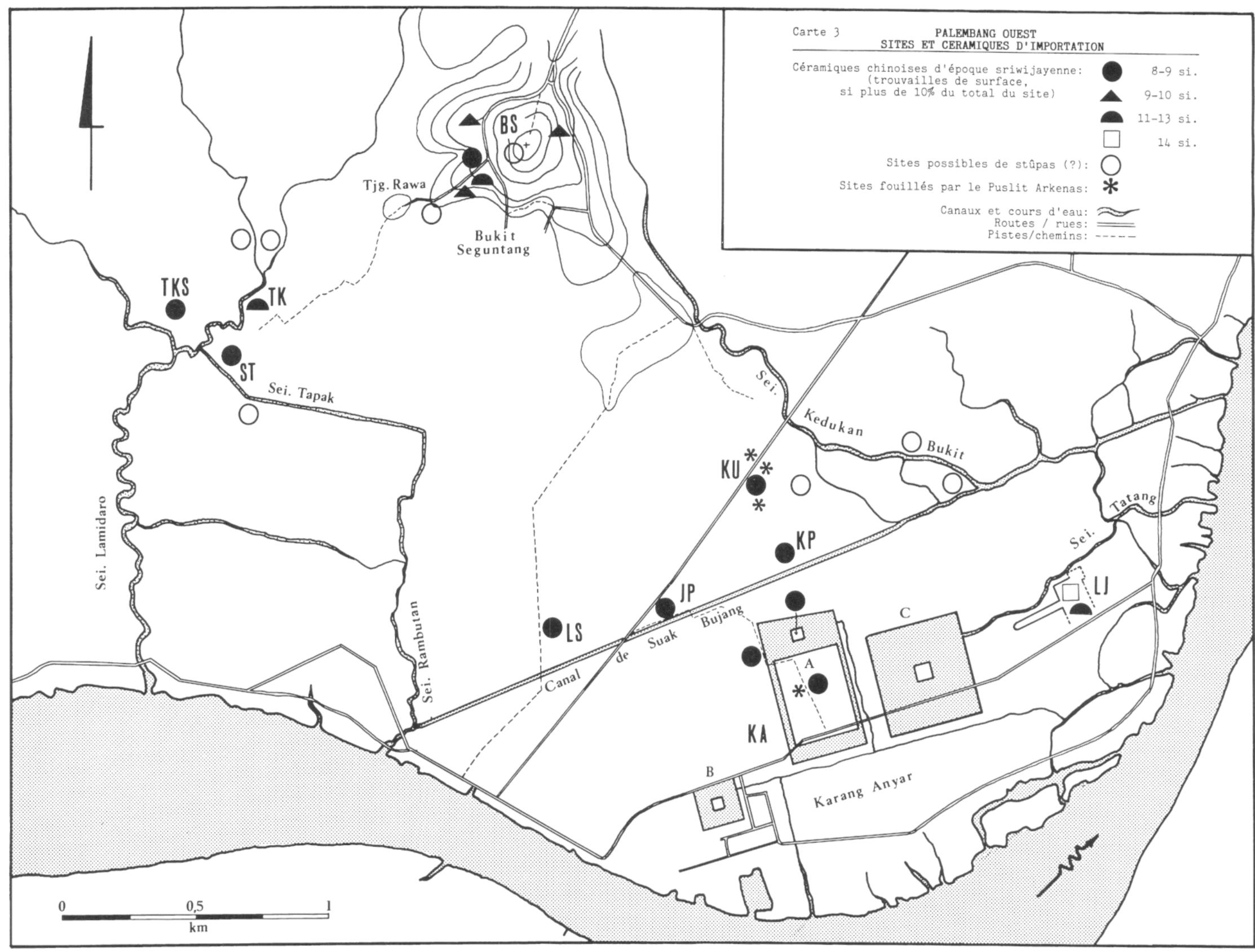

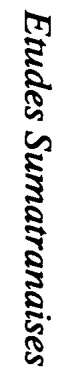




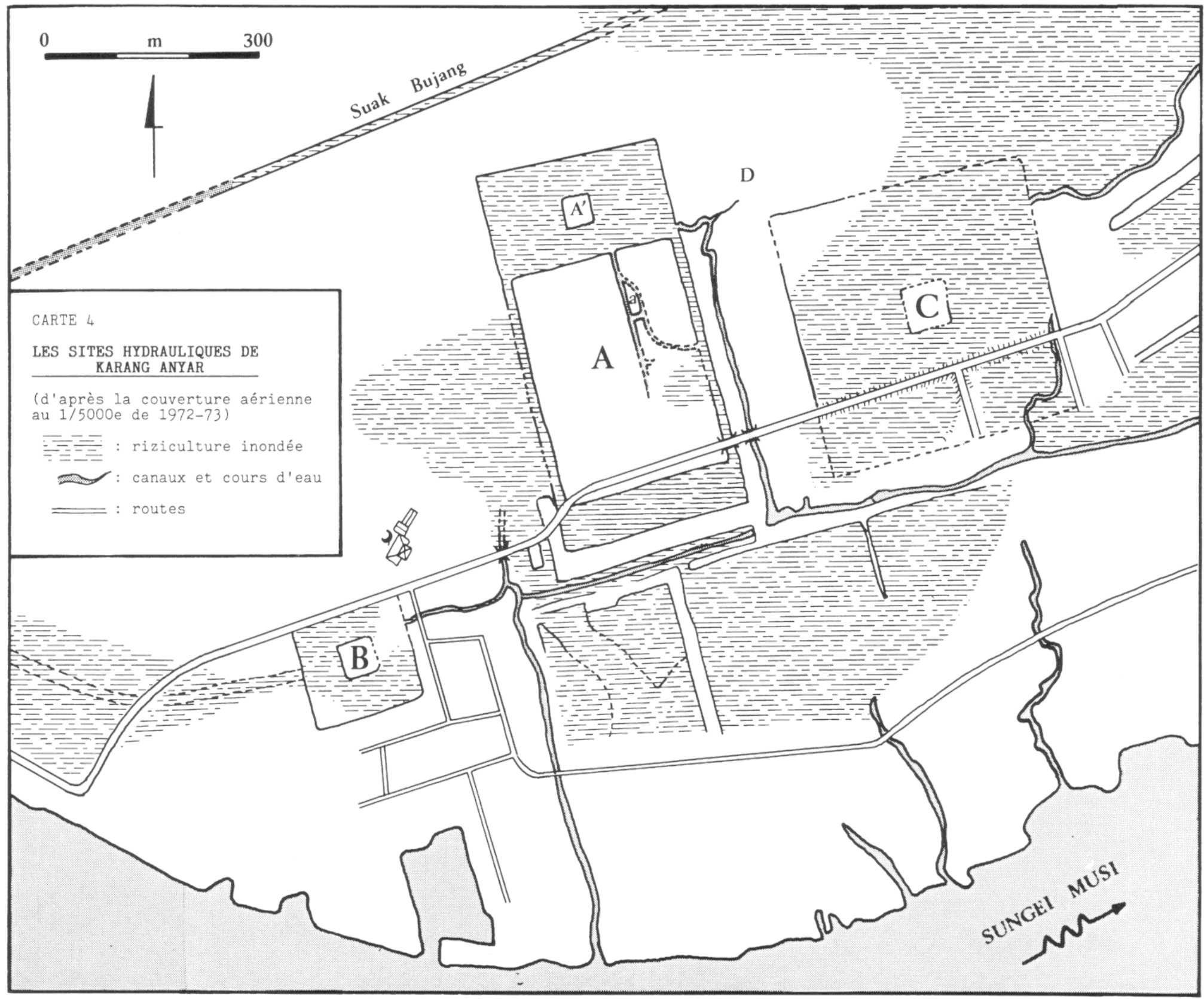

